\title{
$((1-))$ \\ jpen
}

INSTITUTO DE PESQUISAS ENERGÉTICAS E NUCLEARES

Autarquia Associada à Universidade de São Paulo

\section{DETECÇÃO DE LESÕES DE CÁRIE POR FLUORESCÊNCIA: CORRELAÇÃO ENTRE A HISTOLOGIA E OS RESULTADOS OBTIDOS COM O DIAGNOdent E A ESPECTROSCOPIA}

RENATA MACIEL ROCHA-CABRAL

Tese apresentada como parte dos requisitos para obtenção do Grau de Doutor em Ciências na Área de Tecnologia Nuclear - Materiais.

Orientadora: Profa. Dra. Denise Maria Zezell 
INSTITUTO DE PESQUISAS ENERGÉTICAS E NUCLEARES

Autarquia Associada à Universidade de São Paulo

DETECÇÃO DE LESÕES DE CÁRIE POR FLUORESCÊNCIA: CORRELAÇÃO ENTRE A HISTOLOGIA E OS RESULTADOS OBTIDOS COM O DIAGNOdent E A ESPECTROSCOPIA

RENATA MACIEL ROCHA-CABRAL

Tese apresentada como parte dos requisitos para obtenção do Grau de Doutor em Ciências na Área de Tecnologia Nuclear - Materiais.

Orientadora: Profa. Dra. Denise Maria Zezell 


\section{DEDICATÓRIAS}

A meu amado marido Yvan, por ter me esperado tão pacientemente ao longo destes cinco anos, por ser meu amigo, conselheiro e companheiro de todas as horas. Todos os nossos sacrifícios e o sofrimento passados, no futuro, só terão tornado a história do nosso amor ainda mais bonita, tenho certeza disso.

A minha mãezinha Aurígena, sempre tão presente em todos os momentos da minha vida, apoiando, patrocinando meus sonhos, sempre me ouvindo e me agüentando (com toda a paciência do mundo) nos meus dias de insuportável humor. Eu nada seria sem você.

A meu painho Assis, meu eterno herói que saiu do sertão ainda menino para ganhar o mundo. E ganhou. Essa sua força me serve de inspiração para seguir sempre em frente. Amo você, pai.

A meus queridos irmãos Flávia e Alexandre e seus preciosos frutos: Matheus e Gabriela. Vocês dão cor a minha vida.

A minha tia Deda (in memoriam), dentista de reconhecida competência em Campina Grande (PB). Esteja onde estiver, sei que está vibrando por mais esta conquista. 


\section{AGRADECIMENTOS}

A Deus, a meu anjo guardião e espíritos protetores que torcem por mim. Obrigada por tudo. Em especial, por mais esta conquista. Rogo que continuem me intuindo, protegendo e me sustentando nas provas desta vida para que eu consiga sempre seguir no caminho da luz.

À Profa. Dra. Denise Maria Zezell. Serei eternamente grata pelo crédito que me deu ao permitir meu ingresso na Instituição como sua orientada e por seus ensinamentos não só científicos, mas também de vida. Espero não a ter decepcionado. Obrigada também pelo carinho, pelos cuidados e pelas preocupações que me fizeram sentir mais pertinho de casa. Acima de tudo, você é um exemplo de pessoa batalhadora que deve ser seguido.

Ao Prof. Dr. Anderson Gomes, meu "padrinho científico", que sempre com atenção e respeito deu-me todo o apoio financeiro e moral para chegar aonde cheguei. Muito obrigada por acreditar em mim. Sua torcida fez toda a diferença.

Ao Prof. Dr. Ryan Paulo Ferreira Costa Campos (in memoriam) por incentivar meu ingresso na área acadêmica. Se você não tivesse me ensinado a nunca desistir de meus objetivos, nada disso teria acontecido.

Ao amigo e Prof. Dr. Fausto Mendes pelas colaborações, trocas de idéias e pelos valiosos ensinamentos. Aprendi muito com você.

Ao amigo Dr. Walter Miwakawa e a Msc. Daniela Fatesi, pelo carinho e pelo "empurrãozinho físico" no início de tudo.

Ao Carlos Gomes, por estar sempre disposto a tirar minhas dúvidas com toda a simpatia do mundo.

À Profa. Dra. Célia Delgado Rodrigues pelas importantes sugestões durante o desenvolvimento do trabalho, pela atenção e simpatia. 
Ao Dr. Ricardo de Paula Eduardo por ter feito o intercâmbio IPEN - CETAO e ao Dr. Fábio Nauff, que, sempre gentil e educado, permitiu a minha permanência no CETAO.

À Dra. Adriane Lima e à Dra. Érika Khron pela amizade, boa vontade e por seu tempo de produtividade consumido por mim. Vocês foram imprescindíveis à realização deste trabalho.

Ao Dr. Anderson Shigeoa, pela presteza e constante atenção comigo em sua clínica.

Ao Prof. Carlos Bevilaqua e sua esposa, Dra. Katy. Obrigada por terem aberto as portas da $A B O$ para mim sem nenhuma restrição. Isso foi fundamental ao bom andamento do trabalho.

À turma do curso de aperfeiçoamento em cirurgia da Fundecto, em especial à Juliana, por toda a sua atenção e carinho.

Às queridas Márcia Uehara e Sandra Gonzales. Dedicadas e muitíssimo prestativas. Vocês foram dois anjos! Obrigada por tudo.

Aos professores do curso de especialização em cirurgia da Fundecto. Profs. Drs. Waldir Jorge, Bauer, Fernando, Rodrigo, Alexandre, Gláucio e a profa. Renata, por permitirem a minha presença nada discreta na clínica e por toda a atenção dispensada.

À Profa. Dra. Renata Fernandes por seu apoio e valiosas dicas desde a minha graduação.

À Profa. Dra. Martha Ribeiro pelo seu eterno bom humor e carinho.

À Profa. Dra. Sônia Licia Baldochi, por sua gentileza em permitir a utilização do microscópio de luz polarizada do laboratório de Crescimento de Cristais. 
Aos Profs. Drs. Laércio Gomes, Gessé Nogueira e Luiz Tarelho e ao Msc. Anderson Zanardi pelas frutíferas discussões.

À Profa. Dra. Izilda e a Solange pela preparação dos filtros no laboratório de Filmes Finos e pelas dicas de utilização do Cary.

Ao Departamento de Dentística pela permissão em utilizar a cortadeira e a lupa.

Ao Tort pela confecção da adaptação eletrônica com o laser usado.

Ao Marcos e ao Paulo pela confecção de peças tão caprichadas.

A Elsa, Ilze, Vera, Ana, Daniela, Mariuza, Luana, Celestina, Rose, Luciane e Andréa. Sem vocês, nada funciona. Muito obrigada pela atenção, pelos sorrisos, chamegos e cafezinhos.

Ao Valdir, pela amizade e boa vontade em ajudar no experimento.

Ao Marcos Scarpin, pela ajuda com a politriz.

Ao Prof. Dr. Niklaus Wetter, pela ajuda com a caracterização das fibras.

Às minhas grandes amigas Claudia Emilio, Marcella Esteves e Patrícia da Ana por estes anos de maravilhosa convivência com muitas boas risadas, conselhos preciosos e experiências compartilhadas.

À querida Adriana Ribeiro pelos bons momentos na Rose's House e por todos os ensinamentos desde o DF - UFPE.

Ao Prof. Dr. Sandro Stolf e ao Prof. Dr. Luciano Bachmann, pela amizade e por todas as vezes que me ajudaram. 
Aos amigos do Centro de Lasers e Aplicações Aninha, Silvinha, Stella, Fábio, llomar, Filipe Librantz, Karin, Renato, Ilka, Luiz, Aécio, Aguinaldo, Cassius, Ricardo, Tânia, Thiago, Carol e Felipe pela agradável convivência ao longo destes anos.

Ao estatístico Marcus Vinícius e a Thais Cocarelli pelos serviços prestados e por toda a paciência em tirar minhas dúvidas.

A todos os pacientes que participaram do trabalho, sem se opor a testar um novo equipamento e que cederam gentilmente seus dentes extraídos, meu muito obrigada. Sem vocês nada disso seria possível.

Ao Instituto de Pesquisas Energéticas e Nucleares e ao Centro de Lasers e Aplicações pela infra-estrutura para realização deste trabalho.

Ao Departamento de Dentística e ao Laboratório Especial de Lasers em Odontologia da Faculdade de Odontologia da Universidade de São Paulo pelo uso de alguns equipamentos ao longo destes anos.

Ao Sr. Luiz e ao Alex pela constante educação e presteza.

A todos os funcionários do IPEN.

Ao Procad/Capes e ao Cepid.

À Fapesp pelo financiamento deste trabalho com a concessão da bolsa de doutorado direto. 
"O importante não é a saída, mas sim a travessia. Quem passa por nós nunca vai só, nunca nos deixa sós; deixa sempre um pouco de si, leva sempre um pouco de nós." Nathalie Rogers 


\title{
DETECÇÃO DE LESÕES DE CÁRIE POR FLUORESCÊNCIA: CORRELAÇÃO ENTRE A HISTOLOGIA E OS RESULTADOS OBTIDOS COM O DIAGNOdent E A ESPECTROSCOPIA
}

\author{
RENATA MACIEL ROCHA-CABRAL
}

\begin{abstract}
RESUMO
Os objetivos deste estudo foram desenvolver e testar in vivo e in vitro um método de detecção de lesões de cárie utilizando um espectrômetro portátil (EP); analisar o desempenho do EP e do equipamento comercial DIAGNOdent (Dd); correlacioná-los entre si, assim como com o padrão ouro, a área de secção e a profundidade das lesões. Os 66 sítios oclusais de pré-molares foram analisados in vivo com o Dd e, em seguida, a fluorescência induzida por um laser diodo $\left(\lambda_{\text {exc }} \sim 657 \mathrm{~nm}\right)$ foi coletada por fibra óptica, conduzida ao EP e analisada sob a forma de espectros, os quais foram normalizados e para os quais foi calculada a razão da área sob a curva dos espectros cariado e sadio (RACE). Os experimentos foram conduzidos in vitro nos mesmos sítios. O padrão ouro foi obtido por meio de microscopia de luz polarizada. Utilizou-se o índice de correlação linear de Pearson para comparar o Dd e o EP entre si e com a profundidade e área das lesões. A área sob a curva ROC, a sensibilidade, a especificidade e a acurácia foram calculadas e comparadas com o teste de McNemar. O Dd e a RACE apresentaram correlação significante com o padrão ouro ( $p<0,01$ para Dd e $p<0,05$ para RACE) e entre si $(r=0,83$ in vivo e $r=0,87$ in vitro). Os equipamentos apresentaram baixa correlação, porém significante, com a profundidade das lesões tanto in vivo quanto in vitro $(r=\sim 0,43)$. A área de secção transversal da lesão não influenciou nas medidas obtidas com o Dd e o EP. O Dd apresentou maior sensibilidade $(0,76)$ do que o EP $(0,60)$ in vivo $(p<$ $0,05)$, embora isto não tenha aumentado o seu desempenho. In vitro, o EP apresentou maior sensibilidade $(0,88)$ do que o $\mathrm{Dd}(0,79)$, mas essa diferença não foi significante. Os outros parâmetros também não apresentaram diferenças estatisticamente significantes $(p<0,05)$. O EP apresentou correlação positiva com o Dd, igual correlação com a profundidade da lesão e maior capacidade para detectar o tecido cariado in vitro, em relação ao Dd, o que sugere que com ponta convergente e angulada e software dedicado, o método será promissor para utilização em clínicas odontológicas em um futuro próximo.
\end{abstract}




\title{
DETECTION OF OCCLUSAL CARIES LESIONS USING FLUORESCENCE: CORRELATION BETWEEN HISTOLOGY AND OBTAINED RESULTS FOR DIAGNOdent AND SPECTROSCOPY
}

\author{
RENATA MACIEL ROCHA-CABRAL
}

\begin{abstract}
The aims of this study were to develop and test a method to detect caries lesions in vivo and in vitro, using a portable spectrometer (PS); to analyze the performance of PS as well as the commercial device DIAGNOdent (Dd); correlate them with the gold standard, their tranversal section areas and lesions depth and between themselves. 66 occlusal pre-molars sites were examined in vivo with Dd. Sequentially, fluorescence ( $\lambda$ exc $\sim 657 \mathrm{~nm}$ ) was collected by an optical fiber, conducted to PS and then analyzed as spectra, which were normalized and had calculated the Ratios of their Areas Under the Curves (RAUC) of carious and sound tissues. Experiments were conducted in vitro in the same sites. Gold Standard was obtained by polarized light microscopy. Pearson correlation was used to compare the devices with transversal section area, lesions depth and between themselves. The area under ROC curve, sensitivity, specificity as well as accuracy were calculated and verified with McNemar test. Dd and RAUC showed statistically significant correlation with gold standard $(p<0.01$ for Dd and $p<0.05$ for RAUC) and between themselves ( $r=0,83$ in vivo and $r=0,87$ in vitro). Although it was significant, the devices showed low correlation with depth of lesions in vivo and in vitro $(r=\sim 0.43)$. The transversal section area of the lesion had no influence on readings in both devices. Dd showed higher sensitivity $(0.76)$ than PS (0.60) in vivo ( $p<0.05$ ), though this fact was not able to improve its performance. In turn, PS showed higher sensitivity $(0.88)$ than Dd $(0.79)$ in vitro, but this difference was not significantly. The other parameters did not show statistically significant differences $(p<0.05)$ between methods. PS showed positive correlation with $\mathrm{Dd}$, equal correlation with lesions depth and higher ability of detecting the disease in vitro, what suggests that if accompanied with a conic and an angulated probe and a dedicated software, the PS method could be useful in clinics in the near future.
\end{abstract}




\section{SUMÁRIO}

Pág.

1 INTRODUÇÃO

2 OBJETIVOS

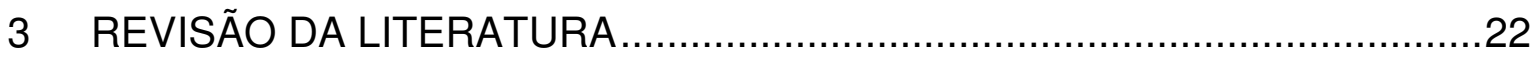

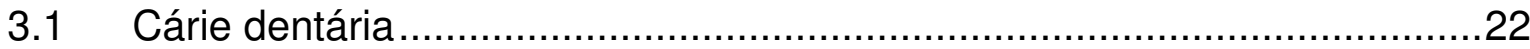

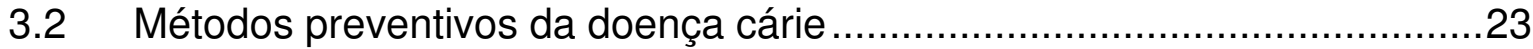

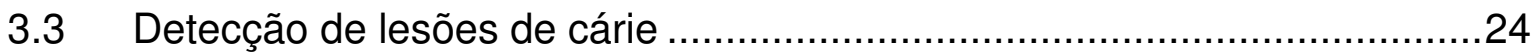

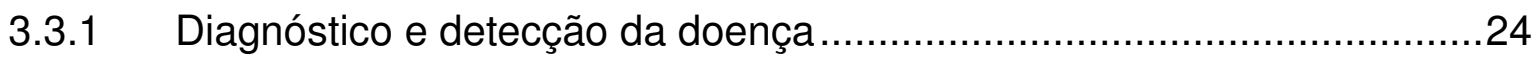

3.3.2 Avaliação dos métodos de detecção da lesão........................................24

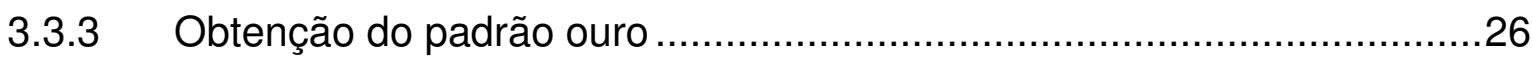

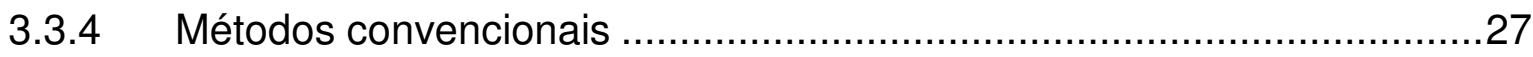

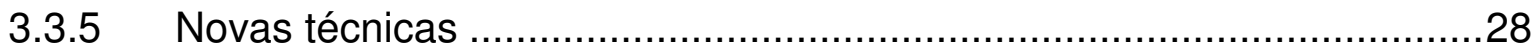

3.3.5.1 Medição da resistência elétrica do dente ...........................................28

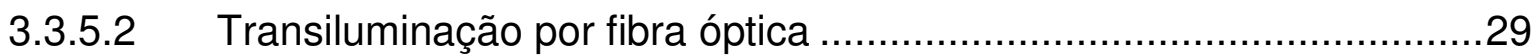

3.3.5.3 Utilização de magnificação por lupas e microscópios clínicos ............29

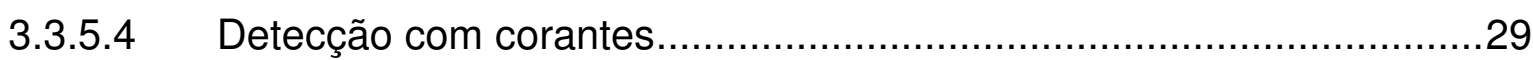

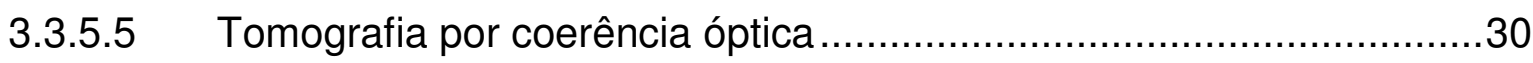

3.3.5.6 Métodos de detecção de lesões de cárie utilizando fluorescência.......30

3.3.6 Interação da luz com o tecido biológico ……........................................30

3.3.6.1 Origem da fluorescência .............................................................32

3.3.6.2 Componentes fluorescentes no tecido dentário ...................................35

3.3.7 Métodos que utilizam fluorescência detecção de lesões de cárie ...........38

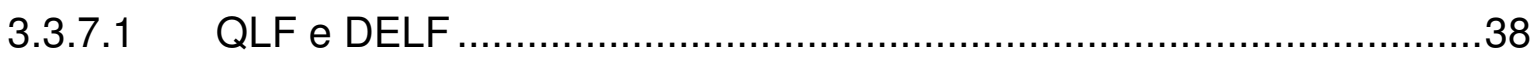

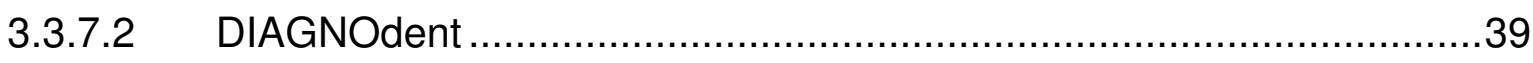

3.3.7.3 Espectroscopia de fluorescência.....................................................42

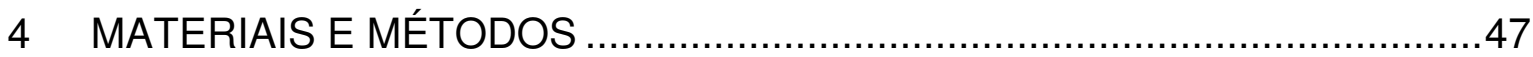

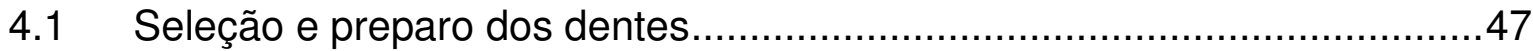

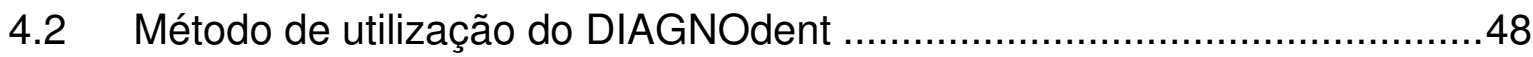

4.3 Elaboração do sistema com espectrômetro portátil....................................48

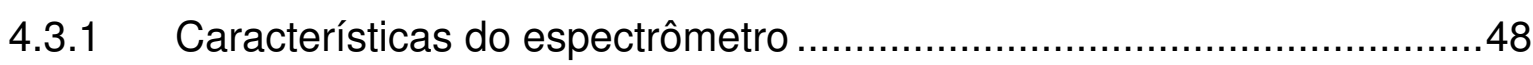

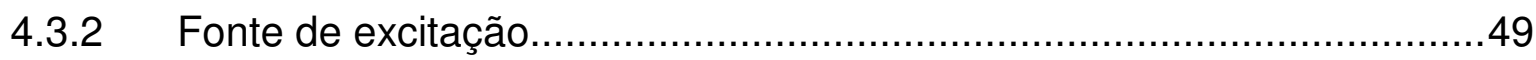

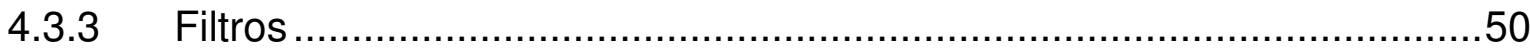


4.3.4 Espectro de transmissão dos filtros ........................................... 50

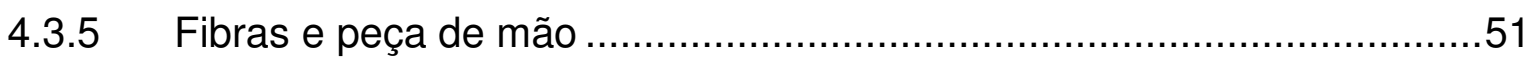

4.3.6 Caracterização das fibras com lâmpada de luz branca ........................53

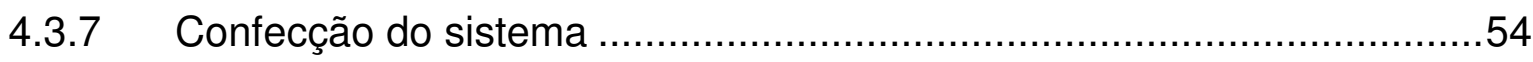

4.3.8 Calibração fonte de excitação...................................................55

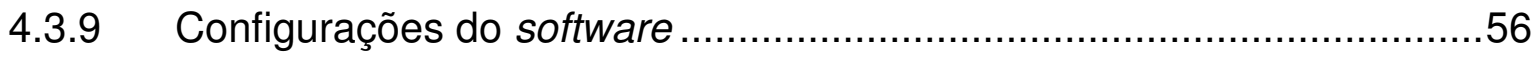

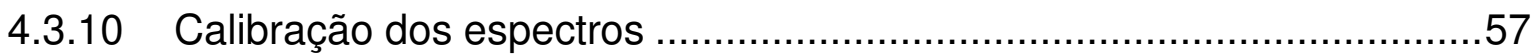

4.4 Modo de utilização in vivo do sistema com espectrômetro........................57

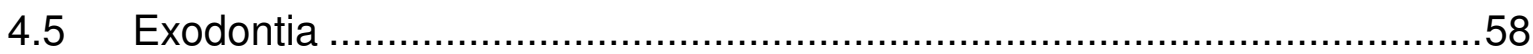

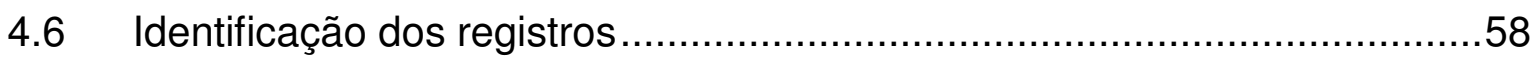

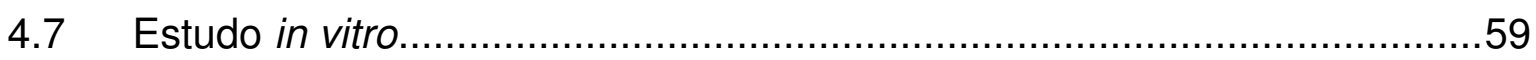

4.8 Obtenção do espectro hidroxiapatita sintética...................................59

4.9 Preparo das amostras para microscopia de luz polarizada ......................60

4.10 Preparo das lâminas...................................................................60

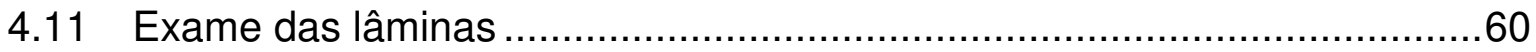

4.12 Análise das imagens histológicas das lesões.....................................62

4.13 Análise estatística .........................................................................63

4.13.1 Desempenho dos equipamentos ................................................64

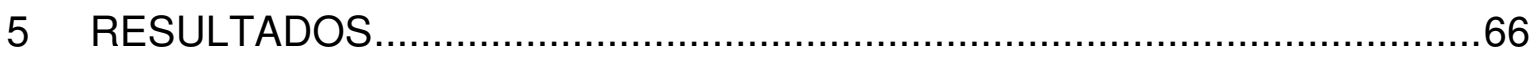

5.1 Estudos com o DIAGNOdent in vivo..............................................66

5.1.1 Correlação: DIAGNOdent x padrão ouro in vivo ................................66

5.1.2 Correlação: DIAGNOdent x profundidade das lesões in vivo ................67

5.2 Estudos com a espectroscopia in vivo...............................................68

5.2.1 Correlação: RACE x padrão ouro in vivo .........................................68

5.2.2 Correlação: RACE do EP x profundidade das lesões in vivo..................69

5.3 Correlação: DIAGNOdent X RACE do EP in vivo..................................70

5.4 Desempenho do DIAGNOdent e do espectrômetro portátil in vivo ............72

5.4.1 Determinação do ponto de corte do DIAGNOdent in vivo.......................72

5.4.2 Determinação do ponto de corte da RACE in vivo................................72

5.4.3 Comparação das Áreas Sob as Curvas ROC (ASC) entre os métodos in

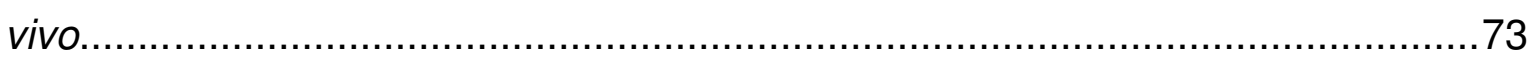

5.4.4 Performance dos equipamentos in vivo ....................................... 74

5.5 Estudos com o DIAGNOdent in vitro ........................................... 75

5.5.1 Correlação: DIAGNOdent x padrão ouro in vitro................................75 
5.5.2 Correlação: DIAGNOdent x profundidade das lesões in vitro.................76

5.6 Estudos com o espectrômetro portátil in vitro.......................................77

5.6.1 Correlação: RACE x padrão ouro in vitro.....................................77

5.6.2 Correlação: RACE x profundidade das lesões in vitro ..........................78

5.7 Correlação: DIAGNOdent x RACE in vitro........................................ 79

5.8 Desempenho do DIAGNOdent e do espectrômetro in vitro.......................80

5.8.1 Determinação do ponto de corte do DIAGNOdent in vitro ......................80

5.8.2 Determinação do ponto de corte da RACE do EP in vitro......................81

5.8.3 Comparação das ASC entre os métodos in vitro ................................82

5.8.4 Performance de ambos os equipamentos in vitro.............................83

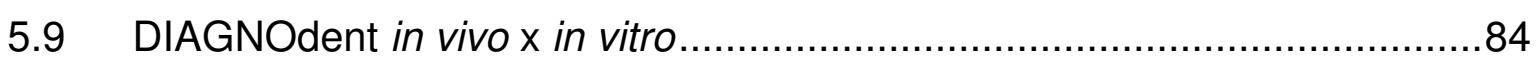

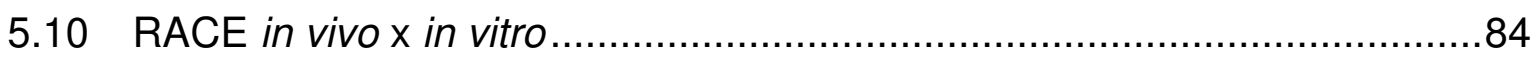

5.11 DIAGNOdent e RACE in vivo e in vitro x área de secção das lesões ........85

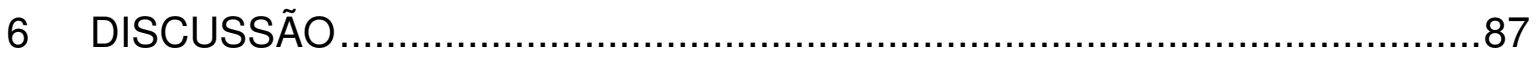

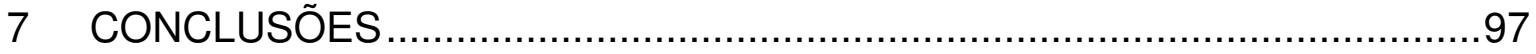

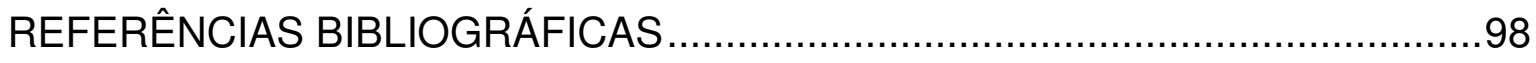




\section{LISTA DE FIGURAS}

FIGURA 1: PossíveIS FENÔMENOS RESULTANTES DA INTERAÇÃO LUZ X TECIDO BIOLÓGICO. (A) REFLEXÃO, (B) ESPALhAmENTO, (C) RETROESPALHAMENTO, (D) TRANSMISSÃO, (E) ABSORÇÃO. EMISSÃO DE FÓTONS COMO POSSÍVEL MECANISMO DE DECAIMENTO APÓS ABSORÇÃO, FOSFORESCÊNCIA OU FLUORESCÊNCIA (F).

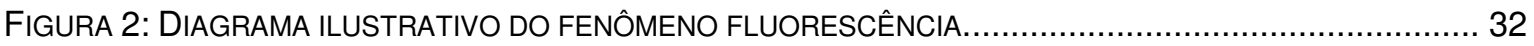

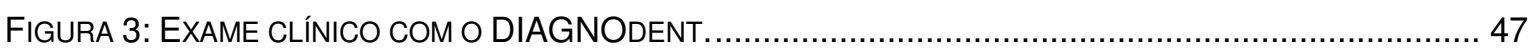

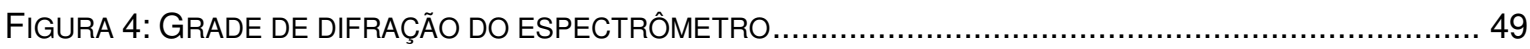

FIGURA 5: ADAPTAÇÃO ELETRÔNICA COM MECANISMO DE CHAVEAMENTO............................................... 49

FIGURA 6: (A) FILTRO MONTADO EM SUPORTE E (B) SUPORTE PARA FILTRO........................................ 50

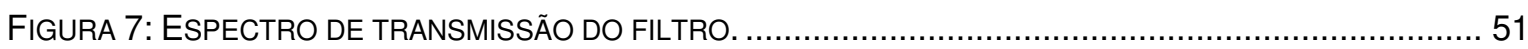

FIGURA 8: PONTA DO DIAGNODENT (A) E DO ESPECTRÔMETRO (B). AS DUAS PONTAS EM RELAÇÃO COM A SUPERFÍCIE (C)..... 52

FIGURA 9: RESPOSTA DAS FIBRAS UTILIZADAS NA REGIÃO DE COMPRIMENTO DE ONDA DE INTERESSE PARA ESTE ESTUDO.

FIGURA 10: Sistema ELABORADO PARA TRANSPORTE PARA CLíNICA. NO DETALHE, A LENTE COLIMADORA UTILIZADA PARA FOCALIZAR A FONTE DE EXCITAÇÃO........................................................ 54

FIGURA 11: SISTEMA ÓPTICO ELABORADO PARA OBTENÇÃO DE MEDIDAS ESPECTROSCÓPICAS. ............... 55

FIGURA 12: POWER METER UTILIZADO PARA AJUSTE DO COMPRIMENTO DE ONDA DA FONTE DE EXCITAÇÃO.

FIGURA 13: PONTA RETA DO ESPECTRÔMETRO POSICIONADA EM MÁXIMA RELAÇÃO DE PERPENDICULARIDADE COM A SUPERFÍCIE EXAMINADA............................................... 57

FIGURA 14: EXEMPLO DE ESPECTROS OBTIDOS DE UM SÍTIO SUSPEITO DE LESÃO DE CÁRIE IN VIVO, APÓS

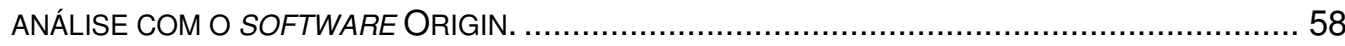

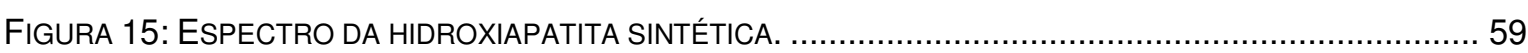

FIGURA 16: MicroscóPIO DE LUZ POLARIZADA LEICA DMLP COM CÂMERA DIGITAL ACOPLADA,

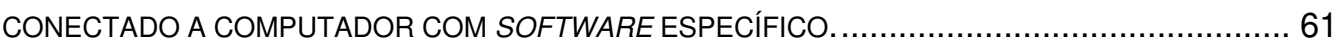

FIGURA 17: EXEMPLOS DE SÍTIOS OBSERVADOS PELO MICROSCÓPIO DE LUZ POLARIZADA (5X)................62

FIGURA 18: METODOLOGIA DA NORMALIZAÇÃO DOS ESPECTROS E OBTENÇÃO DA RACE PARA ESPECTROS

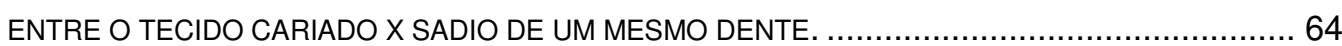

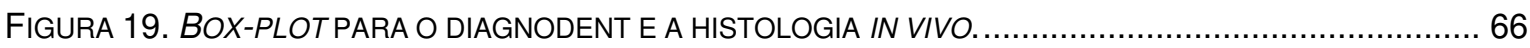

FIGURA 20: DIAGRAMA DE DISPERSÃO ENTRE OS RESULTADOS DA PROFUNDIDADE DAS LESÕES E DAS LEITURAS COM O DIAGNODENT IN VIVO, COM A RETA DE REGRESSÃO E INTERVALOS PARA A PREDIÇÃO. 68

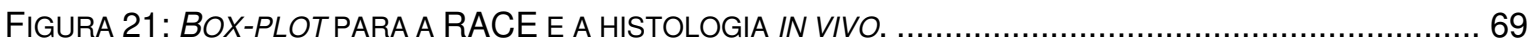

FIGURA 22: DIAGRAMA DE DISPERSÃO ENTRE OS RESULTADOS DA RACE IN VIVOE DA PROFUNDIDADE DAS LESÕES, COM A RETA DE REGRESSÃO E INTERVALOS PARA A PREDIÇÃO. 70

FIGURA 23: DIAGRAMA DE DISPERSÃO ENTRE OS RESULTADOS DA RACE E DO DIAGNODENT IN VIVO, COM A RETA DE REGRESSÃO E INTERVALOS PARA A PREDIÇÃO. 
FIGURA 24: ESPECIFICIDADE, SENSIBILIDADE E SUA SOMA RELACIONADAS COM DIFERENTES PONTOS DE CORTE DO DIAGNODENT IN VIVO PARA O LIMIAR ESMALTE.

FIGURA 25: ESPECIFICIDADE, SENSIBILIDADE E SUA SOMA RELACIONADAS COM DIFERENTES PONTOS DE CORTE DA RACE IN VIVO PARA O LIMIAR ESMALTE. 73

FIGURA 26: COMPARAÇÃO DAS ASC ENTRE OS MÉTOdOS DIAGNOdENT $(0,90)$ E RACE $(0,86)$ IN VIVO . 74

FIGURA 27: BOX-PLOT PARA O DIAGNODENT E A HISTOLOGIA IN VITRO. 76

FIGURA 28: DIAGRAMA DE DISPERSÃO ENTRE OS RESULTADOS DA PROFUNDIDADE DAS LESÕES E DO DIAGNODENT IN VITRO, COM A RETA DE REGRESSÃO E INTERVALOS PARA A PREDIÇÃO. 77

FIGURA 29: BOX-PLOT PARA A RACE E A HISTOLOGIA IN VITRO. 78

FIGURA 30: DIAGRAMA DE DISPERSÃO ENTRE OS RESULTADOS DA RACE E PROFUNDIDADE DAS LESÕES IN VITRO, COM A RETA DE REGRESSÃO E INTERVALOS PARA A PREDIÇÃO. 79

FIGURA 31: DIAGRAMA DE DISPERSÃO ENTRE OS RESULTADOS DA RACE E DO DIAGNODENT IN VITRO, COM A RETA DE REGRESSÃO E INTERVALOS PARA A PREDIÇÃO. 80

FIGURA 32: ESPECIFICIDADE, SENSIBILIDADE E SUA SOMA RELACIONADAS COM DIFERENTES PONTOS DE CORTE DO DIAGNODENT IN VITRO PARA O LIMIAR ESMALTE. 81

FIGURA 33: ESPECIFICIDADE, SENSIBILIDADE E SUA SOMA RELACIONADAS COM DIFERENTES PONTOS DE CORTE DA RACE IN VITRO PARA O LIMIAR ESMALTE. 82

FIGURA 34: COMPARAÇÃO DAS ASC ENTRE OS MÉTOdOS DIAGNOdENT $(0,93)$ E RACE $(0,85)$ IN VITRO .

FIGURA 35: DIAGRAMAS DE DISPERSÃO PARA A RACE DO EP E PARA O DIAGNODENT, IN VIVO E IN VITRO.. 86 


\section{LISTA DE TABELAS}

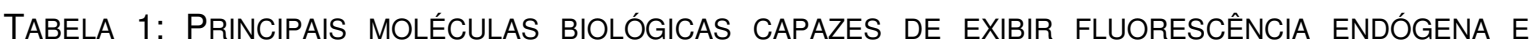
RESPECTIVOS COMPRIMENTOS DE ONDA DE EXCITAÇÃO E EMISSÃO. 35

TABELA 2: COMPRIMENTOS DE ONDA DE EXCITAÇÃO E EMISSÃO DE FLUORESCÊNCIA TESTADOS NA

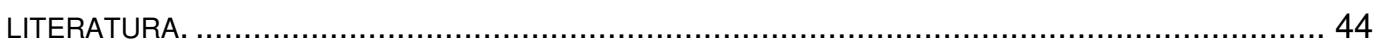

TABELA 3: DIFERENÇAS ENTRE AS FIBRAS UTILIZADAS NO EXPERIMENTO............................................ 52

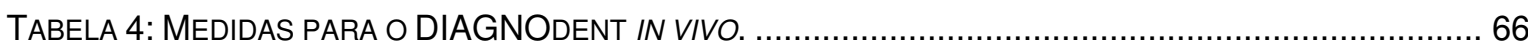

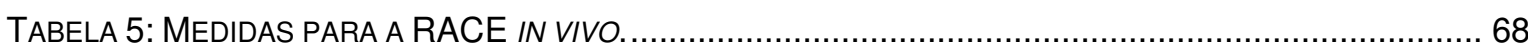

TABela 6: Performance dos EQUiPAMENTOS DIAGNOdENT E ESPECTRÔMETRO PORTÁTIL IN VIVO NA DETECÇÃO DE LESÕES DE CÁRIE, EXPRESSA EM SENSIBILIDADE, ESPECIFICIDADE, ACURÁCIA E ÁREA SOB A CURVA ROC (ASC). PARA O LIMIAR, DO FOI CONSIDERADO SEM LESÃO DE CÁRIE E

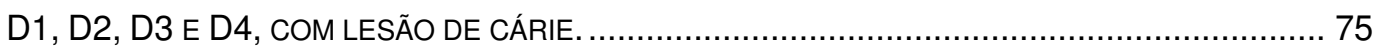

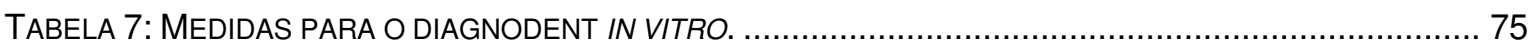

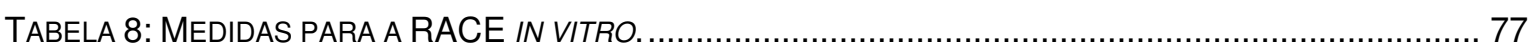

TABela 9: PeRformance dos EQUIPAMENTOS DIAGNOdENT E ESPECTRÔMETRO PORTÁtIL IN VITRO NA DETECÇÃO DE LESÕES DE CÁRIE, EXPRESSA EM SENSIBILIDADE, ESPECIFICIDADE, ACURÁCIA E ÁREA SOB A CURVA ROC (ASC). D0 FOI CONSIDERADO SEM LESÃO DE CÁRIE E D1, D2 E D3, COM LESÃO DE CÁRIE.

Tabela 10: Performance do diagnodent in VIVO E IN Vitro Na DeteCÇÃo de lesões de CÁRIE, EXPRESSA EM SENSIBILIDADE, ESPECIFICIDADE, ACURÁCIA E ÁREA SOB A CURVA ROC (ASC). D0 FOI CONSIDERADO SEM LESÃO DE CÁRIE E D1, D2 E D3, COM LESÃO DE CÁRIE. 84

TABELA 11: PeRFORMANCE do ESPECTRÔMETRO IN VIVO E IN VITRO NA DETECÇÃO DE LESÕES DE CÁRIE, EXPRESSA EM SENSIBILIDADE, ESPECIFICIDADE, ACURÁCIA E ÁREA SOB A CURVA ROC (ASC). D0 FOI CONSIDERADO SEM LESÃo DE CÁRIE E D1, D2, D3 E D4, COM LESÃO DE CÁRIE. 


\section{LISTA DE ABREVIATURAS, SIGLAS E SÍMBOLOS}

\begin{tabular}{ll}
$\sim$ & Aproximadamente \\
AIGalnP & Laser de diodo de Alumínio, Gálio, Índio e Fósforo \\
ASC & Área Sob a Curva ROC \\
CCD & Charge Couple Device \\
D0 & Sem lesão de cárie \\
D1 & Lesão de cárie limitada à metade externa do esmalte \\
D2 & Lesão de cárie limitada à metade interna do esmalte \\
D3 & Lesão de cárie limitada à metade externa da dentina \\
D4 & Lesão cárie envolvendo a metade interna da dentina \\
DELF & Dye Enhanced Light Fluorescence \\
ECM & Electrical Conductance Measurement \\
EP & Espectrômetro Portátil \\
EUA & Estados Unidos da América \\
F & Íon Flúor \\
FN & Falso-Negativo \\
FOTI & Fiber Optics Transillumination \\
FP & Falso-Positivo \\
He-Ne & Laser de Hélio-Neônio \\
IC & Intervalo de Confiança \\
InGaN & Laser de diodo de Índio, Gálio e Nitrogênio \\
$\lambda$ & Lâmbda (comprimento de onda) \\
$\lambda$ em & Lâmbda de emissão \\
$\lambda$ exc & Lâmbda de excitação \\
LIF & Light Induced Fluorescence \\
$>$ & Maior que \\
$<$ & Menor que \\
$\mu m$ & Micrometro \\
ms & Milissegundo \\
$\mathrm{mW}$ & Miliwatt \\
$\mathrm{N}$ & Índice de refração \\
$\mathrm{NAD}$ & Nicotinamida Adenina Dinucleotídeo \\
\hline
\end{tabular}




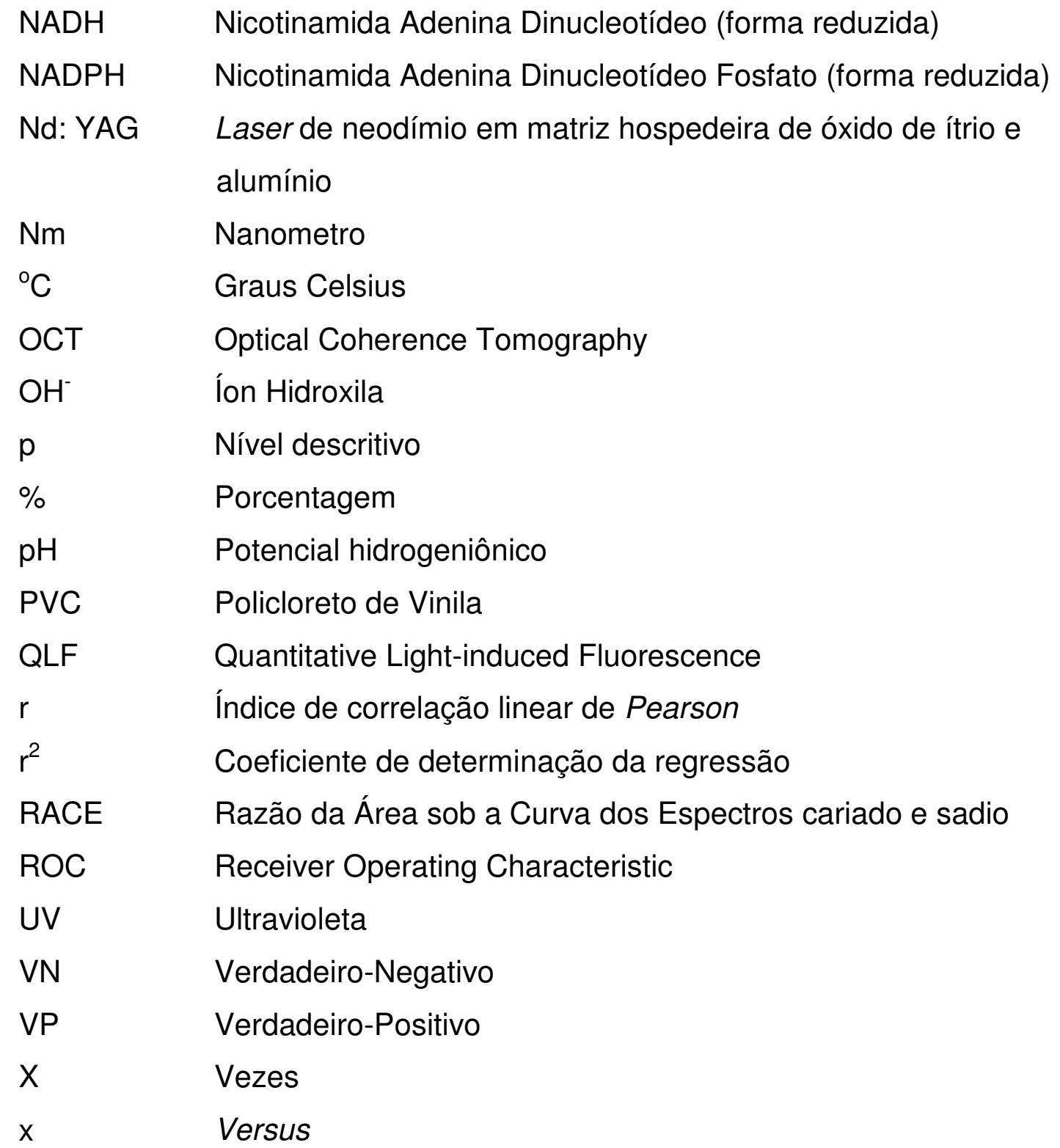




\section{INTRODUÇÃO}

A cárie dentária é uma doença infecciosa, crônica e dinâmica que se desenvolve a partir de alterações bioquímicas e ultra-estruturais e pode causar a destruição do tecido dentário por meio da perda mineral ${ }^{1,2}$.

O maior conhecimento dos fatores envolvidos no processo da doença aliado ao fato de que nos estágios iniciais ela pode ser revertida e paralisada, encorajaram pesquisadores a desenvolver técnicas para prevenir a sua evolução 3,4

Utilizados com esse intuito, os compostos fluoretados foram introduzidos na vida cotidiana da população na água, sob a forma de soluções, em dentrifícios. Como resultado, uma relevante diminuição na incidência e na prevalência da doença foi observada. Contudo, constatou-se que, devido a sua configuração anatômica, as superfícies lisas são mais beneficiadas pela ação dos fluoretos em detrimento das superfícies oclusais. Assim, apesar de representarem apenas cerca de $12 \%$ do total das superfícies dentárias presentes na cavidade bucal, as superfícies oclusais são as mais afetadas pelo processo carioso ${ }^{5,6,7}$.

Nestas superfícies, a utilização de fluoretos promoveu alterações na macromorfologia da doença, de forma que as lesões não cavitadas ou em estágios iniciais de desenvolvimento se tornaram mais prevalentes do que as lesões cariosas cavitadas. Isso pode ser atribuído ao fato de que o flúor age remineralizando a camada mais superficial do esmalte, enquanto a lesão progride

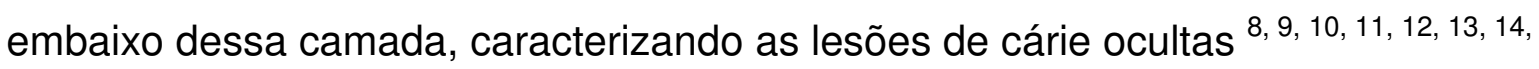
$15,16,17$.

Essa mudança no processo da cárie tem acentuado a necessidade de métodos de deteç̧ão mais precisos e objetivos, que apresentem bom desempenho diante de mínimas alterações minerais ${ }^{18,19,20,21,22,23,24 .}$

Os métodos convencionais utilizados para a detecção de lesões de cárie incluem a inspeção visual, a sondagem táctil e a imagem radiográfica. Apesar de esses métodos apresentarem uma alta especificidade (capacidade em detectar o tecido sadio), apresentam baixa sensibilidade (capacidade em detectar a doença) e baixa reprodutibilidade, uma vez que são métodos subjetivos ${ }^{25}$. Nesses termos, concebe-se que são métodos limitados, principalmente no que diz respeito à detecção de lesões iniciais. 
Métodos baseados na medição da fluorescência tecidual têm sido investigados como uma nova alternativa para a detecção de lesões de cárie por permitirem o exame não invasivo e quantitativo da substância dura do elemento dentário 26, 27, 28, 29.

A quantificação da fluorescência induzida por luz (QLF) utiliza um laser de argônio ( $\lambda \sim 488 \mathrm{~nm}$ ) e tem sido usada em faces lisas para medir pequenas alterações minerais ${ }^{25,30}$. Apesar de apresentar bons resultados em lesões iniciais, o método não é adequado para detecção de lesões oclusais e não é de fácil utilização para a prática clínica.

Um sistema baseado na captação da fluorescência emitida pelo tecido cariado foi desenvolvido. Denominado DIAGNOdent, o equipamento possui um laser diodo que emite luz vermelha $(\lambda \sim 655 \mathrm{~nm})$, a qual é absorvida por componentes orgânicos e inorgânicos do tecido dentário ${ }^{31,32,33}$, de modo que a região desmineralizada exibe maior fluorescência que a sadia. Apesar de ser um aparelho portátil e de fácil utilização, fatores como a presença de placa na superfície examinada, manchas, restaurações, autoclavagem de pontas podem interferir na interpretação dos dados obtidos com o equipamento $34,35,36,37,38,39,40$.

A técnica de espectroscopia de fluorescência vem sendo estudada e a excitação do tecido com vários comprimentos de onda foi testada em experimentos in vitro, apresentando resultados promissores na detecção de lesões de cárie. O método permite que a lesão seja detectada com alta sensibilidade e especificidade por meio da diferenciação entre espectros de regiões sadias e desmineralizadas, mas ainda não é prático em clínicas odontológicas ${ }^{41,42,43}$.

A utilização de um espectrômetro portátil para detecção de lesões de cárie em clínicas seria interessante para verificar se há uma eventual melhora no desempenho em relação ao DIAGNOdent, com referência a lesões de cárie mais iniciais. Esse fator aliado à necessidade de estudos clínicos validados histologicamente foi preponderante para o desenvolvimento desta pesquisa. 


\section{OBJETIVOS}

Os objetivos deste estudo foram:

- Desenvolver e testar um método quantitativo para a detecção de lesões de cárie iniciais, utilizando um espectrômetro portátil;

- Analisar o desempenho in vivo e in vitro do espectrômetro portátil e do equipamento comercial DIAGNOdent e

- Correlacionar os resultados obtidos com os equipamentos entre si, assim como com o padrão ouro, a área da secção transversal e a profundidade das lesões. 


\section{REVISÃO DA LITERATURA}

\subsection{Cárie dentária}

O dente é uma estrutura complexa constituída por diferentes tecidos. A porção visível à boca denomina-se coroa dentária. Na porção mais interna da coroa encontra-se a polpa, sobre a qual se situa a dentina, que, por sua vez, é recoberta pelo esmalte dentário.

O esmalte dentário, portanto, é a camada mais externa do dente e primariamente atingida pela doença cárie. Trata-se do tecido mais mineralizado do corpo humano, consistindo em cerca de $95 \%$ em massa de conteúdo inorgânico, $3 \%$ de água e $2 \%$ de conteúdo orgânico composto essencialmente por proteínas ${ }^{44,45}$. O conteúdo inorgânico é constituído principalmente por sais de fosfato de cálcio, dispostos em uma estrutura cristalina denominada hidroxiapatita que pode incorporar vários íons durante a formação do esmalte e é susceptível à dissolução pela ação de ácidos.

Os carboidratos fermentáveis ingeridos na dieta, como a sacarose, constituem-se em substratos que são metabolizados por microorganismos presentes na placa bacteriana. Como resultado, ocorre a produção de ácidos que podem solubilizar o mineral do dente. Isto acontece porque quando o $\mathrm{pH}$ intra-oral está baixo ocorre uma inversão de equilíbrio entre o meio e a hidroxiapatita, de forma que a saliva e o fluido da placa se tornam subsaturados em relação à porção mineral do dente, favorecendo com que os íons hidrogênio desloquem os íons de cálcio e fosfato da hidroxiapatita para a saliva, o que caracteriza a desmineralização. O fenômeno inverso acontece em condições fisiológicas $(\mathrm{pH}$ próximo ao neutro), nas quais a saliva e o fluido da placa encontram-se supersaturadas em relação ao sais de fosfato de cálcio, permitindo que novos cristais sejam incorporados ao esmalte; é conhecido como processo de remineralização ${ }^{1}$. A cárie dentária acontece como resultado de um desequilíbrio decorrente desta constante troca iônica, em favor da desmineralização.

Assim, o desenvolvimento e estabelecimento da doença dependem da interação entre os fatores: presença de bactérias acidogênicas, susceptibilidade do hospedeiro (em relação às características da estrutura dentária e saliva), substratos por meio da dieta (carboidratos fermentáveis) e o tempo. A presença 
isolada de qualquer um destes fatores não é capaz de conduzir à doença. Nem mesmo a coexistência dos três primeiros fatores simultaneamente resulta em perda mineral imediata. Para isso, é necessário que esta situação persista por algum tempo para que ocorra desmineralização ${ }^{2}$. Portanto, a doença cárie tem caráter dinâmico, uma vez que pode ser revertida, e possui etiologia multifatorial.

\subsection{Métodos preventivos da doença cárie}

O maior conhecimento dos fatores envolvidos no processo da doença cárie aliado ao fato de que nos estágios iniciais ela pode ser revertida e paralisada encorajaram pesquisadores a desenvolver métodos para prevenir a evolução da doença. Entre essas técnicas encontram-se o uso do flúor, o controle químico e mecânico da placa, a substituição da sacarose por adoçantes menos cariogênicos e a irradiação com lasers de alta intensidade ${ }^{\text {9, } 46}$.

A acentuada diminuição na prevalência e incidência da doença cárie pode ser atribuída ao aumento da disponibilidade de compostos com baixa dosagem de flúor tanto na água fluoretada como em dentrifícios, enxaguatórios bucais e em aplicações clínicas ${ }^{47}$. Os fluoretos interferem no equilíbrio dinâmico da interface dente / fluidos orais ${ }^{48}$.

Em soluções supersaturadas, em que o flúor está disponível juntamente com íons cálcio e fósforo, os íons flúor são prontamente incorporados na estrutura da apatita, através de precipitação. A substituição do $\mathrm{OH}^{-}$pelo $\mathrm{F}^{-}$provoca um forte aumento na estabilidade química da estrutura, reduzindo a sua solubilidade e, portanto, aumentando a resistência do esmalte à desmineralização ${ }^{49}$.

Contudo, constatou-se que devido a sua configuração anatômica, as superfícies lisas são mais beneficiadas pela ação dos fluoretos em detrimento das fóssulas e fissuras das superfícies oclusais. Assim, apesar de representarem apenas cerca de $12 \%$ do total das superfícies dentárias presentes na cavidade bucal, as superfícies oclusais são as mais afetadas pelo processo carioso 4, 5, 9, 50, $51,52,53$

Nestas superfícies, a utilização de fluoretos promoveu alterações na macromorfologia da doença, de forma que as lesões não cavitadas ou em estágios iniciais de desenvolvimento se tornaram mais prevalentes do que as lesões cariosas cavitadas. Isso pode ser atribuído ao fato de que o flúor age 
remineralizando a camada mais superficial do esmalte, enquanto a lesão progride embaixo dessa camada, caracterizando as lesões de cárie ocultas ${ }^{8,9,13,15,16,17 .}$

Essa mudança no processo da doença cárie tem acentuado a necessidade de métodos de detecção mais precisos e objetivos, que apresentem bom desempenho diante de mínimas alterações minerais 14, 17, 18, 19, 20, 21, 22, 23, 24, 54.

\subsection{Detecção de lesões de cárie}

\subsubsection{Diagnóstico e detecção da doença}

Diagnóstico é a habilidade de distinguir a doença por meio dos seus sinais e sintomas. A sintomatologia da doença refere-se às suas características subjetivas observadas do ponto de vista do indíviduo doente, como dor ou histórico. Por sua vez, o termo detecção de lesões de cárie designa a constatação dos sinais da doença, como cor ou aspecto da lesão ${ }^{55}$. Assim, como este trabalho se limita a estudar o desempenho de equipamentos diante da detecção dos sinais da doença cárie, sem considerar os sintomas da doença, ao longo do trabalho, será utilizado apenas o termo detecção. Contudo, é válido ressaltar que antes da decisão por intervenção operatória na clínica diária, os métodos de detecção de lesões de cárie devem ser utilizados levando-se em consideração o histórico clínico, o risco de cárie e os hábitos alimentares do paciente ${ }^{36}$.

\subsubsection{Avaliação dos métodos de detecção da lesão}

Os resultados de um método de detecção de lesões de cárie deve ser comparado com um padrão ouro, que se trata de uma técnica mais precisa e geralmente invasiva que identifica o verdadeiro estágio da doença. Desta correlação são possíveis os resultados:

- Verdadeiro-Positivo (VP) - padrão ouro e teste indicam a presença da doença;

- Falso-Positivo (FP) - padrão ouro indica a ausência e o teste indica a presença da doença;

- Verdadeiro-Negativo (VN) - padrão ouro e teste indicam a ausência da doença; 
- Falso-Negativo (FN) - padrão ouro indica a presença e o teste indica a ausência da doença.

Um método ideal para a detecção de lesões de cárie, portanto, deveria proporcionar um número máximo de detecções verdadeiras e um mínimo de falsas detecções, visto que estas podem conduzir o clínico a um subtratamento, no caso de resultado FN ou a um sobretratamento, no caso de resultado FP.

Os índices mais utilizados para avaliar o desempenho de um método são a sensibilidade e a especificidade. A sensibilidade é a capacidade do sistema em detectar a doença quando o tecido está realmente afetado, ou seja, é a razão do número total de deteç̧ões VP pela soma das detecções VP e FN. A especificidade é a capacidade do teste em ser negativo entre os dentes sadios, ou seja, é a razão do número total de detecções VN pela soma das detecções VN e FP. Esses índices são expressos em porcentagem de acertos nos indivíduos doentes (sensibilidade) e nos indivíduos sem a doença (especificidade). Assim, quanto mais próximos de 1,0 forem a sensibilidade e a especificidade, melhor 0 método de detecção ${ }^{56,57}$.

Contudo, geralmente quando um teste apresenta alta sensibilidade, apresenta uma especificidade reduzida, em contrapeso. Da mesma forma, quando a especificidade é alta, ocorre uma diminuição da sensibilidade ${ }^{58}$. A decisão por um teste com alta especificidade ou sensibilidade deverá, portanto, ser baseada na prevalência da doença. Quando uma população apresenta baixos índices de lesões de cárie, é mais adequada a utilização de métodos com alta especificidade, pois se é utilizado um método com alta sensibilidade em detrimento da especificidade, um maior número de FP irá acontecer. O mesmo raciocínio se aplica para lesões com alta prevalência de lesões de cárie ${ }^{59}$.

A acurácia representa o índice total de acertos, ou seja, é o número de resultados verdadeiros (VP + VN) dividido pelo número de sítios examinados ${ }^{56}$. Para avaliar a severidade da doença, ainda é possível utilizar a análise ROC (Receiver Operating Characteristic). A curva ROC se constitui em uma escala de decisões sobre a presença ou ausência da lesão de cárie baseada em diferentes pontos de corte. $\mathrm{Na}$ dependência do ponto de corte escolhido, a proporção de dentes com presença ou ausência da doença é diferente. Assim, em um valor abaixo deste ponto crítico, a descalcificação não seria considerada cárie, por exemplo ${ }^{56}$. 
A curva ROC é obtida pela construção de um gráfico que relaciona a proporção VP (sensibilidade) contra a proporção FP (1-especificidade). A partir deste gráfico, pode-se calcular a área sob a curva, o que proporciona um valor numérico para o teste. Assim, quanto maior for a área sob a curva ROC, melhor o desempenho do teste. Valores próximos a 0,5 indicam que o desempenho do teste não é adequado e valores próximos a 1 indicam o seu desempenho máximo. A área sob a curva ROC possibilita a fácil visualização das diferenças entre os métodos $^{13}$.

A comparação dos valores de cada parâmetro para cada método pode ser verificada estatisticamente, por exemplo, com o teste de McNemar ${ }^{60}$.

\subsubsection{Obtenção do padrão ouro}

Os métodos aceitos para realização do padrão ouro para lesões de cárie geralmente são invasivos, isto é, requerem a secção do dente examinado, por exemplo. Assim, por motivos éticos, só podem ser utilizados em estudos in vitro, in situ ou após a exodontia do dente. Contudo, outras análises como a profundidade e a área da lesão podem ser feitas a partir das secções do dente. Essas análises são obtidas com o auxílio de lupa estereoscópica ou microscopia 3 .

Para as lesões de cárie oclusal, a avaliação da severidade das lesões normalmente segue uma classificação de 5 escores ${ }^{61}$ :

- $\mathrm{D0}=$ sem lesão de cárie;

- D1= lesão de cárie limitada à metade externa do esmalte;

- D2= lesão de cárie limitada à metade interna do esmalte, sem atingir a dentina;

- D3= lesão de cárie limitada à metade externa da dentina e

- D4= lesão de cárie envolvendo a metade interna da dentina.

Para se obter um bom contraste entre o esmalte sadio e a lesão utilizando-se a microscopia de luz polarizada, o uso de água destilada como meio de embebição e a sobreposição de uma lâmina de quartzo facilitam o processo ${ }^{57}$.

Após confrontar essas análises com os resultados obtidos com 0 equipamento, tem-se a validação histológica. 


\subsubsection{Métodos convencionais}

Os métodos convencionais mais freqüentemente utilizados pelos cirurgiões-dentistas para detecção de lesões de cárie incluem o método tátil e radiográfico e a inspeção visual. Esses métodos oferecem uma performance diagnóstica relativamente boa. Apresentam índice de especificidade variando de 0,63 a 1,00. Contudo, apresentam baixa sensibilidade $(0,01$ a 0,67$)$ e são métodos subjetivos, ou seja, a interpretação dos resultados depende dos conhecimentos, da análise crítica e da capacidade de percepção do indivíduo que julga os casos. Portanto, os métodos convencionais não possibilitam o monitoramento da lesão ao longo do tempo, ou seja, não são reprodutíveis. Considerando estas limitações, outros métodos e parâmetros foram combinados aos métodos tradicionais para melhorar a capacidade de detecção e evitar suas

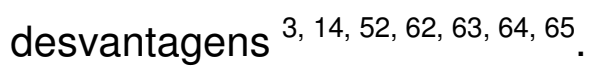

Assim, em 1924, o método tátil baseava-se na utilização de uma sonda pontiaguda com pressão sobre o esmalte e, se fosse necessário o menor esforço para remover a sonda, esta região deveria ser marcada para restauração mesmo que não houvesse sinal de lesão de cárie ${ }^{66}$. Hoje se preconiza a utilização de sondas com ponta romba, pois verifica-se que uma sonda exploradora pontiaguda utilizada com pressão pode desestruturar uma superfície com potencial de remineralização e assim induzir lesões de cárie ${ }^{13,67}$.

A técnica de inspeção visual para detecção de lesões de cárie oclusal apresenta alta especificidade, porém baixa sensibilidade, o que permite um maior número de diagnósticos falso-negativos e também apresenta baixa reprodutibilidade, não se mostrando adequado para o monitoramento de lesões ${ }^{3}$, $21,62,68$.

Com o intuito de melhorar a sensibilidade e a reprodutibilidade do método, a iluminação dos refletores odontológicos foi magnificada e um sistema de escores baseados nas características ópticas das lesões foi desenvolvido ${ }^{69,70 \text {, }}$ ${ }^{71}$ e a utilização de exame radiográfico interproximal como coadjuvante no diagnóstico é recomendada ${ }^{62,63,71,72}$.

O método radiográfico foi aperfeiçoado. A dose de radiação foi reduzida, o equipamento de raios-X e a película radiográfica foram melhorados $\mathrm{e}$ o método ainda tem sido complementado com técnicas digitais. Contudo, uma vez 
que a grande quantidade de tecido sadio presente nas lesões iniciais altera a obtenção da imagem radiolúcida e a anatomia das faces oclusais causa a sobreposição deste complexo sobre o filme, o método só permite a detecção da doença quando a desmineralização já atingiu a dentina e, portanto, lesões oclusais em esmalte não são detectadas ${ }^{57,65,73,74}$.

\subsubsection{Novas técnicas}

Diante da nova realidade epidemiológica da cárie dentária, os métodos convencionais de detecção podem ser considerados inadequados ou limitados, principalmente no que diz respeito às lesões incipientes e/ou ocultas. Desta forma, muitas investigações vêm sendo realizadas com a finalidade de se desenvolver um método ideal.

Esse método hipotético deveria possuir ótimo desempenho, isto é, ser capaz de detectar mínimas alterações sem prejuízo da detecção de lesões mais extensas, ser quantitativo e não invasivo, ter baixo custo operacional, ser fácil de manusear e de transportar e ainda permitir o monitoramento objetivo da lesão ao longo do tempo.

Entre as técnicas desenvolvidas encontram-se a medição da resistência elétrica do dente (ECM); a transiluminação por fibra óptica (FOTI); a utilização de lupas e microscópios clínicos; a pigmentação com corantes e a tomografia por coerência óptica (OCT) e ainda os métodos que se baseiam na fluorescência: a fluorescência induzida por laser com utilização de corantes (DELF), a quantificação da fluorescência induzida por luz (QLF); o DIAGNOdent e a espectroscopia por fluorescência.

\subsubsection{Medição da resistência elétrica do dente}

A técnica de medição da resistência elétrica do dente ou Electrical Conductance Measurement (ECM) baseia-se na diferença de condutividade elétrica entre a região sadia e cariada em um mesmo dente ${ }^{14}$. A resistência do esmalte diminui com o aumento da porosidade. Quando o esmalte está desmineralizado, portanto, a condutividade elétrica do dente aumenta ${ }^{75}$. A técnica mostrou-se mais efetiva do que o método radiográfico, com a vantagem de 
possibilitar o monitoramento das lesões ao longo do tempo ${ }^{76}$. O método apresenta sensibilidade mais alta que a inspeção visual, porém sua especificidade é mais baixa ${ }^{13}$.

\subsubsection{Transiluminação por fibra óptica}

O método de transiluminação por fibra óptica ou Fiber Optics Transillumination (FOTI) é um método qualitativo que avalia a diferença de transmissão da luz entre a região sadia e cariada em um mesmo dente. Foi proposto como uma alternativa à detecção de lesões interproximais para substituição das radiografias ${ }^{72}$. Apresenta como vantagem diante das radiografias a facilidade no uso, não utilizar radiação ionizante e não requerer 0 uso de equipamentos pesados e de alto custo. Contudo, apesar de mostrar resultados melhores do que a inspeção visual e o método radiográfico para lesões em dentina, a técnica mostra baixa sensibilidade na deteç̧ão de lesões de cárie iniciais na superfície oclusal e o contraste entre a região sadia e cariada depende da direção de iluminação pelo operador ${ }^{26,64,77}$.

\subsubsection{Utilização de magnificação por lupas e microscópios clínicos}

A utilização de lupas e microscópios clínicos permite a visualização da lesão com vários graus de magnificação. Contudo, a sua utilização para detecção precoce de lesões de cárie tem sido questionada. Enquanto alguns estudos afirmam que, utilizando microscópio com 10X e 20X de magnificação, a técnica não apresenta desempenho superior ao da inspeção visual sem magnificação ${ }^{24}$, 53 , outros relatam um aumento na sensibilidade utilizando lupa com $3 X$ de aumento ${ }^{63,78}$.

\subsubsection{Detecção com corantes}

A técnica de detecção de lesões de cárie utilizando corante permite a identificação da doença por meio da pigmentação da matriz orgânica da dentina menos mineralizada ${ }^{79}$. Assim, tecidos desmineralizados retêm mais o corante, criando contraste entre as lesões e o tecido circunjacente. Contudo, o método apresenta baixa especificidade e pode corar indevidamente dentes sem lesões de 
cárie, devido ao conteúdo orgânico presente no dente; é subjetivo, devido à avaliação individual da escala de cores. Além disso, a pigmentação por corantes e a penetração bacteriana são fenômenos independentes, o que limita o uso de corantes com este fim $^{80,81}$.

\subsubsection{Tomografia por coerência óptica}

A Tomografia por coerência óptica ou Optical Coherence Tomography (OCT) é uma técnica não invasiva baseada na construção de imagens internas bi e tridimensionais de estruturas biológicas, que correspondem a cortes transversais da amostra. O método utiliza um interferômetro de baixa coerência e é capaz de medir a luz retroespalhada em função da profundidade do tecido, tipicamente com $10 \mu \mathrm{m}$ de resolução e, portanto, permite a quantificação de pequenas alterações nas propriedades ópticas do dente, como, por exemplo, a detecção de lesões iniciais de cárie. Apesar de ser um método objetivo que apresenta alta performance, a técnica ainda está em fase de estudo laboratorial no campo da odontologia. Além disso, atualmente seu alto custo inviabiliza a utilização clínica ${ }^{82,83,84}$.

\subsubsection{Métodos de detecção de lesões de cárie utilizando fluorescência}

A fluorescência induzida por luz ou Light Induced Fluorescence (LIF) tem sido considerada uma grande proposta para detectar lesões de cárie por permitir a sua quantificação de forma não invasiva e com boa performance.

Entre os métodos que se baseiam na fluorescência, a fluorescência induzida por laser com utilização de corantes (DELF), a quantificação da fluorescência induzida por luz (QLF) e, principalmente, o DIAGNOdent e a espectroscopia por fluorescência serão estudados mais detalhadamente.

\subsubsection{Interação da luz com o tecido biológico}

Os possíveis fenômenos simultâneos resultantes da interação luz $x$ tecido dentário estão representados na Figura 1 e compreendem: reflexão (a), espalhamento (b), retroespalhamento (c), transmissão (d), absorção (e). Para os 
casos em que ocorrer a absorção, entre os mecanismos de decaimento está a emissão da fosforescência ou da fluorescência (f).

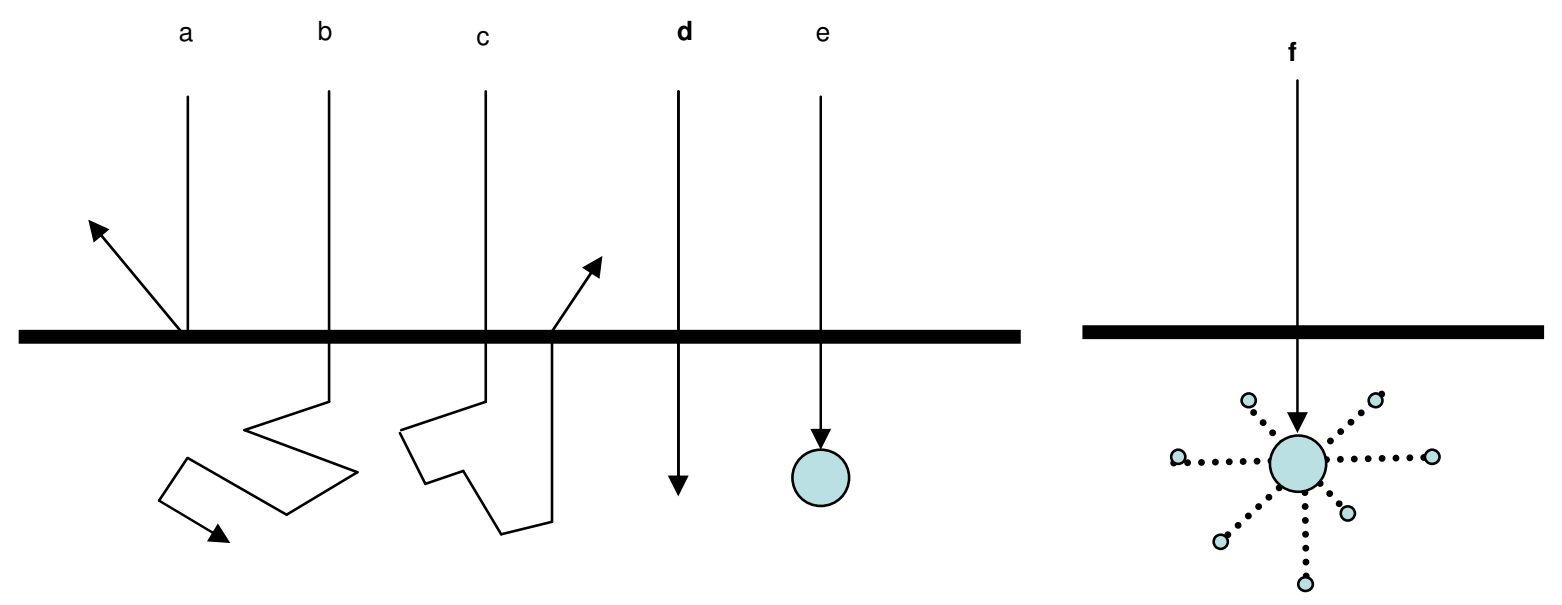

Figura 1: Possíveis fenômenos resultantes da interação luz $x$ tecido biológico. (a) reflexão, (b) espalhamento, (c) retroespalhamento, (d) transmissão, (e) absorção.

Emissão de fótons como possível mecanismo de decaimento após absorção, fosforescência ou fluorescência (f).

A aparência visual do dente depende da luz que o ilumina, se ela é espalhada ou absorvida. O espalhamento é o processo no qual o fóton muda de direção enquanto se propaga no dente, mas não perde energia (Figura 1, b) . Já a absorção é o processo no qual a luz é convertida para outras formas de energia (Figura 1,e).

Em uma lesão incipiente, o espalhamento é muito maior que no esmalte sadio. A luz muda de direção várias vezes e, conseqüentemente, muitas vezes os fótons são retroespalhados antes de alcançar a dentina. Portanto, uma lesão inicial parece ser mais branca que as outras partes do dente. $O$ aspecto de lesões marrons se deve à presença de material absorvedor na lesão. Assim, quando se observa uma lesão na superfície oclusal, o examinador observa uma sombra escura, a qual deverá ser considerada como suspeita de lesão. Como toda a luz muda de direção devido ao espalhamento antes da absorção, a sombra é difusa, o que a torna de difícil deteç̧ão ${ }^{85}$.

A fluorescência ocorre como um dos possíveis fenômenos decorrentes da absorção. Ao absorver a radiação eletromagnética, os elétrons são 
transferidos para estados mais elevados de energia. Esse processo é conhecido como excitação e os elétrons encontram-se, portanto, em um estado excitado. No processo de desexcitação, os elétrons podem decair um ou mais níveis de energia, podendo retornar ao seu nível energético fundamental. Este decaimento pode se dar sob a forma de emissão luminosa. Dependendo do tempo de vida da emissão, ela pode ser classificada como fosforescência ou fluorescência.

A cor da fluorescência corresponderá à energia emitida durante o decaimento. Devido à perda de energia nesse processo, a banda de fluorescência emitida possui comprimentos de onda maiores que o da fonte de excitação (Figura 2).

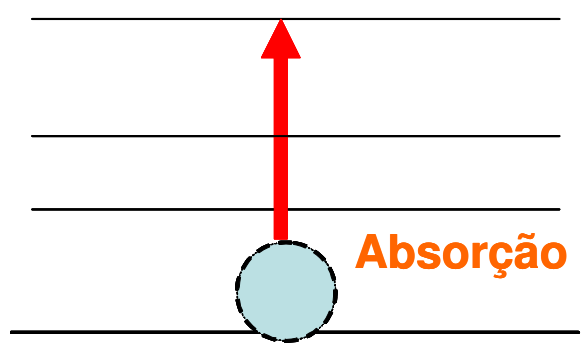

Estado fundamental

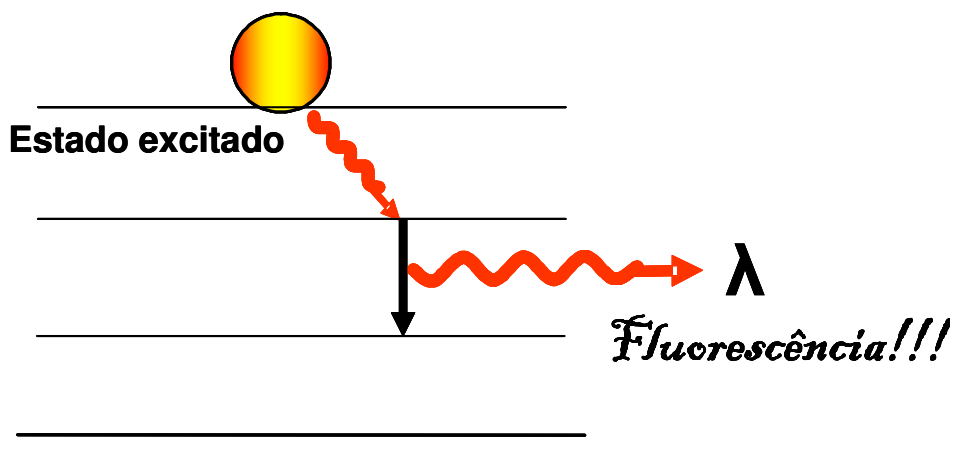

Estado fundamental

Figura 2: Diagrama ilustrativo do fenômeno fluorescência.

\subsubsection{Origem da fluorescência}

Apesar de a fluorescência ser bastante estudada, a origem dessa emissão nos tecidos dentários ainda não está completamente esclarecida. Muitas são as teorias e poucas são as evidências para explicar o fenômeno. Além disso, os estudos não são consistentes entre si. Contudo, acreditamos que para desenvolver um método de detecção de lesões de cárie se faz necessário ter conhecimento acerca da sua fundamentação. Assim, foi feita uma revisão da literatura, primeiramente enumerando as moléculas biológicas capazes de exibir fluorescência com seu comprimento de onda de excitação e de emissão. Em seguida, essa revisão foi separada por diferentes comprimentos de onda de 
excitação e direcionada aos tecidos dentários, com a intenção de melhor organizála.

A desmineralização do tecido dentário é acompanhada por alterações ópticas no tecido, nas quais se fundamentam os métodos de detecção que utilizam a fluorescência. A emissão desta luz varia em função do comprimento de onda de excitação do tecido, de forma que a excitação no UV dá origem a emissão entre o violeta e o azul; a excitação no azul origina a fluorescência azul, verde ou amarela e da excitação vermelha, provém a fluorescência vermelha ou infravermelha próxima. Os comprimentos de onda de excitação e de emissão utilizados para detecção de lesões de cárie serão abordados com detalhes subseqüentemente.

No tecido cariado ocorre um maior espalhamento da luz devido às diferenças dos índices de refração entre as condições sadio e doença. No tecido sadio a hidroxiapatita $(n=1,62)$ predomina em relação à agua e na presença da cárie ocorre um aumento de água $(n=1,33)$ nos espaços intercristalinos em substituição à hidroxiapatita, de forma que um maior espalhamento da luz pode ser observado ${ }^{86,87}$.

O esmalte sadio é constituído por uma estrutura de prismas com propriedades de guiar ondas e, se o dente for irradiado com fótons, estes penetrarão profundamente no dente. Quando a estrutura do esmalte está alterada, as propriedades de guiamento de ondas diminuem ou desaparecem e assim a radiação não penetra tão profundamente. Dessa forma, um aumento significante no espalhamento da luz pode ser observado no processo da doença. O maior espalhamento da luz no tecido cariado induz a uma menor intensidade de fluorescência, devido ao fato de diminuir a quantidade de luz que chega até os compostos fluorescentes ou por ocultar a fluorescência da dentina ou da ligação amelo-dentinária. Portanto, o sinal de fluorescência obtido apresenta menor intensidade quando comparado com a fluorescência do tecido sadio, quando o dente é excitado com luz azul, por exemplo ${ }^{88,89,90 .}$

À medida que se aumenta o comprimento de onda de excitação, a intensidade geral da fluorescência vai diminuindo e esse decréscimo é mais acentuado para o tecido sadio, de forma que utilizando comprimentos de onda de excitação maiores do que 500nm, a lesão de cárie passa a apresentar maior 
intensidade de fluorescência do que o tecido sadio, embora esta intensidade geral seja menor quando a excitação é feita com comprimentos de onda maiores ${ }^{91}$.

O sinal de fluorescência é maior em relação ao tecido sadio quando o dente é excitado com luz vermelha porque a cor vermelha é menos espalhada pelo esmalte do que comprimentos de ondas mais curtos e, por isso, ela penetra mais profundamente no dente, o que a permite alcançar os compostos fluorescentes mesmo que estes se encontrem na dentina ou na ligação amelodentinária ${ }^{88}$.

Os possíveis componentes fluorescentes citados na literatura absorvem os fótons de maneira distinta frente a diferentes comprimentos de onda de excitação. Na cárie, isso acontece porque a doença é constituída por uma estrutura complexa com diferentes absorvedores e derivados de produtos bacterianos, onde cada um deles contribui na obtenção do sinal ${ }^{90}$. Entretanto, destes possíveis fatores dos quais se origina a fluorescência no tecido dentário, alguns são consenso entre a maioria dos autores e, portanto, serão definidos previamente.

Os cromóforos compreendem todas as moléculas de origem orgânica ${ }^{89}$ que absorvem luz. Os fluoróforos são os cromóforos capazes de reemitir parte desta luz que foi absorvida e, portanto, de exibir fluorescência e as porfirinas são fluoróforos com propriedades autofluorescentes. As porfirinas são moléculas precursoras da síntese heme e são produzidas por diversos tipos de bactérias presentes na cavidade oral ${ }^{29,92,93 .}$

Entre as moléculas biológicas conhecidas na literatura capazes de exibir fluorescência, podem-se citar os aminoácidos, as proteínas estruturais, as enzimas e coenzimas, as vitaminas, os lipídios e as porfirinas (Tabela1). 
Tabela1: Principais moléculas biológicas capazes de exibir fluorescência endógena e respectivos comprimentos de onda de excitação e emissão ${ }^{93,94}$.

\begin{tabular}{|c|c|c|c|}
\hline \multicolumn{2}{|c|}{ Fluoróforos endógenos } & Excitação (nm) & Emissão (nm) \\
\hline \multirow{3}{*}{ Aminoácidos } & Triptofano & 280 & 350 \\
\hline & Tirosina & 275 & 300 \\
\hline & Fenilalanina & 260 & 280 \\
\hline \multirow{2}{*}{ Proteínas estruturais } & Colágeno & 325 & 400,405 \\
\hline & Elastina & 290,325 & 340,400 \\
\hline \multirow{3}{*}{ Enzimas e coenzimas } & Flavinas & 450 & 535 \\
\hline & $\mathrm{NADH}$ & 290,351 & 440,460 \\
\hline & NADPH & 336 & 464 \\
\hline \multirow{3}{*}{ Vitaminas } & A & 327 & 510 \\
\hline & $\mathrm{K}$ & 335 & 480 \\
\hline & $\mathrm{D}$ & 390 & 480 \\
\hline \multirow{6}{*}{$\begin{array}{c}\text { Vitamina } \mathrm{B}_{6} \mathrm{e} \\
\text { compostos }\end{array}$} & Piridoxina & 332,340 & 400 \\
\hline & Piridoxamina & 335 & 400 \\
\hline & Piridoxal & 330 & 385 \\
\hline & Ácido Piridóxico & 315 & 425 \\
\hline & Fosfato piridoxal 5 & 330 & 400 \\
\hline & Vitamina $B_{12}$ & 275 & 305 \\
\hline \multirow{2}{*}{ Lipídios } & Fosfolipídios & 436 & 540,560 \\
\hline & Lipofucsina & $340-395$ & $540,430-460$ \\
\hline Porfirinas & Porfirinas & $400-450$ & 630,690 \\
\hline
\end{tabular}

\subsubsection{Componentes fluorescentes no tecido dentário}

- $\lambda_{\text {exc }} \mathrm{UV}(\lambda<400 \mathrm{~nm})$

Componentes inorgânicos (hidroxiapatita sintética e esmalte) e orgânicos fluorescem quando excitados com comprimento de onda no ultravioleta 40,93

Entre os compostos orgânicos fluorescentes podem-se incluir os produtos bacterianos, fluoróforos não identificados e alguns componentes de origem protéica como a tirosina, o triptofano e a piridina ${ }^{92,93,95,96}$. As porfirinas não são os principais responsáveis pela alteração na intensidade da fluorescência excitada com UV ${ }^{92}$. 
A diminuição do $\mathrm{pH}$ no processo da cárie não é um fator responsável pela alteração no sinal da fluorescência nesta região de comprimento de onda ${ }^{43}$.

\section{- $\quad \lambda_{\text {exc }}$ violeta e azul $(407<\lambda<488 \mathrm{~nm})$}

A diminuição da fluorescência quando o tecido cariado é excitado com estes comprimentos de onda pode ser atribuída, em parte, à mudança na estrutura da superfície, causada pelos processos de desmineralização ${ }^{90}$.

Para alguns autores, uma melhor explicação poderia ser a incorporação de moléculas fluorescentes exógenas durante o processo carioso, como as proteínas do plasma. Entre elas, a albumina, a qual ganharia acesso a estes tecidos pela via circulatória. Essas moléculas se encontram em pequenas quantidades na dentina sadia e suas concentrações poderiam ser aumentadas quando o processo de degradação se iniciasse ${ }^{89}$.

Para outros, importantes fluoróforos responsáveis pela origem da fluorescência excitando com azul são os aminoácidos triptofano e tirosina, as coenzimas NADH, NADPH, flavinas, colágeno e elastina. Além desses fluoróforos, a fluorescência vermelha é geralmente baseada em porfirinas endógenas fluorescentes, mais especificamente, as protoporfirinas IX. Diferentes microorganismos são capazes de sintetizar essas moléculas ${ }^{29,98,99}$. Todos esses fluoróforos, exceto as porfirinas, são excitados pela radiação UV - azul, enquanto as porfirinas são excitadas pela luz azul e vermelha ${ }^{92}$.

Entretanto, as bactérias envolvidas no processo inicial da cárie como $S$. mutans e lactobacilos não fluorescem significantemente. Os estreptococos fluorescem mais intensamente no verde e os lactobacilos não apresentam fluorescência no vermelho. Assim seria necessária a presença de bactérias em lesões de cárie de dentina para que esses microorganismos fossem responsáveis pela fluorescência ${ }^{98,100,101,102}$.

Essas bactérias que sintetizam porfirinas fluorescentes incluem a Prevotella intermedia, Actinomyces odontolyticus, Corynebacterium spp., Candida albicans e Pseudomonas aeruginosa. Desta forma, é provável que outros fatores estejam associados à origem da fluorescência em lesões iniciais de cárie ${ }^{98}$. 
A diminuição do $\mathrm{pH}$ no processo da cárie bem como as proteases exógenas não parecem estar relacionadas com alteração no sinal da fluorescência também com esta faixa de comprimento de onda de excitação ${ }^{101}$.

\section{- $\lambda_{\text {exc }}$ vermelha (633 a $\left.655 \mathrm{~nm}\right)$}

De acordo com a tabela de fluoróforos endógenos apresentada (Tabela1), a origem da fluorescência infravermelha proveniente da excitação no comprimento de onda vermelho não seria devido à presença de nenhum destes componentes, já que a emissão máxima entre eles seria observada com as porfirinas, que fluoresceriam somente no vermelho $(\lambda<690 \mathrm{~nm})$.

Em relação ao tecido dentário especificamente, essa assertiva contraria alguns experimentos realizados com este comprimento de onda de excitação. Ao incubar bactérias, constatou-se que não só elas apresentavam fluorescência, mas também o meio de cultura circunjacente, o que sugeriu que os produtos bacterianos contribuíssem para a presença deste sinal. Para verificar se as porfirinas se encontravam entre esses produtos, soluções com diferentes concentrações de protoporfirina IX foram excitadas $(\lambda \sim 655 \mathrm{~nm})$. Observou-se que quanto mais concentrada era a solução, maior era a intensidade do sinal e, portanto, constatou-se que era provável que os metabólitos bacterianos responsáveis pelo aumento da fluorescência neste comprimento de onda fossem as porfirinas, ainda porque seu espectro de emissão em muito se assemelhava com o espectro observado na lesão de cárie. Contudo, ainda não está esclarecido se elas são dominantes ou se existem outros componentes fluorescentes envolvidos neste processo. Assim, as porfirinas fluoresceriam também na região do infravermelho próximo ${ }^{15,29,92}$, apesar de absorverem a luz principalmente na região do azul ${ }^{99}$.

Considera-se que o aumento da fluorescência do tecido cariado quando excitado com vermelho se deva mais aos metabólitos bacterianos do que à desintegração cristalina ${ }^{103}$.

Entre os microorganismos que aumentam as concentações de porfirinas, encontram-se algumas espécies de bactérias anaeróbicas Bacteroides, que produzem protoporfirina IX e fazem parte da microbiota oral. Além dessas 
bactérias, a Propionibacterium, algumas linhagens da bactéria Clostridium e da Actinomyces sintetizam porfirinas ${ }^{92}$.

Além das lesões de cárie, estudos demonstraram que a placa bacteriana fluoresce fortemente quando excitada e se sugere que esta fluorescência se deva à presença de porfirinas em bactérias da placa, particularmente as Gram-negativas anaeróbicas, as quais são mais numerosas na placa tardia ${ }^{92,35}$.

Os fosfatos de cálcio que constituem a hidroxiapatita não parecem ser os principais responsáveis pela origem da emissão neste comprimento de onda ${ }^{29}$.

Esses são os fatores citados na literatura que estão envolvidos na origem da fluorescência quando o tecido dentário é excitado com os comprimentos de onda testados. É possível que outros fatores contibuam na origem do sinal e, ainda, diferentes comprimentos de onda podem ser utilizados com este mesmo fim.

\subsubsection{Métodos que utilizam fluorescência detecção de lesões de cárie}

\subsubsection{QLF e DELF}

A técnica de quantificação da fluorescência induzida por luz (QLF) se baseia na excitação do tecido dentário com laser de argônio operando em 488nm (azul). A fluorescência amarela resultante desta interação é transportada para uma câmera CCD que capta a imagem do dente. Esta câmera possui um filtro passa alta que permite apenas a transmissão de comprimentos de onda maiores que 540nm. As imagens são armazenadas e analisadas com o auxílio de um software apropriado. As áreas desmineralizadas aparecem como manchas escuras, contrastando com o tecido sadio. Este programa ainda permite a quantificação da perda mineral por meio da diferença entre a fluorescência das regiões sadias e cariadas do dente, já que com excitação neste comprimento de onda, a intensidade da fluorescência é mais intensa no tecido sadio do que no tecido cariado ${ }^{75}$.

O método tem sido testado em vários estudos in vitro ${ }^{104,105}$ e in vivo 106, 107 e apresentou boa correlação com perda mineral em lesões iniciais em faces lisas ${ }^{108,109}$ e alta confiabilidade em um estudo in vivo ${ }^{107}$. Contudo, o método não 
é indicado para o diagnóstico de lesões oclusais, tampouco para lesões em dentina ${ }^{110}$ e seus resultados podem ser afetados por vários fatores como a hidratação do dente ${ }^{111,112}$, qualidade / tipo da câmera utilizada ${ }^{113}$, a luz ambiente 114 e a presença de pigmentação ${ }^{115}$.

A técnica de fluorescência induzida por laser com utilização de corantes ou Dye Enhanced Laser Fluorescence (DELF) utiliza corantes fluorescentes com a intenção de melhorar a performance de detecção do QLF. Alguns estudos apontam para o aumento da sensibilidade da técnica com 0 corante em relação ao que não utiliza o corante ${ }^{52,116}$. Contudo, há evidências de que a técnica não permite a discriminação adequada da perda mineral devido às moléculas dos pigmentos serem grandes e não penetrarem totalmente na lesão e continua sendo indicado apenas para faces lisas. Outra dificuldade em relação ao uso destes corantes, é a diferenciação entre lesões de cárie e outras porosidades que podem ocorrer no dente, como hipocalcificações devidas a trauma, fluorose ou infecção periapical e o desprendimento de tempo para a sua aplicação ${ }^{117}$.

Assim, embora o QLF tivesse se mostrado viável em estudos in vivo, o método não é facilmente disponível nem utilizado na prática clínica. Além disso, não apresenta bom desempenho diante de lesões em superfícies oclusais, tampouco para lesões em dentina ${ }^{110}$.

\subsubsection{DIAGNOdent}

Comercialmente disponível desde 1998, este equipamento foi desenvolvido após a constatação de que ao excitar o tecido dentário com luz no comprimento de onda no vermelho, obtinha-se uma intensidade da fluorescência bem maior em tecidos cariados do que em tecidos sadios ${ }^{103}$.

O equipamento, baseado na fluorescência induzida pelo laser de diodo (InGalnP), emite luz vermelha com comprimento de onda de 655nm e potência na faixa de $1 \mathrm{~mW}$. Essa luz é conduzida por uma fibra central e direcionada à superfície do dente a ser examinada. A luz é absorvida por componentes

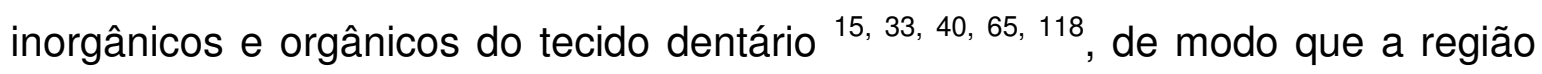
desmineralizada exibe maior fluorescência que a sadia.

A fluorescência infravermelha resultante da interação tecidual é coletada por nove fibras periféricas arranjadas concentricamente ao redor da fibra 
central condutora de luz. Essas fibras são conectadas a uma ponta, que pode ser convergente para superfícies oclusais, ou reta para superfícies lisas.

Comprimentos de onda menores que 680nm são bloqueados por um filtro e a luz refletida é eliminada. O feixe de luz e a detecção são sincronizadas para evitar que a luz ambiente influencie na obtenção das medidas. Um fotodetector mede a quantidade total da fluorescência que passa pelo filtro e 0 mostrador mostra o valor em tempo real e o valor máximo (escala relativa de 0 a 99) $29,31,119$.

O equipamento requer calibração antes que qualquer medida seja realizada. Para isso, um padrão de cerâmica com valor de fluorescência conhecido e estável acompanha o equipamento ${ }^{29}$. A ponta a ser utilizada na detecção deve ser posicionada sobre a referência e o equipamento, acionado. Caso seja utilizado algum invólucro sobre a ponta para prevenção de contaminação cruzada, como o filme PVC, esta deverá ser calibrada com a proteção ${ }^{34}$. O fabricante recomenda proceder a esta calibração freqüentemente.

O fabricante ainda recomenda uma limpeza prévia dos dentes que serão examinados com o equipamento e uma calibração individual para cada paciente. Esse procedimento é realizado posicionando a ponta sobre uma região visivelmente sadia do mesmo dente que será analisado, ao mesmo tempo que se aciona um dispositivo. O valor observado no mostrador é eletronicamente subtraído das medidas subseqüentes.

Após as calibrações, a ponta deve ser posicionada em contato e perpendicularmente ao sítio suspeito realizando movimentos pendulares. $O$ valor máximo deve ser, então, registrado.

Além de permitir a detecção de lesões de cárie de forma quantitativa e não invasiva, o DIAGNOdent é um equipamento de fácil utilização, alimentado por cinco baterias $(7,5 \mathrm{~V})$, compacto e portátil $(600 \mathrm{~g})$, e ainda oferece alta sensibilidade e reprodutibilidade na detecção de cárie quando comparado com os métodos convencionais $16,120,121,122$. Porém, apesar de mostrar-se uma técnica revolucionária do ponto de vista da odontologia diagnóstica há algumas décadas, principalmente porque o equipamento é um desafio à detecção de lesões em 
superfícies oclusais e lesões de cárie ocultas, existem estudos que apontam para algumas limitações do equipamento $24,38,123$.

Essas limitações vêm sendo bastante pesquisadas de forma que foram levantados vários fatores capazes de influenciar nas leituras com o equipamento, diminuindo sua performance e induzindo à realização de sub ou sobretratamentos.

Entre os fatores relacionados com o aumento do valor das leituras no equipamento, conseqüente aumento da sensibilidade e do número de detecções falso-positivas, podem-se incluir a pigmentação dos sítios avaliados e a utilização de pastas de dente e profiláticas com propriedades fluorescentes ${ }^{37,67,124}$.

Já os fatores tempo de uso do equipamento, o desgaste das pontas e o uso inadequado do filme PVC podem induzir a uma diminuição nos valores das leituras, com conseqüente aumento da especificidade e do número de detecções falso-negativas ${ }^{23,34}$.

Existem ainda fatores que podem aumentar ou diminuir os valores das leituras do equipamento, ambas as possibilidades contribuem para uma diminuição no desempenho do equipamento.

A presença de biofilme e cálculos pode se tornar uma fonte de fluorescência por conter depósitos orgânicos e bactérias e, neste caso, aumentar as leituras 125, 126, ou pode aumentar o espalhamento da luz, diminuir a quantidade de luz que atinge a lesão e, assim, diminuir os valores das medidas ${ }^{35}$.

Manchas e restaurações podem bloquear a fluorescência ou se tornar fontes de fluorescência, e ainda, a diferença no ponto de corte adotado para as leituras, a calibração inadequada do DIAGNOdent ou distúrbios no desenvolvimento dentário e soluções de armazenamento em estudos laboratoriais podem aumentar ou diminuir esses valores, a depender da metodologia de uso ${ }^{23}$, $34,71,110,127,128$

Acredita-se que o equipamento reflete preferencialmente mudanças no material orgânico, relacionadas à presença de bactérias e produtos bacterianos, do que no conteúdo inorgânico do dente, provavelmente devido à presença de porfirinas nas lesões de cárie ${ }^{15,17,28,33,38,65,118,129}$. 


\subsubsection{Espectroscopia de fluorescência}

Em termos gerais, a espectroscopia de fluorescência consiste em uma técnica quantitativa e não invasiva na qual um tecido é excitado com luz monocromática com subseqüente captação do sinal resultante da interação tecidual por fibras. Um detector converte o sinal óptico em sinal digital, o qual é visualizado sob a forma de espectros (comprimento de onda $x$ intensidade do sinal) com o auxílio de um computador. Os espectros são diferenciados entre o tecido sadio e doente.

Com fins odontológicos, a técnica permite que alterações minerais mínimas sejam detectadas com alta sensibilidade e especificidade, proporcionando uma detecção de lesões acurada $88,91,93,130,131$.

O estudo da espectroscopia passou a ser de interesse de vários pesquisadores quando se descobriu que o dente exibia fluorescência e que na presença de lesão de cárie, o padrão dessa emissão era alterado.

Os primeiros estudos espectroscópicos envolvendo tecidos dentários tiveram início em 1911 quando Stübel (apud Buchalla et al., 2005) excitou o dente humano com luz UV e tiveram continuidade com os estudos de Benedict (1928) e Hartles e Leaver (1953), que comprovaram a existência da emissão da fluorescência do dente quando este era excitado com esta radiação (apud Buchalla et al., 2005) ${ }^{91}$.

Assim, várias outras investigações foram feitas utilizando outros comprimentos de onda e modificando a metodologia com o intuito de desenvolver uma nova técnica de detecção de lesões de cárie.

Os comprimentos de onda de excitação em 337, 488, 515 e 633nm foram testados e foi observado que o tecido cariado era melhor diferenciado do sadio excitando em $488 \mathrm{~nm}$, de forma que quando havia desmineralização, o sinal da emissão diminuía. Não foi observada fluorescência com excitação no vermelho, entrentanto, os autores não investigaram se havia presença do sinal na região do infravermelho próximo ${ }^{26}$. Assim, estudos com excitação no vermelho foram esquecidos durante alguns anos, enquanto os estudos envolvendo excitação no azul foram aperfeiçoados e técnicas foram desenvolvidas baseandose nestes princípios. 
Recentemente, foi avaliada a capacidade de um sistema espectroscópico em discriminar o tecido dentário sadio e cariado utilizando os comprimentos de onda de excitação de 442, 532 e 632nm. Um alto contraste entre a região sadia e doente pôde ser observado para os comprimentos de onda extremos, enquanto o contraste com excitação em 532nm foi menos evidente ${ }^{74}$.

Bons resultados foram obtidos ao analisar a eficiência de um laser diodo ( $\lambda \sim 405 \mathrm{~nm}$ ) em diferenciar lesões de cárie não cavitadas com diferentes aspectos, constatando que o método permite distinguir diferentes estágios de progressão da doença ${ }^{131}$.

Assim, é possível constatar que várias são as fontes de excitação que podem ser utilizadas para distinção de tecidos. Deve ser destacado que os picos de emissão de fluorescência podem variar a depender da influência da curva de transmissão dos filtros, do detector utilizado, bem como do grupo de dente estudado ${ }^{97}$.

A seguir apresenta-se o resumo dos resultados obtidos de alguns trabalhos realizados utilizando a técnica de espectroscopia por fluorescência para o diagnóstico de lesões de cárie (Tabela 2). 
Tabela 2: Comprimentos de onda de excitação e emissão de fluorescência testados na literatura.

\begin{tabular}{|c|c|c|c|c|}
\hline Laser/luz & Excitação & $\begin{array}{l}\text { Diferenciação } \\
\text { cariado x sadio }\end{array}$ & $\begin{array}{l}\text { Fluorescência } \\
\text { (pico principal) }\end{array}$ & Referência \\
\hline $\mathrm{HeCd}$ & $\begin{array}{c}\text { UV } \\
(325 \mathrm{~nm})\end{array}$ & Sim & $\begin{array}{l}\text { Violeta } \\
(425 \mathrm{~nm})\end{array}$ & Song et al., $2005^{95}$ \\
\hline Nitrogênio & $\begin{array}{c}\text { UV } \\
(337 \mathrm{~nm})\end{array}$ & Sim & $\begin{array}{c}\text { Azul } \\
(\sim 490 \mathrm{~nm})\end{array}$ & $\begin{array}{l}\text { Subhash et al., } 2005^{9 /} ; \\
\text { Borisova et al., } 2004^{43}\end{array}$ \\
\hline Diodo (InGaN) & $\begin{array}{c}\text { Azul } \\
(405 \mathrm{~nm})\end{array}$ & Sim & $\begin{array}{c}\text { Azul-verde } \\
(480-520 \mathrm{~nm})\end{array}$ & Ribeiro et al., $2005^{131}$ \\
\hline Kriptônio & $\begin{array}{c}\text { Azul } \\
(407 \mathrm{~nm})\end{array}$ & Sim & $\begin{array}{c}\text { Amarela/laranja } \\
(590-635 \mathrm{~nm})\end{array}$ & Konig et al., $1993^{98}$ \\
\hline $\mathrm{HeCd}$ & $\begin{array}{c}\text { Azul } \\
(442 \mathrm{~nm})\end{array}$ & Sim & $\begin{array}{c}\text { Azul } \\
(522 \mathrm{~nm})\end{array}$ & $\begin{array}{c}\text { Ribeiro Figueiredo et } \\
\text { al., } 2005^{74}\end{array}$ \\
\hline Argônio & $\begin{array}{l}\text { Azul/verde } \\
(488 \mathrm{~nm})\end{array}$ & Sim & $\begin{array}{l}\text { Amarela } \\
(>540 \mathrm{~nm})\end{array}$ & $\begin{array}{c}\text { Bjelkhagen et al., } 1982 \\
\text { 25; Hibst Paulus, } 1999 \\
27\end{array}$ \\
\hline Nd: YAG & $\begin{array}{c}\text { Verde } \\
(532 \mathrm{~nm})\end{array}$ & Baixa & $\begin{array}{c}\text { Amarela } \\
(574-594 \mathrm{~nm})\end{array}$ & $\begin{array}{c}\text { Ribeiro Figueiredo et } \\
\text { al., } 2005^{74}\end{array}$ \\
\hline $\mathrm{He}-\mathrm{Ne}$ & $\begin{array}{l}\text { Vermelho } \\
(633 \mathrm{~nm})\end{array}$ & Sim & $\begin{array}{c}\text { Vermelha } \\
(683-686 \mathrm{~nm})\end{array}$ & $\begin{array}{c}\text { Taubinsky et al.2000 }{ }^{92} \text {; } \\
\text { Ribeiro Figueiredo et } \\
\text { al., } 2005^{74}\end{array}$ \\
\hline $\begin{array}{l}\text { Diodo (AIGalnP) } \\
\text { DIAGNOdent }\end{array}$ & $\begin{array}{l}\text { Vermelho } \\
(655 \mathrm{~nm})\end{array}$ & Sim & $\begin{array}{c}\text { Infravermelha } \\
\text { (736nm) }\end{array}$ & Hibst, Paulus $1999^{27}$ \\
\hline $\begin{array}{c}\text { Diodo } \\
\text { (este trabalho) }\end{array}$ & $\begin{array}{l}\text { Vermelho } \\
(657 \mathrm{~nm})\end{array}$ & Sim & $\begin{array}{c}\text { Infravermelha } \\
\text { (730nm) }\end{array}$ & $\begin{array}{l}\text { Rocha-Cabral et al., } \\
2006^{34}\end{array}$ \\
\hline
\end{tabular}

De todos os comprimentos de onda testados, pôde ser observado que apenas o verde não se mostrou adequado para discriminação de lesões de cárie, o que sugere que para os demais comprimentos de ondas estudados, a técnica é bastante viável para detecção de lesões de cárie. Entretanto, todas as investigações espectroscópicas, citadas na Tabela 2, foram realizadas in vitro.

O DIAGNOdent foi desenvolvido a partir de um estudo da década de 1990 que testou a excitação no vermelho e constatou não só a existência da emissão da fluorescência no infravermelho próximo, como também que a diferenciação entre o tecido sadio e cariado nos espectros era bem mais evidente do que com a excitação no azul ${ }^{27}$. 
Contudo, apesar de ter sido elaborado a partir de resultados espectroscópicos tão promissores, o equipamento utiliza apenas o pico de intensidade do sinal de fluorescência como parâmetro para ponto de corte, de forma que outros tipos de análise dos espectros poderiam ser realizados para que o resultado fosse o mais fidedigno possível.

Uma pesquisa propôs um parâmetro denominado "contraste" para analisar os espectros. O dente foi iluminado com os comprimentos de onda de excitação em 442, 532 e 632nm. A emissão do tecido cariado ocorreu em 522 , 594 e 683nm, respectivamente. De posse dos espectros, a normalização foi feita a partir da razão entre o pico de luz espalhada pela fonte de excitação pelo pico de fluorescência. Em seguida, mediu-se a diferença relativa entre os dados normalizados. Assim, o "contraste" era obtido por meio da subtração do valor da dentina cariada pelo esmalte ou dentina sadia divididos pela fluorescência do esmalte ou dentina sadios ${ }^{74}$.

Outra forma de analisar os espectros entre tecido sadio e cariado foi descrita por Ribeiro et al. (2005). A normalização foi feita a partir da subtração de uma linha-base criada para cada espectro. Essa linha foi construída por meio da média dos pontos de um intervalo de comprimento de onda onde o sinal não mais provocasse influência. Em seguida, os autores selecionaram dois estreitos intervalos de comprimento de onda, dos quais foi obtida a área e calculada a razão entre elas. Esse procedimento foi repetido para cada espectro ${ }^{131}$. $\mathrm{O}$ comprimento de onda de excitação foi em 405nm e a emissão centrada na faixa entre 480 e 520nm permitiu não só a diferenciação entre o tecido cariado e sadio, mas também entre os estágios de progressão da doença.

A normalização para o pico de emissão e subseqüente razão entre os picos dos espectros cariado e sadio foi o método adotado por Hibst, Paulus (1999) para a análise dos espectros ${ }^{27}$.

Outra possibilidade é proceder à normalização determinando como valor máximo do pico de fluorescência 1,0. Em seguida, calcula-se a diferença dos espectros sadio e cariado de um mesmo dente considerando-se o valor de intensidade à meia altura (Full Width at Half Maximum) na sua metade máxima ${ }^{91}$.

As mudanças nas formas espectrais da fluorescência do dente permitem obter uma visão mais completa do crescimento de lesões de cárie, em termos de propriedades de fluorescência. Cada variação nessas propriedades 
espectrais pode fornecer informações importantes sobre a origem da lesão e seu estágio e estrutura, permitindo, portanto, seu monitoramento ao longo do tempo ${ }^{92}$, 90

Assim, a espectroscopia por fluorescência pode ser considerada uma técnica de detecção de lesões de cárie mais promissora do que as demais por:

- Ser quantitativa e não destrutiva;

- Diferenciar o tecido sadio de lesões iniciais de cárie com alta sensibilidade e especificidade ${ }^{88,91,93,130}$;

- Permitir o monitoramento da lesão em tempo real e ao longo do tempo por meio do armazenamento dos espectros;

- Possibilitar que mais análises sejam feitas a partir da forma dos espectros;

- Permitir o exame clínico.

As qualificações da presente técnica motivaram estes autores a realizar o presente estudo. 


\section{MATERIAIS E MÉTODOS}

\subsection{Seleção e preparo dos dentes}

O protocolo da pesquisa foi aprovado pelo Comitê de Ética em Pesquisa em Seres Humanos do Instituto de Pesquisas Energéticas e Nucleares (parecer $n^{\circ} .078 / 2003$ ).

Os exames clínicos foram realizados em pacientes com idade entre 18 -35 anos nas clínicas de cirurgia do Centro de Estudos-Treinamento e Aperfeiçoamento em Odontologia (Cetao), da Associação Paulista de Cirurgiões Dentistas (APCD - Ipiranga), da Fundação para o Desenvolvimento Científico e Tecnológico da Odontologia (Fundecto) e da Associação Brasileira de Odontologia (ABO - SP).

Após assinarem o consentimento livre e esclarecido, os pacientes com indicação de exodontia de pré-molares foram previamente examinados utilizando os seguintes critérios de exclusão: restaurações, lesões de cárie visivelmente aparentes, selantes e cálculos dentários. Procedeu-se à limpeza com jato de bicarbonato de sódio não fluorescente (Prophy Jet, Kondortech, Brasil) dos elementos dentários que se enquadraram no experimento, durante 10 segundos em cada face a ser examinada. Após a profilaxia, o campo operatório foi isolado com roletes de algodão e os elementos foram secos com ar comprimido por 3 segundos. Para melhor visualização do dente e padronização do foco de luz, foi utilizada uma lupa de cabeça $(2,5 \mathrm{X})$ com iluminação profissional (Nissho Optical Accessories, Hong Kong).

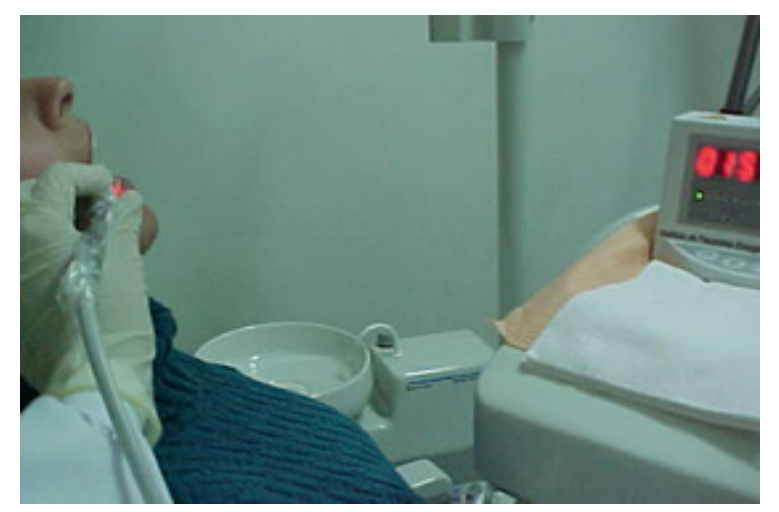

Figura 3: Exame clínico com o DIAGNOdent. 
O dente era examinado para verificação da existência de um ou mais sítios suspeitos de lesão de cárie inicial. Foram selecionadas para exame com 0 DIAGNOdent (Figura 3) e com o espectrômetro as faces oclusais de 42 prémolares. Sítios não contíguos em um mesmo dente e dentes de um mesmo paciente foram considerados no experimento, de forma que 66 pontos suspeitos de lesão foram examinados.

\subsection{Método de utilização do DIAGNOdent}

O DIAGNOdent (2095, KaVo, Biberach, Alemanha) foi operado por um único operador treinado seguindo as recomendações do fabricante. 0 DIAGNOdent era calibrado no padrão de cerâmica que acompanha o equipamento com valor de fluorescência conhecido, a cada dez medições, assim como em cada paciente, em uma região hígida da estrutura dentária, normalizando as medidas para cada dente. A ponta angulada apropriada para análise em superfícies oclusais $(A)$ foi selecionada. Esta era posicionada perpendicularmente ao sítio, fazendo um ciclo de três movimentos rotacionais, de forma que varresse toda a lesão e suas margens. O operador não visualizava o monitor com os valores das medidas durante sua obtenção. Um único registro de cada sítio era obtido, arquivando o valor máximo exibido no mostrador do equipamento e marcando os sítios na ficha do paciente. As ponteiras e a peça de mão eram protegidas com uma camada de filme PVC, para prevenção de contaminação cruzada ${ }^{34}$.

\subsection{Elaboração do sistema com espectrômetro portátil}

\subsubsection{Características do espectrômetro}

A configuração interna do equipamento (USB2000, Ocean Optics, EUA) conta com grade de difração \#4, 600 linhas / mm, cuja resposta encontra-se

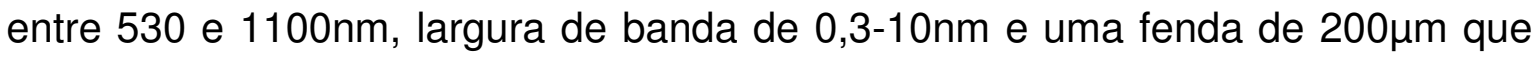
possibilita que o espectrômetro seja capaz de captar a fluorescência advinda da estrutura dentária sem saturar o sinal na grade de difração. Um detector CCD 
altamente sensível converte o sinal óptico em sinal digital. A resolução óptica espectral calculada para este equipamento é de aproximadamente 7,6 nm.

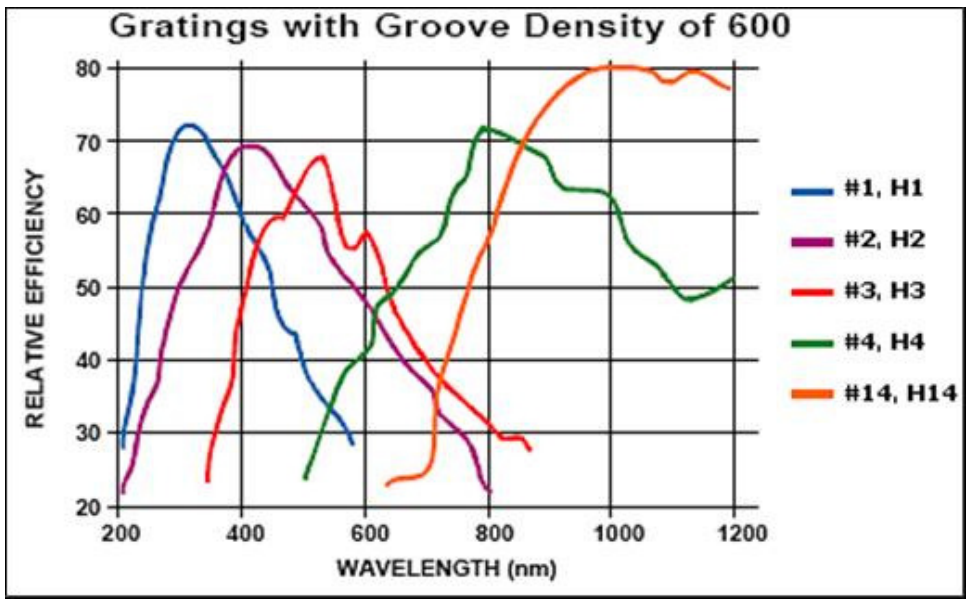

Figura 4: Grade de difração do espectrômetro (www.oceanoptics.com)

\subsubsection{Fonte de excitação}

A fonte de excitação utilizada foi um laser de diodo ( $\lambda \sim 657 \mathrm{~nm}$ ), comercialmente conhecido como apontador a laser, com potência máxima de $1 \mathrm{~mW}$ para o qual foi confeccionada uma adaptação eletrônica, de forma que a fonte era alimentada por 4 pilhas alcalinas $(6,0 \mathrm{~V})$ e acionado por um mecanismo de chaveamento que permitia seu funcionamento contínuo quando em uso (Figura 5).

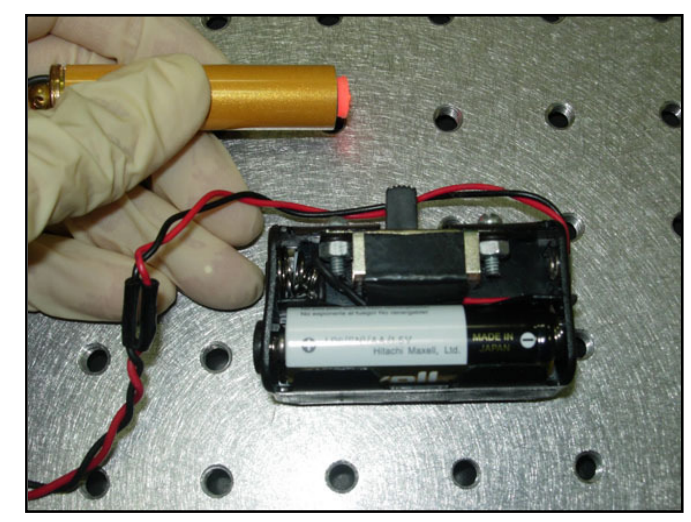

Figura 5: Adaptação eletrônica com mecanismo de chaveamento. 


\subsubsection{Filtros}

Constatou-se que a luz laser espalhada e a luz ambiente conferiam saturação aos espectros, de forma que o sinal só era visto com muito ruído. Por esta razão, filtros passa-bandas específicas foram confeccionados para impedir a passagem de comprimentos de onda abaixo de 700nm que pudessem prejudicar a obtenção do sinal de fluorescência. Foi confeccionado também um suporte para o filme para que este se ajustasse perfeitamente ao suporte de filtros (In-line filter holder for LVFS, Ocean Optics, EUA), Figura 6.

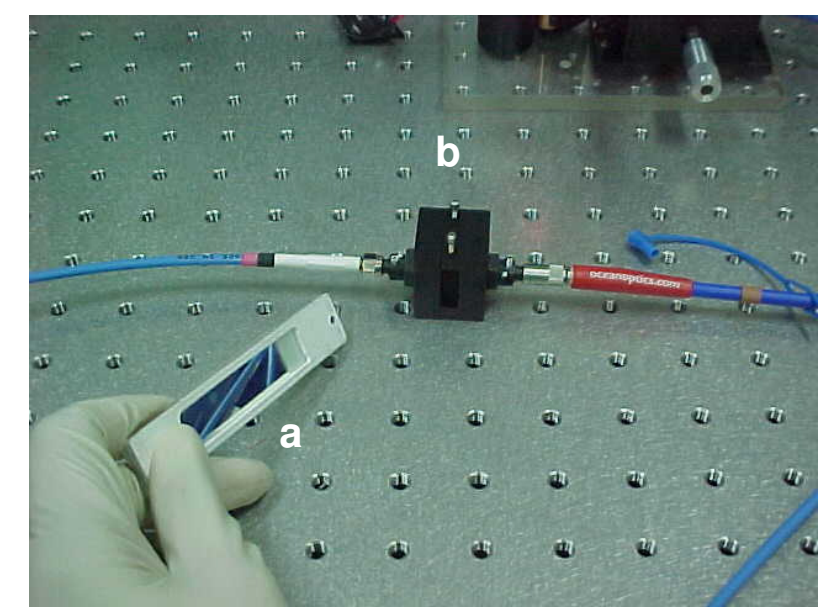

Figura 6: (a) Filtro montado em suporte e (b) suporte para filtro.

\subsubsection{Espectro de transmissão dos filtros}

Utilizamos o espectrofotômetro de absorção (Olis 17D, Cary, EUA) para confirmar se os filmes elaborados estavam impedindo os comprimentos de onda abaixo de 700nm de forma adequada. Foi observado um comprimento de onda de corte em 700nm (Figura 7). 


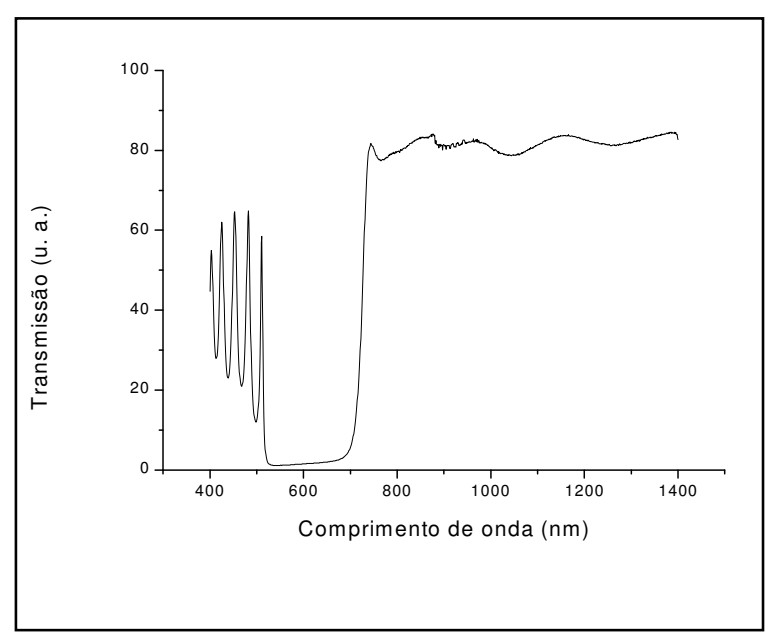

Figura 7: Espectro de transmissão do filtro.

\subsubsection{Fibras e peça de mão}

A fibra principal utilizada com o espectrômetro (R400-7-VIS/NIR, Ocean Optics, EUA) se caracteriza por ser em forma de Y. Uma das partes é composta por duas fibras, uma que conduz a luz até o dente (com 6 fibras periféricas, $400 \mu \mathrm{m})$ e outra que coleta a fluorescência resultante (central - 400 $\mathrm{m}$ ). Esses dois conjuntos de fibras convergem para a peça de mão, que apresenta a ponta reta $(\mathrm{d}=6,31 \mathrm{~mm})$.

A fibra do espectrômetro difere da fibra do DIAGNOdent porque neste a fibra que leva a luz até a amostra é única e central, enquanto a fibra coletora é composta por nove fibras periféricas. Além disso, o DIAGNOdent apresenta uma ponta angulada ( $d=1,38 \mathrm{~mm}$ ) que facilita o acesso às lesões (Figura 8 ).

Para conectar o suporte do filtro com o espectrômetro e com o computador, uma fibra de acoplamento (QP 600-025 VIS-NIR, Ocean Optics, EUA) de $600 \mu \mathrm{m}$ de diâmetro foi utilizada (Tabela 3). 

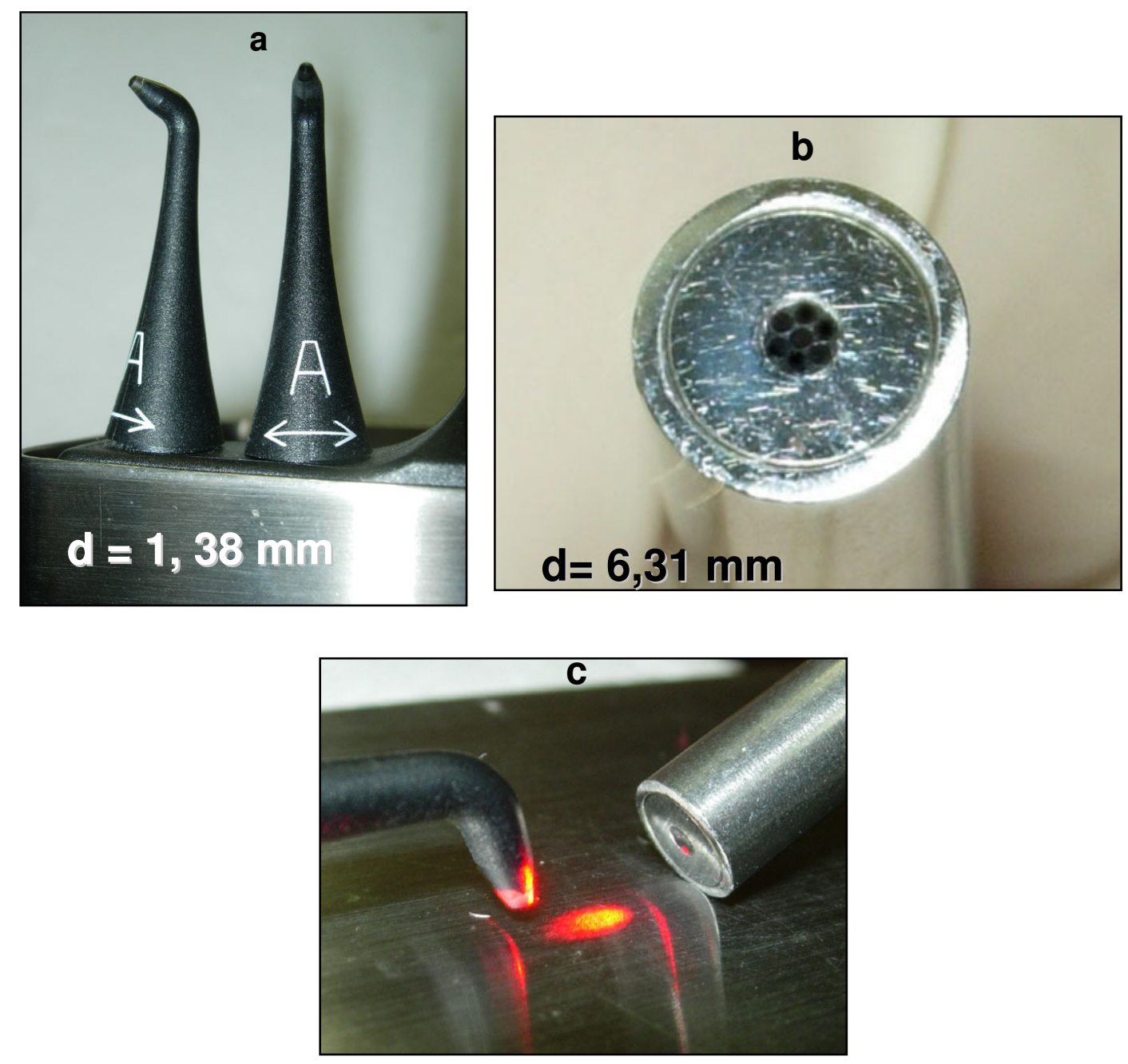

Figura 8: Ponta do DIAGNOdent (a) e do espectrômetro (b). As duas pontas em relação com a superfície (c).

Tabela 3: Diferenças entre as fibras utilizadas no experimento.

\begin{tabular}{|c|c|c|}
\hline Características & DIAGNOdent & Ocean Optics \\
\hline Forma & $\mathrm{Y}$ & $\mathrm{Y}$ \\
\hline Fibras periféricas & 9 (coletam o sinal) $-250 \mu \mathrm{m}$ & 6 (levam a luz) $-400 \mu \mathrm{m}$ \\
\hline Fibra central & 1 (leva a luz) $-500 \mu \mathrm{m}$ & 1 (coleta o sinal) - \\
& & $400 \mu \mathrm{m}$ \\
\hline Ponta & Angulada & Reta \\
\hline
\end{tabular}




\subsubsection{Caracterização das fibras com lâmpada de luz branca}

Para verificar a resposta das fibras, utilizou-se luz branca para sua caracterização.

- Caracterização da fibra em Y: a peça de mão foi posicionada diante de um espelho, de forma que as fibras que levam a luz (periféricas) foram direcionadas à fonte de luz branca (Pulsed Xenon PX-2, Ocean Optics, EUA) e a fibra de retorno de luz (central) foi posicionada diante do espectrômetro.

- Caracterização da fibra de acoplamento: a peça de mão da fibra em Y foi direcionada ao espelho, as fibras que levam a luz foram posicionadas em frente à fonte de luz branca. Conectadas ao suporte de filtro estavam a fibra de retorno de luz e a fibra de acoplamento, esta, ligada ao espectrômetro.

Pôde ser observada uma resposta linear em função do comprimento de onda na região de interesse, o que significa que as fibras não possuem absorção significante neste intervalo de comprimento de onda (Figura 9) .

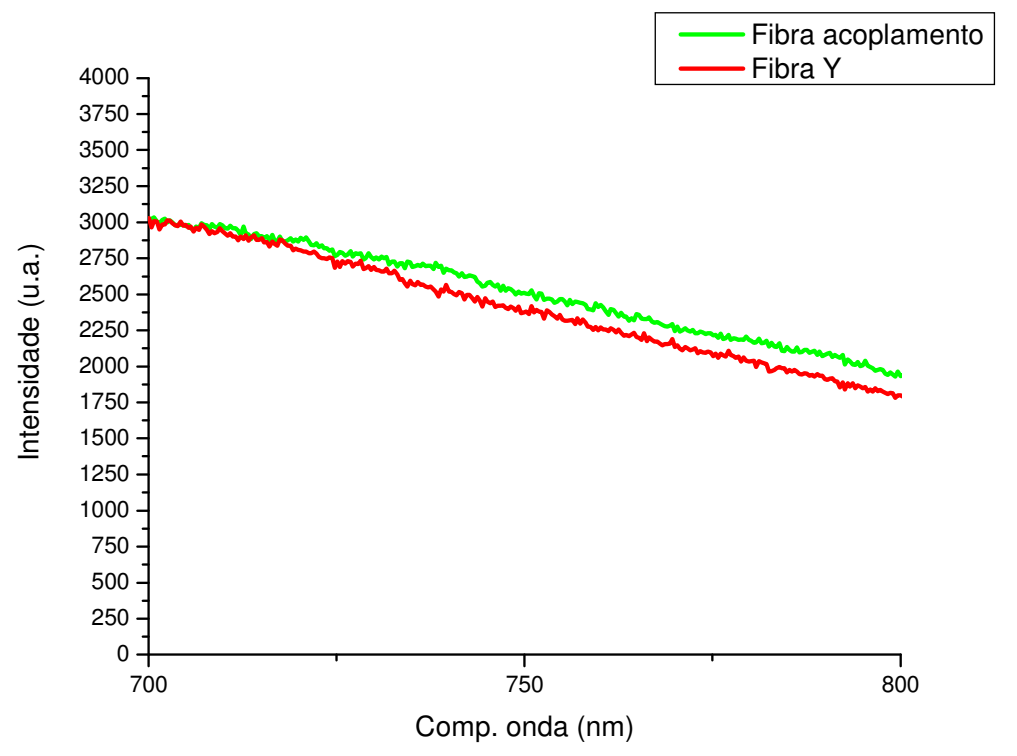

Figura 9: Resposta das fibras utilizadas na região de comprimento de onda de interesse para este estudo. 


\subsubsection{Confecção do sistema}

O laser de excitação foi fixado a um suporte e sua tampa rosqueada foi removida. A fibra condutora de luz foi fixada diante do laser em um suporte $X Y Z$ que permitia sua movimentação em torno destes eixos para encontrar a maior potência da fonte de excitação. Na saída da luz foi acoplada uma lente (L2 Detector collection lens, Ocean Optics, EUA), Figura 10, que focalizava a luz laser, facilitando a excitação do tecido dentário.

A fibra coletora era conectada ao suporte para filtro. Na outra saída do suporte, era interligada a fibra de acoplamento que, por sua vez, era interligada a um computador portátil (A40-S161, Toshiba, EUA), Figura 11.

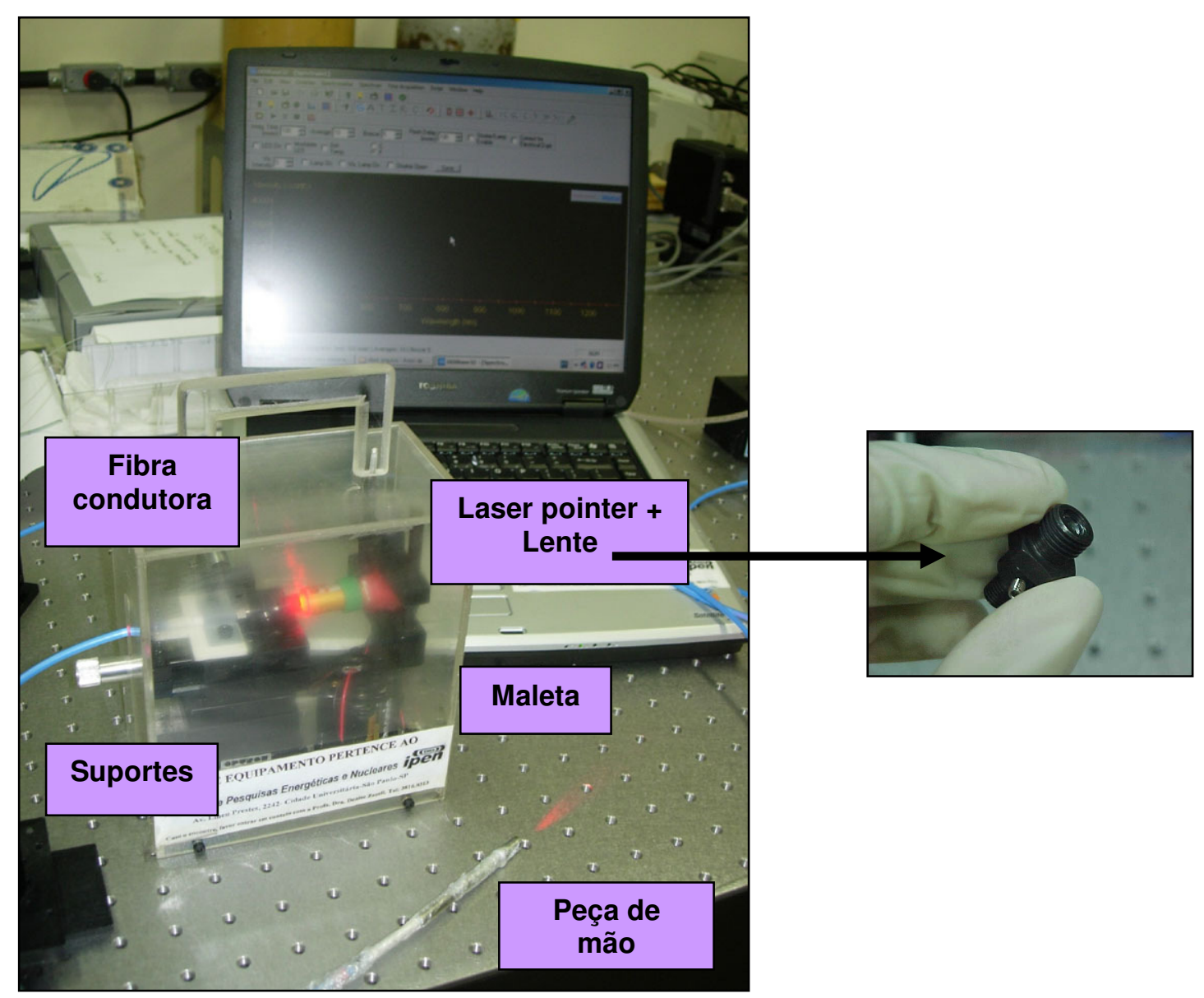

Figura 10: Sistema elaborado para transporte para clínica. No detalhe, a lente colimadora utilizada para focalizar a fonte de excitação. 


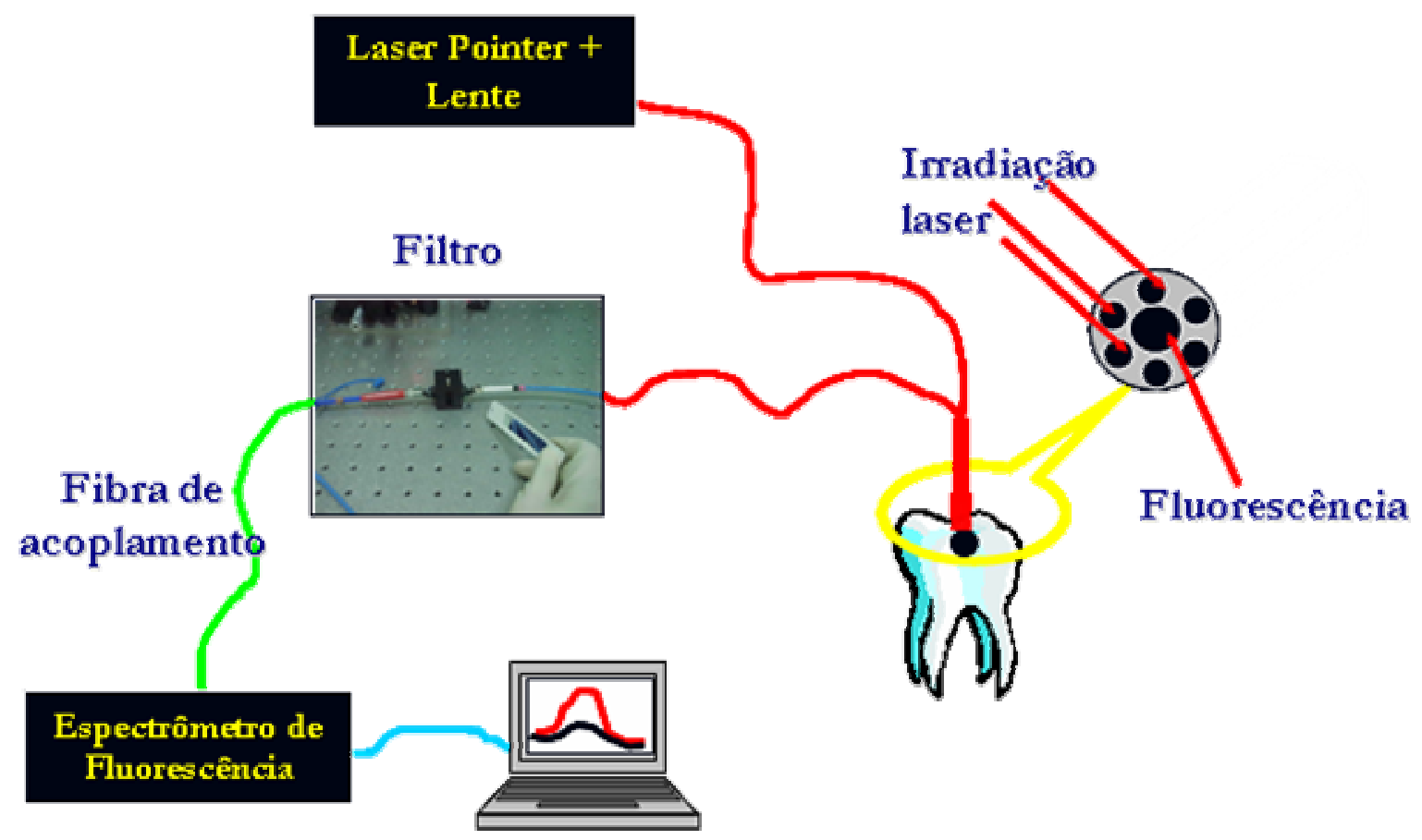

Figura 11: Sistema óptico elaborado para obtenção de medidas espectroscópicas.

\subsubsection{Calibração fonte de excitação}

Constatamos que a potência mínima para o laser excitar o tecido dentário era de $2 \mathrm{~mW}$, aproximadamente. Para assegurar que a potência estivesse sempre acima deste valor crítico, antes das medidas era feita uma calibração da fonte de excitação. Para tanto, a fibra condutora da luz era posicionada diante de um Power Meter digital com detector adequado para seu comprimento de onda (LM10i, Fieldmaster, Coherent Inc., EUA), Figura 12. 


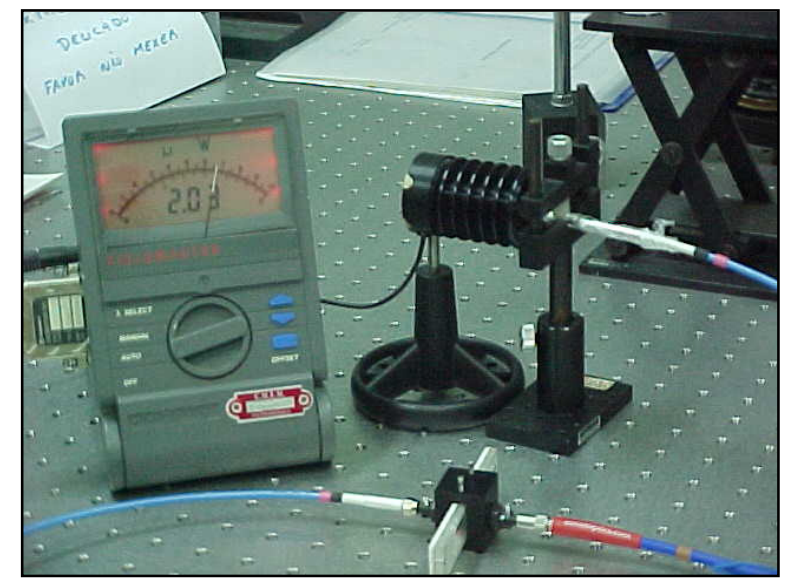

Figura 12: Power Meter utilizado para ajuste do comprimento de onda da fonte de excitação.

\subsubsection{Configurações do software}

O software que acompanha o espectrômetro (OOIBase32) exibe o sinal captado em tempo real e permite que os parâmetros para visualização de espectros e aquisição de dados sejam selecionados e controlados. A forma de visualização dos espectros selecionada para o experimento foi o modo scope, por traduzir as características espectrais da amostra e permitir a análise relativa do tecido dentário cariado com o sadio. A função tempo de integração possibilita ajustar o intervalo tempo com o qual o detector captará fótons. O tempo de integração utilizado neste experimento foi selecionado a partir de teste para obtenção da maior intensidade de sinal, conforme as instruções do fabricante, e já foi utilizado em um estudo ${ }^{97}$. A função spectra to average especifica o número de aquisições espectrais acumuladas antes de mostrar o espectro e a função boxcar smoothing width executa a média entre dados espectrais. Quanto maiores forem os valores determinados para as duas últimas funções, maior será o ruído. Valores muito altos podem resultar em uma diminuição da resolução espectral. Portanto, os parâmetros utilizados neste estudo foram:

- Tempo de integração: 100 ms

- Spectra to average: 10

- Boxcar smoothing width: 5 


\subsubsection{Calibração dos espectros}

Antes de se obter os primeiros dados espectrais, procedeu-se à calibração dos espectros. A calibração consistia em salvar permanentemente nas configurações do software uma situação de completo escuro (comando store dark), com a fonte de excitação desligada e salvar uma referência, obtida com a fonte acionada e a ponta da fibra direcionada para o vazio (store reference).

\subsection{Modo de utilização in vivo do sistema com espectrômetro}

A peça de mão era posicionada o mais perpendicularmente possível ao sítio Figura 13, fazendo um ciclo de três movimentos rotacionais, de forma que varresse toda a lesão e suas margens. O operador visualizava o monitor com os espectros durante sua obtenção para que a maior intensidade de fluorescência pudesse ser registrada. Um único registro de cada sítio era obtido. A peça de mão era protegida com uma camada de filme PVC, para prevenção de contaminação cruzada ${ }^{34}$. Os espectros foram analisados com o sofware Origin 7.0 (Scientific Graphing and Analysis Software), Figura 14.

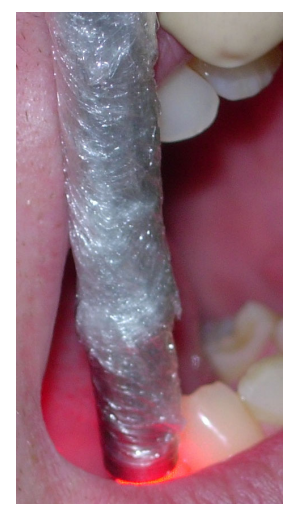

Figura 13: Ponta reta do espectrômetro posicionada em máxima relação de perpendicularidade com a superfície examinada. 


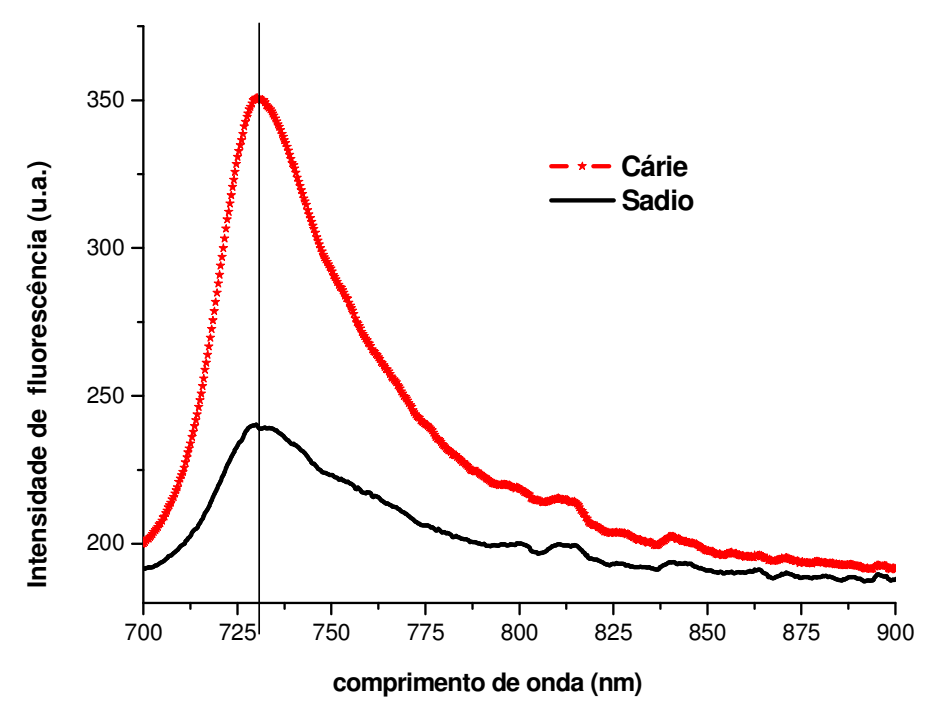

Figura 14: Exemplo de espectros obtidos de um sítio suspeito de lesão de cárie in vivo, após análise com o software Origin.

\subsection{Exodontia}

Após a análise com o DIAGNOdent e com o espectrômetro, os pacientes eram submetidos à cirurgia pelos profissionais responsáveis pela clínica para remoção dos elementos, o que se dava imediatamente em seguida às mensurações, evitando qualquer alteração mineral na superfície dentária.

\subsection{Identificação dos registros}

Logo após a cirurgia, os dentes tinham sua face mesial coberta com esmalte de unha para facilitar posterior identificação dos sítios e garantir o mesmo posicionamento da ponta no estudo laboratorial. As raízes dos dentes eram removidas e os dentes, montados em lâminas de cera utilidade, posicionados de acordo com o desenho inicial dos dentes e respectivos sítios. Os dentes eram então fotografados e nas fotos eram marcados com caneta os sítios observados com os equipamentos. Esses dentes foram limpos de restos de sangue e debris provenientes do procedimento cirúrgico com escova de dente e água corrente. Nenhuma solução antibacteriana foi utilizada. Foram armazenados individualmente em água deionizada, sob refrigeração $\left(\sim 5^{\circ} \mathrm{C}\right)$, até a utilização no estudo in vitro. A água era trocada semanalmente. 


\subsection{Estudo in vitro}

As medidas in vitro dos mesmos sítios foram realizadas aproximadamente dois meses após a exodontia dos dentes. Não foi realizada nova limpeza antes destas medidas para que isto não se contituísse em uma nova variante.

Os dentes foram fixados individualmente em um pequeno bloco de cera. Os sítios foram identificados pelas fotos. O protocolo para obtenção das medidas foi o mesmo do estudo in vivo, contudo, no caso do espectrômetro, a peça de mão foi fixa em um suporte para facilitar a obtenção dos registros.

\subsection{Obtenção do espectro hidroxiapatita sintética}

Realizaram-se as medidas espectrais de um padrão de hidroxiapatita sintética - National Institute of Standards and Technology (39,2\% de cálcio e $22,8 \%$ de fósforo) para verificar a influência desse componente estrutural do dente sobre as medidas feitas (Figura 15). Para tanto, foi utilizado o mesmo protocolo descrito para o estudo in vitro com o espectrômetro portátil.

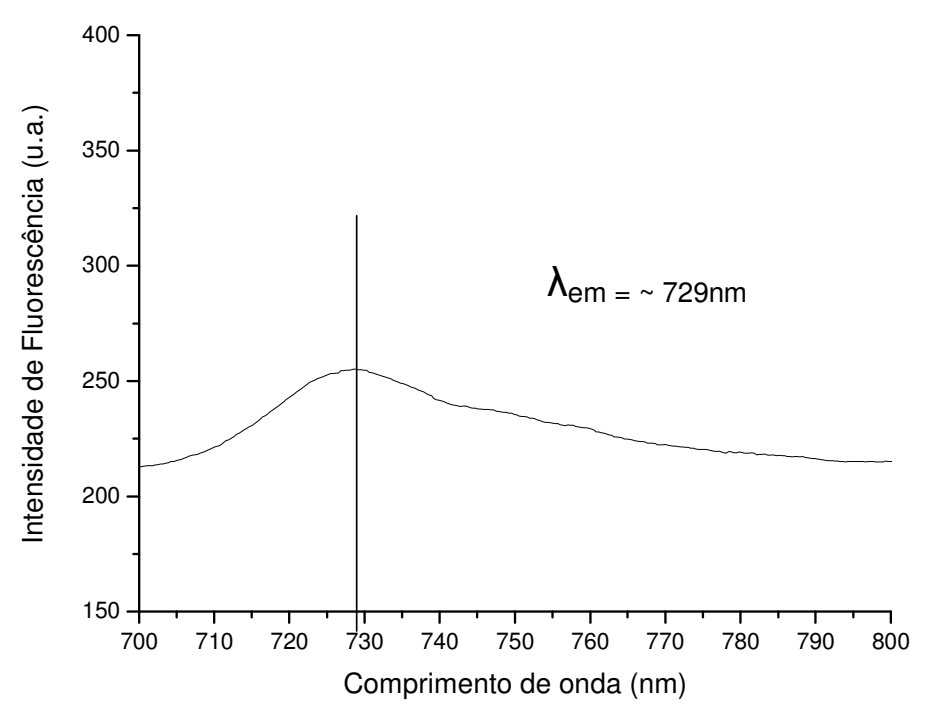

Figura 15: Espectro da hidroxiapatita sintética. 


\subsection{Preparo das amostras para microscopia de luz polarizada}

Após os experimentos, os dentes foram incluídos em resina ortoftálica transparente (Resina 2110, Redelease, Brasil). Foram levados à cortadora com disco diamantado (Isomet II-II80, Buehler, EUA), onde foram feitas secções de

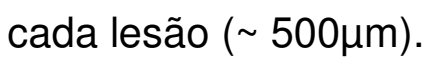

\subsection{Preparo das lâminas}

Para o preparo das lâminas, seguiu-se o mesmo protocolo utilizado por Mendes (2002) ${ }^{132}$, modificando apenas a granulação das lixas. Assim, um lado da secção foi polido com seqüência de lixas d'água de carboneto de silício com granulações decrescentes de 240, 400, 600, 1200 e 2500. Esse polimento foi feito com a secção imersa em água. A fatia do dente foi colada pelo lado polido em lâminas de microscópio com resina epóxica de secagem lenta (Araldite Profissional 24 horas, Brascola, Brasil). Após leve pressão, as lâminas com as fatias foram mantidas em estufa a $50{ }^{\circ} \mathrm{C}$ por 24 horas. Após a secagem da resina, a parte não colada da seção do dente foi desgastada, inicialmente utilizando lixa d'água 240 em uma máquina politriz refrigerada por água. Após esse desgaste inicial, as lâminas foram desgastadas manualmente com seqüência de lixas d'água de números 400, 600, 1200 e 2500. A espessura do corte do dente foi desgastada até aproximadamente $100 \mu \mathrm{m}$, medida com paquímetro digital (Série 500, Mitutoyo, Brasil). As lâminas foram numeradas de acordo com a amostra correspondente. Quando duas secções de uma mesma lesão foram obtidas, a lesão maior foi escolhida, por meio de exame no microscópio.

\subsection{Exame das lâminas}

Para o exame das lâminas foi utilizado um microscópio de luz polarizada (Leica DMLP, Alemanha) com câmera digital acoplada (Figura 16). Um software específico (Remote Capture) permitia que a imagem fosse mostrada em tempo real no monitor do computador. O exame foi feito com luz transmitida polarizada e com uma placa de quartzo. 


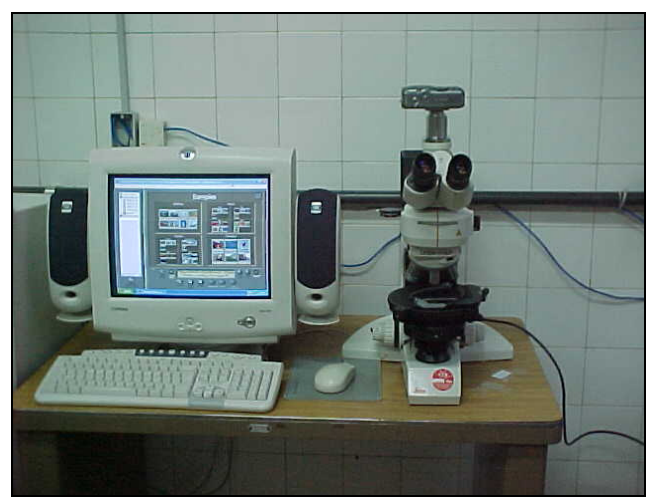

Figura 16: Microscópio de luz polarizada Leica DMLP com câmera digital acoplada, conectado a computador com software específico.

As lâminas permaneceram mergulhadas em água destilada por pelo menos 24 horas antes do exame. No momento da observação, uma gota de água deionizada foi colocada sobre o dente, cobrindo-o com uma lamínula. As lâminas foram vistas com aumento de 5 e 10 vezes, de modo que contivessem toda a lesão (Figura 17). As lesões foram classificadas em uma escala de 5 escores ${ }^{61}$ :

- $\mathrm{DO}$ = sem lesão de cárie;

- D1 = lesão de cárie limitada à metade externa do esmalte;

- $\mathrm{D} 2$ = lesão de cárie limitada à metade interna do esmalte, sem atingir a dentina;

- D3 = lesão de cárie limitada à metade externa da dentina e

- D4 = lesão de cárie envolvendo a metade interna da dentina. 

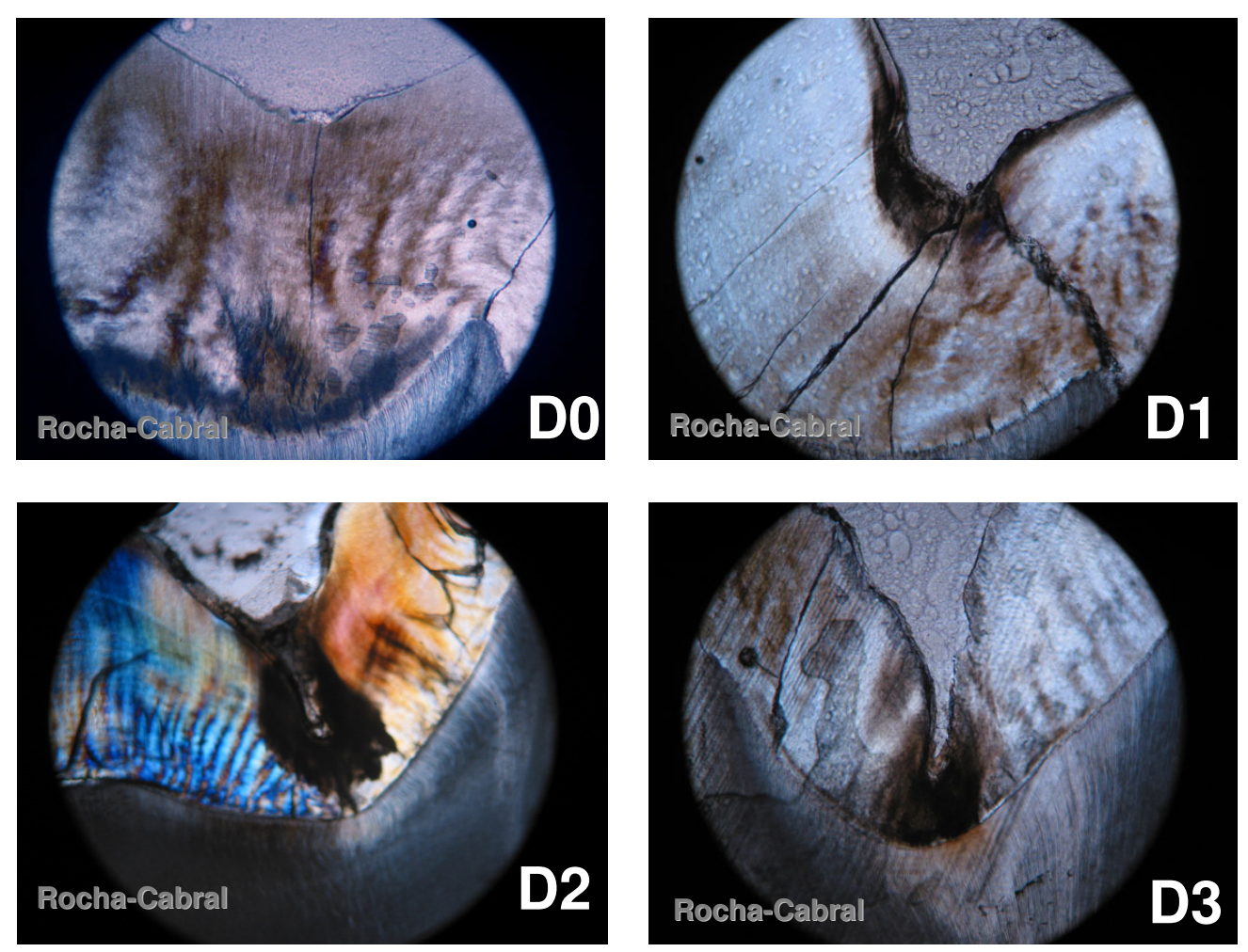

Figura 17: Exemplos de sítios observados pelo microscópio de luz polarizada $(5 X)$. Não houve lesões profundas em dentina (D4).

\subsection{Análise das imagens histológicas das lesões}

Após obtenção das imagens, as lesões de cárie foram dimensionalmente medidas com auxílio de um programa de análise de imagens (Image $\mathrm{J}$ - Java image processing program - software livre da Web) quanto à área de secção transversal e à profundidade da lesão.

O programa funciona com uma escala de cinzas. Assim, as imagens foram transformadas em 8-bit. Uma escala real do esmalte em milímetros era fornecida para o programa, a lesão era delimitada pelo operador e a área de secção transversal da lesão $\left(\mathrm{mm}^{2}\right)$, fornecida pelo programa. Para obter a profundidade máxima ${ }^{61,133}$, delimitava-se o ponto mais profundo da lesão e o programa a fornecia em milímetros. 


\subsection{Análise estatística}

O teste de Anderson-Darling foi utilizado para avaliar a normalidade das medidas obtidas com o DIAGNOdent. Pôde ser verificado que as medidas não se encontravam em distribuição normal.

O teste não paramétrico para amostras não vinculadas Kruskal-Wallis foi realizado para correlacionar os dois equipamentos com os respectivos dados histológicos. Para os casos em que existia diferença estatisticamente significantes, era feito o teste de Dunn discriminar entre quais grupos se encontravam essas diferenças. A análise de correlação de Pearson ${ }^{121}$ para dados contínuos foi realizada para estudar a correlação entre os dados com os equipamentos entre si e correlacionados com a área de secção transversal e a profundidade das lesões.

Para as medidas obtidas com o espectrômetro, procedeu-se à normalização dos espectros obtidos. Para tanto, selecionou-se um intervalo de comprimento de onda (700 a 800nm) e uma linha base foi feita para cada espectro com as médias dos pontos na região de 805 a $900 \mathrm{~nm}$. Todos os espectros foram normalizados. Em seguida, foi calculada a Razão da Área sob a Curva dos Espectros do dente cariado e sadio (RACE), de acordo com a metodologia proposta para esse trabalho (Figura 18). A RACE foi, então, comparada com os achados histológicos da mesma forma que o DIAGNOdent. 


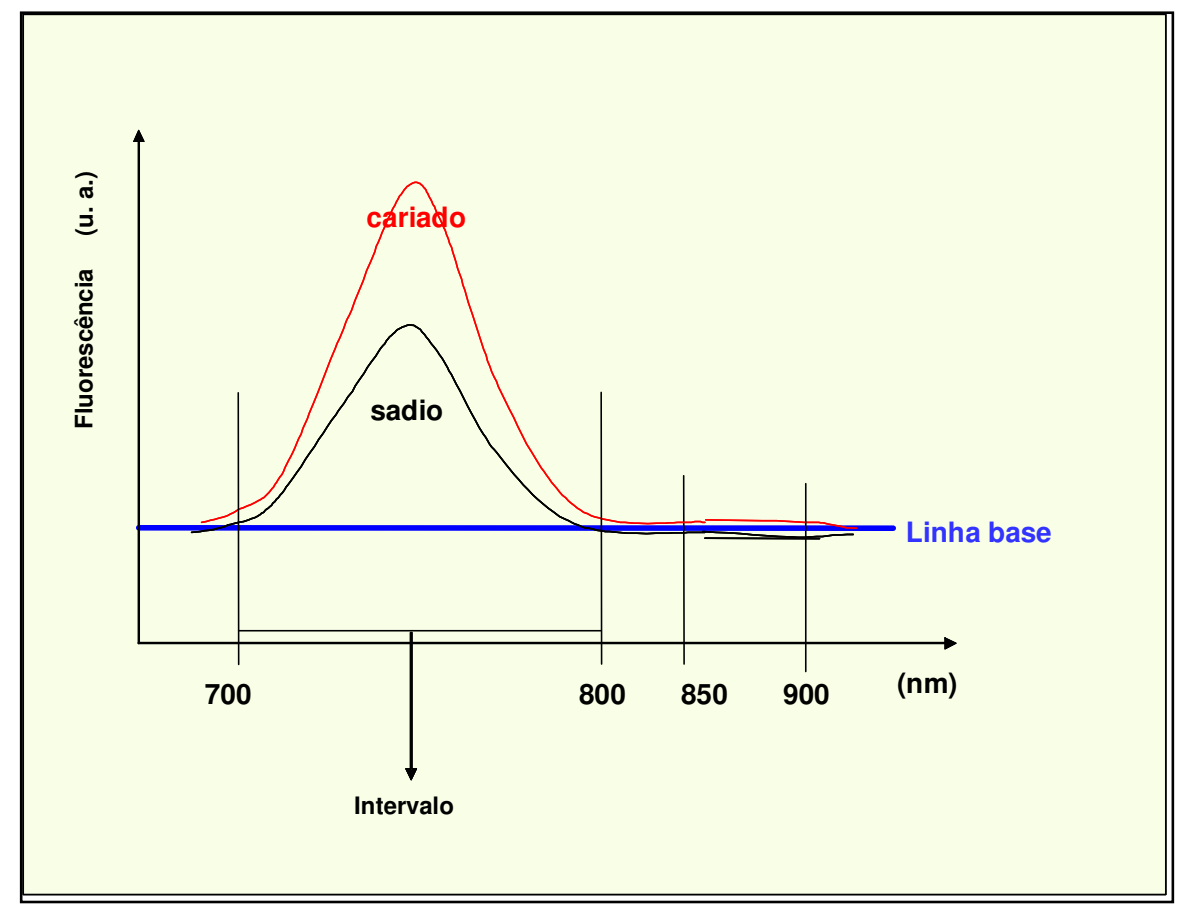

Figura 18: Metodologia da normalização dos espectros e obtenção da RACE para espectros entre o tecido cariado x sadio de um mesmo dente.

Desta forma, foram criadas as seguintes correlações:

- DIAGNOdent x histologia (padrão ouro),

- RACE x histologia (padrão ouro) e

- Dados obtidos com os dois equipamentos entre si e cada equipamento com a área e a profundidade das lesões.

Todos os testes foram repetidos no estudo in vivo e in vitro separadamente.

\subsubsection{Desempenho dos equipamentos}

Para esse experimento também foi realizada uma análise $\mathrm{ROC}$ e também os parâmetros diagnósticos de sensibilidade, especificidade e acurácia, que foram calculados para o DIAGNOdent e para o espectrômetro tanto in vivo quanto in vitro. 
A análise $\mathrm{ROC}$ foi realizada para escolha dos melhores pontos de corte. Como a análise ROC requer uma amostra dicotomizada com relação à presença da doença, os resultados obtidos para D0 (sem lesão de cárie) foram considerados como ausência de lesão de cárie, e os resultados obtidos para D1(lesão inicial em esmalte), D2 (lesão profunda em esmalte) e D3 (lesão inicial em dentina) foram considerados como presença de lesão de cárie. $\mathrm{Na}$ amostragem deste trabalho, não houve lesões classificadas como D4. Em seguida, foi calculada a área sob a curva ROC de cada método e esta foi comparada entre os métodos. O melhor ponto de corte entre dentes sadios e cariados foi determinado a partir do ponto mais extremo da soma da sensibilidade e especificidade para cada método ${ }^{134}$. A sensibilidade, a especificidade e a acurácia foram calculadas utilizando esses valores de pontos de corte. A comparação desses parâmetros entre os métodos foi feita com o teste de McNemar. Para todos os testes estatísticos de desempenho realizados, o nível de significância adotado foi de $5 \%(p<0,05)$. 


\section{RESULTADOS}

\subsection{Estudos com o DIAGNOdent in vivo}

\subsubsection{Correlação: DIAGNOdent x padrão ouro in vivo}

$\mathrm{Na}$ Tabela 4 encontram-se as medidas realizadas para o DIAGNOdent considerando o padrão ouro (histologia), as quais estão representadas no Boxplot (Figura 18). Nesta figura, os círculos representam as médias; os asteriscos são os valores extremos; a caixa representa $50 \%$ dos dados mais centrais (percentil 25 a 75) e a linha no meio da caixa é a mediana (valor que divide a distribuição ao meio com a mesma quantidade de valores).

Assim, pôde ser observado um aumento nas médias e na variabilidade, com a observação de alguns pontos deslocados representados por asteriscos.

Tabela 4: Medidas para o DIAGNOdent in vivo.

\begin{tabular}{c|cccccc}
\hline Histologia & Média & Mediana & Desvio Padrão & Mínimo & Máximo & N $^{0}$.amostras \\
\hline D0 & 3,5 & 3,5 & 1,9 & 1,0 & 6,0 & 8 \\
D1 & 11,4 & 10,0 & 6,2 & 5,0 & 24,0 & 7 \\
D2 & 16,8 & 10,5 & 19,4 & 1,0 & 85,0 & 34 \\
D3 & 16,4 & 16,0 & 11,1 & 1,0 & 41,0 & 17 \\
\hline
\end{tabular}

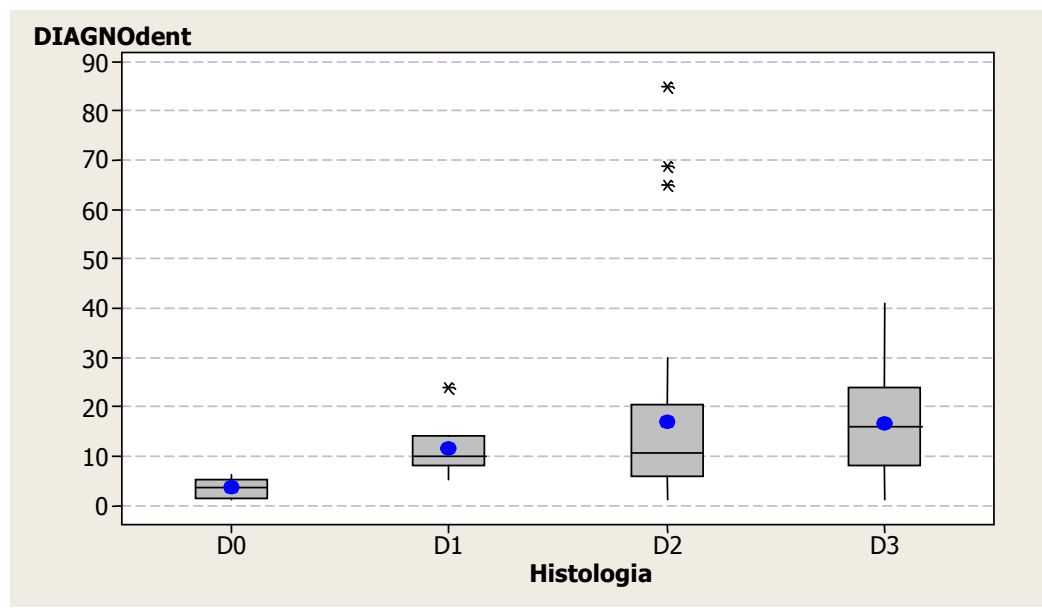

Figura 19. Box-plot para o DIAGNOdent e a histologia in vivo. 
O teste de Kruskal-Wallis verificou diferenças estatisticamente significantes entre os grupos $(p<0,01)$. O teste de Dunn demonstrou que o grupo D0 diferia significantemente dos demais.

\subsubsection{Correlação: DIAGNOdent x profundidade das lesões in vivo}

$\mathrm{Na}$ figura a seguir (Figura 20) está representado o diagrama de dispersão para as duas medidas. Pode ser observada uma relação positiva entre elas.

Obteve-se o valor de 0,41 para o índice de correlação linear de Pearson, o que indica uma correlação baixa a razoável entre as medidas. Comparou-se o valor de "r" com os valores críticos tabelados e se verificou que esta correlação é estatisticamente significante $(p<0,01)$.

Para determinar a reta de regressão e verificar se a relação linear é realmente significativa, uma Análise de Regressão Linear foi realizada entre as medidas. Foi feita a análise de variância para a regressão, onde foi obtido um nível descritivo de 0,001 . Assim, conclui-se que existe correlação significativa ( $p<$ $0,01)$ entre as leituras do DIAGNOdent in vivo e as profundidades das lesões.

Dos resultados dos fatores, obtiveram-se os valores dos coeficientes constante $(4,51)$ e profundidade $(12,27)$. Desta forma, a reta de regressão entre o DIAGNOdent e a profundidade fica:

\section{DIAGNOdent $=4,51+12,21$. Profundidade}

ou seja, para cada unidade a mais de profundidade, o resultado esperado do DIAGNOdent aumenta em 12,27 à leitura.

Para explicar o grau de ajuste do modelo, procedeu-se ao Coeficiente de Explicação da regressão $\left(\mathrm{R}^{2}\right)$. Esse coeficiente é definido pela relação entre a variação explicada pela variação total (explicada e não explicada) na predição dos dados. Quanto maior for a variação explicada, isto é, quanto mais ajustados estiverem os dados, maior será o coeficiente e menor será o erro na predição dos valores por meio da reta de regressão. Neste caso, o coeficiente ficou em 16,5\%, indicando que a explicação não é muito boa, ou seja, apesar de a regressão ser significativa, observa-se uma tendência a erro na predição dos valores e, portanto, essa função não deve ser utlizada . 


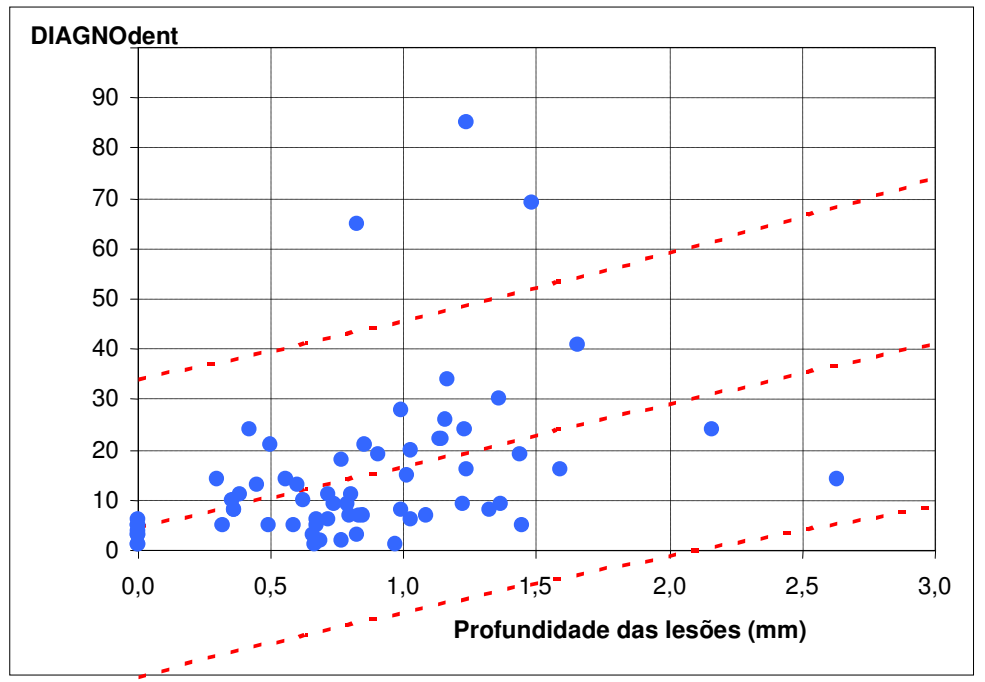

Figura 20: Diagrama de dispersão entre os resultados da profundidade das lesões e das leituras com o DIAGNOdent in vivo, com a reta de regressão e intervalos para a predição.

\subsection{Estudos com a espectroscopia in vivo}

\subsubsection{Correlação: RACE x padrão ouro in vivo}

$\mathrm{Na}$ Tabela 5 encontram-se as medidas realizadas para a RACE considerando o padrão ouro (histologia), as quais estão representadas no Boxplot (Figura 21). Pôde ser observado um aumento nas médias e na variabilidade, com a observação de alguns pontos deslocados.

Tabela 5: Medidas para a RACE in vivo.

\begin{tabular}{c|cccccc}
\hline Histologia & Média & Mediana & Desvio Padrão & Mínimo & Máximo & $N^{\circ}$. amostras \\
\hline D0 & 1,2 & 1,2 & 0,2 & 1,0 & 1,5 & 8 \\
D1 & 1,8 & 1,8 & 0,4 & 1,2 & 2,4 & 7 \\
D2 & 2,0 & 1,6 & 1,3 & 1,0 & 7,5 & 34 \\
D3 & 2,1 & 1,6 & 1,1 & 1,1 & 5,8 & 17 \\
\hline
\end{tabular}




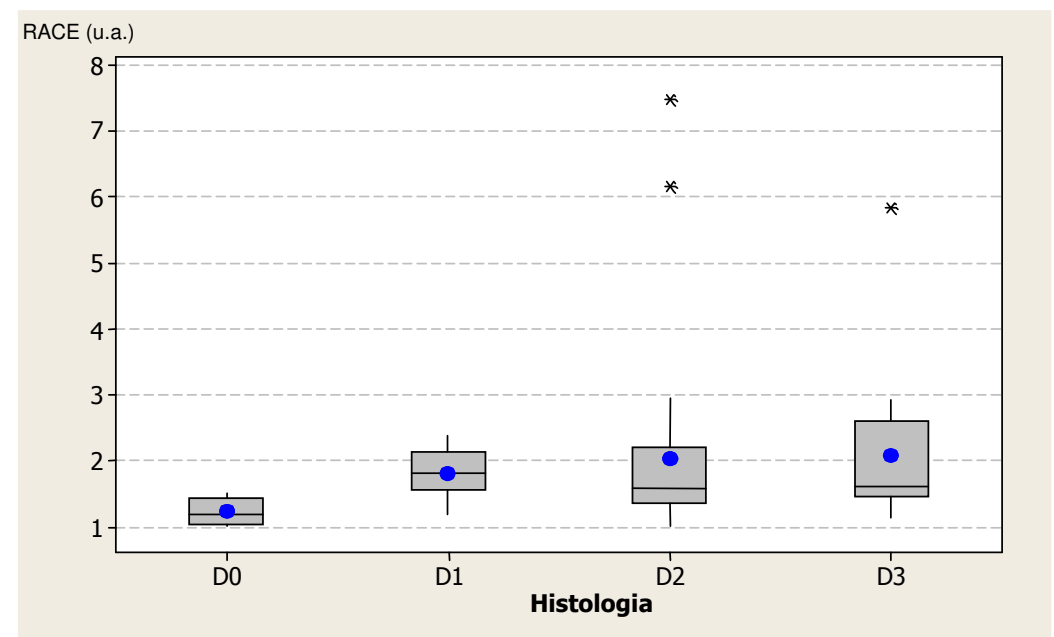

Figura 21: Box-plot para a RACE e a histologia in vivo.

O teste de Kruskal-Wallis detectou diferenças estatisticamente significantes entre os grupos $(p<0,05)$. Apenas o grupo D0 apresentou diferença estatisticamente significante entre os grupos, como o DIAGNOdent (teste de Dunn).

\subsubsection{Correlação: RACE do EP x profundidade das lesões in vivo}

$\mathrm{Na}$ figura a seguir (Figura 22) está representado o diagrama de dispersão para as duas medidas. Pode ser observada uma relação positiva entre elas.

Obteve-se o valor de 0,42 para o índice de correlação linear de Pearson, o que indica uma correlação baixa a razoável entre as medidas. Comparou-se o valor de "r" com os valores críticos tabelados e se verificou que esta correlação é estatisticamente significante $(p<0,001)$.

Para determinar a reta de regressão e verificar se a relação linear é realmente significativa, uma Análise de Regressão Linear foi realizada entre as medidas. Foi feita a análise de variância para a regressão, onde foi obtido um nível descritivo de 0,012. Assim, conclui-se que a regressão é significativa, ou seja, existe correlação significativa $(p<0,05)$ entre a razão das áreas sob as curvas e as profundidades das lesões. Dos resultados dos fatores, obtiveram-se 
os valores dos coeficientes constante $(1,17)$ e profundidade $(0,92)$. Desta forma, a reta de regressão entre a RACE e a profundidade fica:

$$
\mathrm{RACE}=1,17+0,92 \text {. Profundidade }
$$

ou seja, para cada unidade a mais de profundidade, o resultado esperado da RACE aumenta em 0,92.

Para explicar o grau de ajuste do modelo, procedeu-se ao Coeficiente de Explicação da regressão $\left(R^{2}\right)$, o qual ficou em $17,5 \%$, indicando que a explicação não é muito boa, ou seja, apesar de a regressão ser significativa, observa-se uma tendência de erro na predição dos valores e, portanto, essa função não deve ser utlizada.

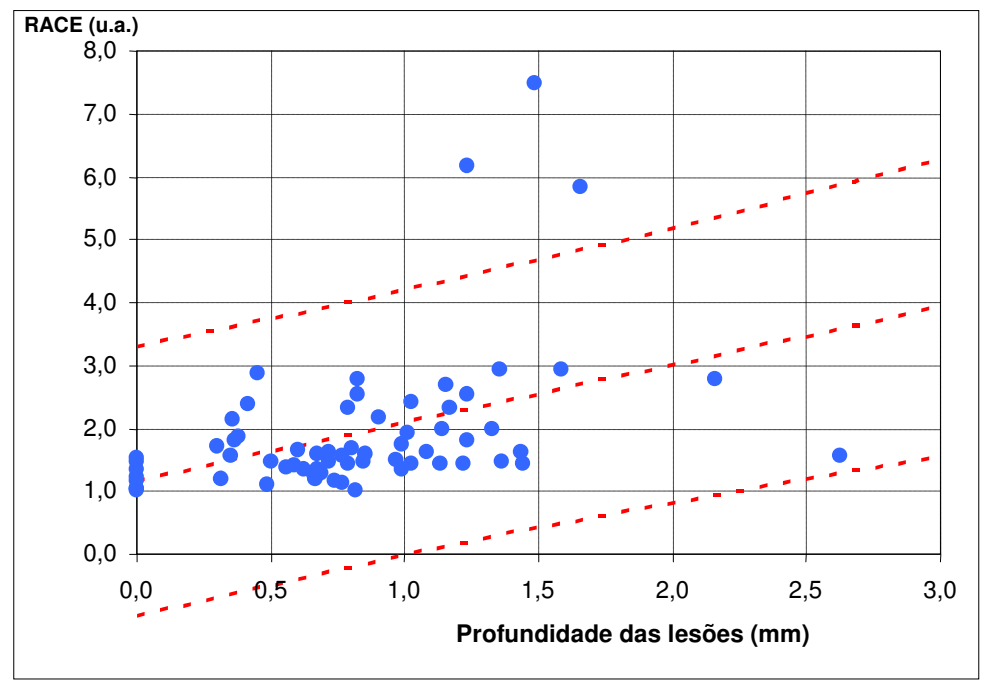

Figura 22: Diagrama de dispersão entre os resultados da RACE in vivo e da profundidade das lesões, com a reta de regressão e intervalos para a predição.

\subsection{Correlação: DIAGNOdent X RACE do EP in vivo}

Na Figura 23 estão representados os valores de cada lesão para os dois equipamentos, a reta de regressão entre as medidas e também um intervalo de confiança (com 95\% de confiança) para a predição dos valores. Pôde ser observada uma relação positiva entre elas.

Obteve-se o valor de 0,83 para o índice de correlação linear de Pearson, o que indica uma boa correlação entre as medidas (quanto mais próximo do $r=1$, maior será a correlação entre as variáveis). Comparou-se o 
valor de "r" com os valores críticos tabelados (nível descritivo < 0,001) e se verificou que esta correlação é estatisticamente significante $(p<0,001)$.

Para determinar a reta de regressão e verificar se a relação linear é realmente significativa, foi realizada entre as medidas uma Análise de Regressão Linear, a qual consiste em encontrar uma expressão matemática em que uma variável dependente está em função de outra independente. Foi feita a análise de variância para esta regressão, onde foi obtido um nível descritivo de aproximadamente 0,0001. Assim, conclui-se que a regressão é significativa, ou seja, existe correlação significativa $(p<0,001)$ entre a RACE do EP e as leituras com o DIAGNOdent. Dos resultados dos fatores, obtiveram-se os valores dos coeficientes constante $(1,04)$ e DIAGNOdent $(0,06)$. Desta forma, a reta de regressão entre a RACE e o DIAGNOdent fica:

$$
\text { RACE }=1,04+0,06 \text { DIAGNOdent }
$$

ou seja, para cada unidade a mais que o DIAGNOdent detecta, o resultado esperado da RACE aumenta em 0,06.

Ao se ajustar a reta, espera-se que ela explique o conjunto de dados coletados. Para verificar o grau de ajuste do modelo, procedeu-se ao Coeficiente de Explicação ou coeficiente de determinação da regressão $\left(\mathrm{R}^{2}\right)$. O coeficiente resultou em 68,9\%, indicando que a explicação é razoável, ou seja, mesmo a regressão sendo significativa, pode-se considerar um pequeno erro na predição dos valores.

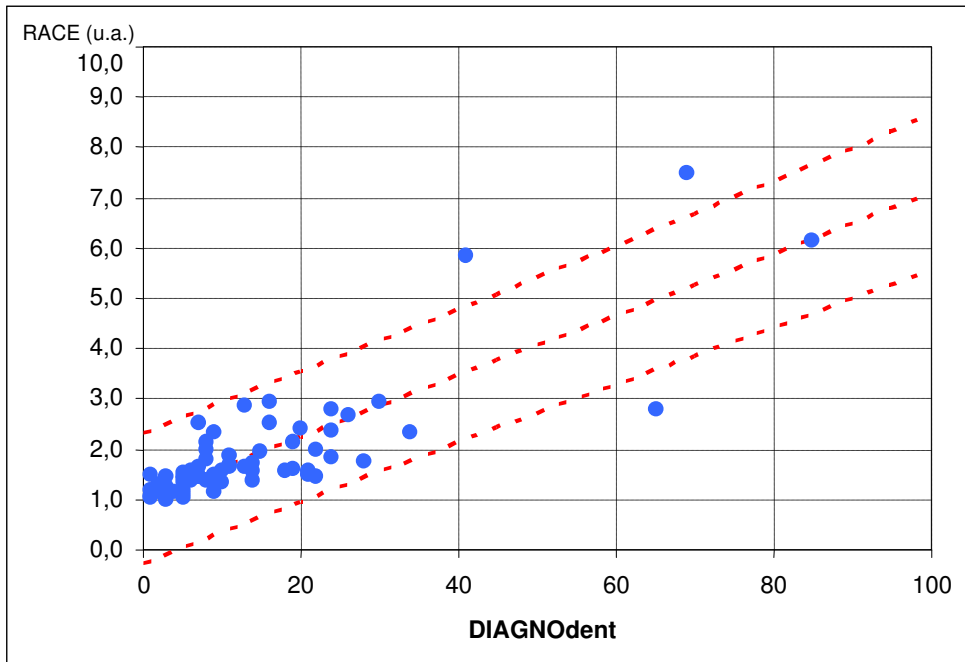

Figura 23: Diagrama de dispersão entre os resultados da RACE e do DIAGNOdent in vivo, com a reta de regressão e intervalos para a predição. 


\subsection{Desempenho do DIAGNOdent e do espectrômetro portátil in vivo}

\subsubsection{Determinação do ponto de corte do DIAGNOdent in vivo}

Para que se obtivesse uma boa especificidade sem perda substancial da sensibilidade, o melhor ponto de corte para o DIAGNOdent in vivo foi calculado por meio da soma dos parâmetros sensibilidade e especificidade dados pela análise ROC.

Assim, considerando o limiar de que Do representou a ausência da doença e D1, D2 e D3 representaram a presença da doença, o melhor ponto de corte foi $>6$ e está representado no gráfico abaixo pelo ponto mais extremo da linha amarela. Portanto, um valor igual ou maior que 7 nas leituras com este equipamento indicou presença de lesão de cárie. A sensibilidade e a especificidade foram extraídas a partir deste ponto de corte e a acurácia, calculada com estes índices (Figura 24).

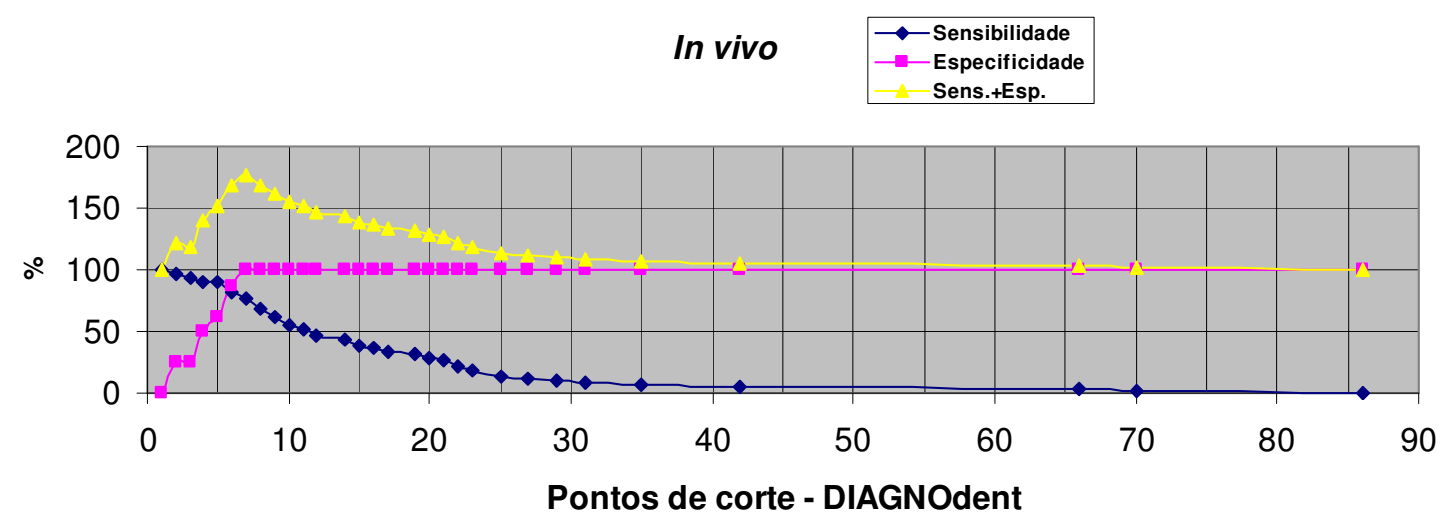

Figura 24: Especificidade, sensibilidade e sua soma relacionadas com diferentes pontos de corte do DIAGNOdent in vivo para o limiar esmalte.

\subsubsection{Determinação do ponto de corte da RACE in vivo}

Da mesma forma que o DIAGNOdent, para que se obtivesse uma boa especificidade sem perda substancial da sensibilidade, o melhor ponto de corte para a RACE in vivo foi calculado por meio da soma dos parâmetros sensibilidade e especificidade dados pela análise ROC.

Assim, considerando o limiar de que D0 representou a ausência da doença e D1, D2 e D3 representaram a presença da doença, o melhor ponto de corte da RACE foi > 1,52 e está representado no gráfico a seguir pelo ponto mais 
extremo da linha amarela. Portanto, um valor maior que este nas leituras com este equipamento indicou presença de lesão de cárie. A sensibilidade e a especificidade foram extraídas a partir deste ponto de corte e a acurácia, calculada com estes índices (Figura 25).

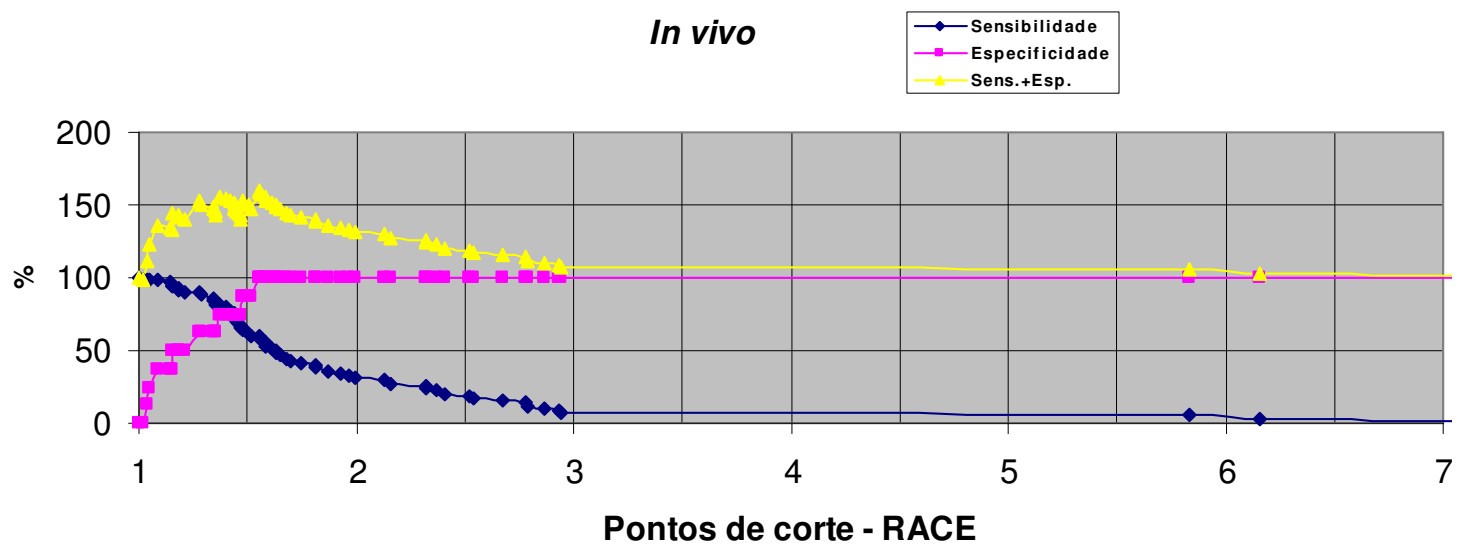

Figura 25: Especificidade, sensibilidade e sua soma relacionadas com diferentes pontos de corte da RACE in vivo para o limiar esmalte.

\subsubsection{Comparação das Áreas Sob as Curvas ROC (ASC) entre os métodos in vivo}

Na figura a seguir (Figura 26) podem-se observar as ASC entre os dois métodos de medidas. O teste de McNemar revelou que não houve diferenças estatisticamente significantes entre os métodos in vivo. 


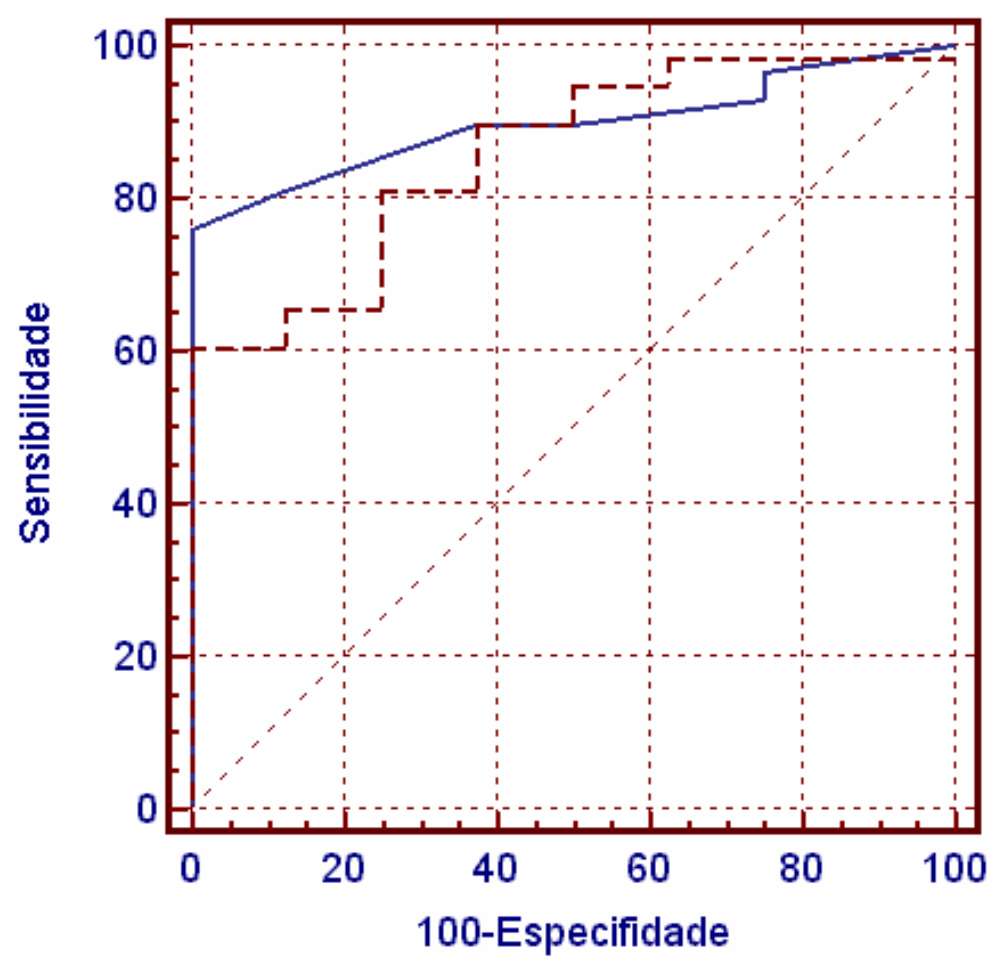

- DIAGNOdent RACE

Figura 26: Comparação das ASC entre os métodos DIAGNOdent $(0,90)$ e RACE $(0,86)$ in vivo .

\subsubsection{Performance dos equipamentos in vivo}

A tabela abaixo permite uma visão geral da performance dos dois métodos de detecção de lesões de cárie in vivo. O DIAGNOdent apresentou sensibilidade de $76 \%$, enquanto o espectrômetro portátil apresentou sensibilidade de 60\% (Tabela 6). O teste McNemar revelou diferença estatisticamente significante $(p<0,05)$ entre a sensibilidade dos métodos, revelando um melhor desempenho do DIAGNOdent comparado com o espectrômetro. A especificidade, a acurácia e a área sob a curva ROC não mostraram difereças estatisticamente significantes. 
Tabela 6: Performance dos equipamentos DIAGNOdent e espectrômetro portátil in vivo na detecção de lesões de cárie, expressa em sensibilidade, especificidade, acurácia e área sob a curva ROC (ASC). Para o limiar, D0 foi considerado sem lesão de cárie e D1, D2, D3 e D4, com lesão de cárie.

\begin{tabular}{ccccc}
\hline & Sensibilidade & Especificidade & Acurácia & ASC \\
\hline Espectrômetro in vivo & $0,60^{\mathrm{a}}$ & $1,00^{\mathrm{a}}$ & $0,95^{\mathrm{a}}$ & $0,86^{\mathrm{a}}$ \\
DIAGNOdent in vivo & $0,76^{\mathrm{b}}$ & $1,00^{\mathrm{a}}$ & $0,97^{\mathrm{a}}$ & $0,90^{\mathrm{a}}$ \\
\hline Letras diferentes expressam diferenças estatisticamente significantes entre os valores de uma mesma coluna $(\mathrm{p}<0,05)$. \\
\hline
\end{tabular}

\subsection{Estudos com o DIAGNOdent in vitro}

\subsubsection{Correlação: DIAGNOdent x padrão ouro in vitro}

$\mathrm{Na}$ Tabela 7 encontram-se as medidas para o DIAGNOdent considerando o padrão ouro (histologia). No Box-plot (Figura 27), pode ser observado um aumento nas médias e na variabilidade.

Tabela 7: Medidas para o DIAGNOdent in vitro.

\begin{tabular}{c|cccccc}
\hline & Média & Mediana & Desvio Padrão & Mínimo & Máximo & N $^{\circ}$. amostras \\
\hline D0 & 3,0 & 3,0 & 1,6 & 1,0 & 6,0 & 8 \\
D1 & 14,9 & 15,0 & 6,9 & 7,0 & 28,0 & 7 \\
D2 & 19,1 & 10,0 & 22,6 & 1,0 & 99,0 & 34 \\
D3 & 20,6 & 18,0 & 15,7 & 2,0 & 61,0 & 17 \\
\hline
\end{tabular}




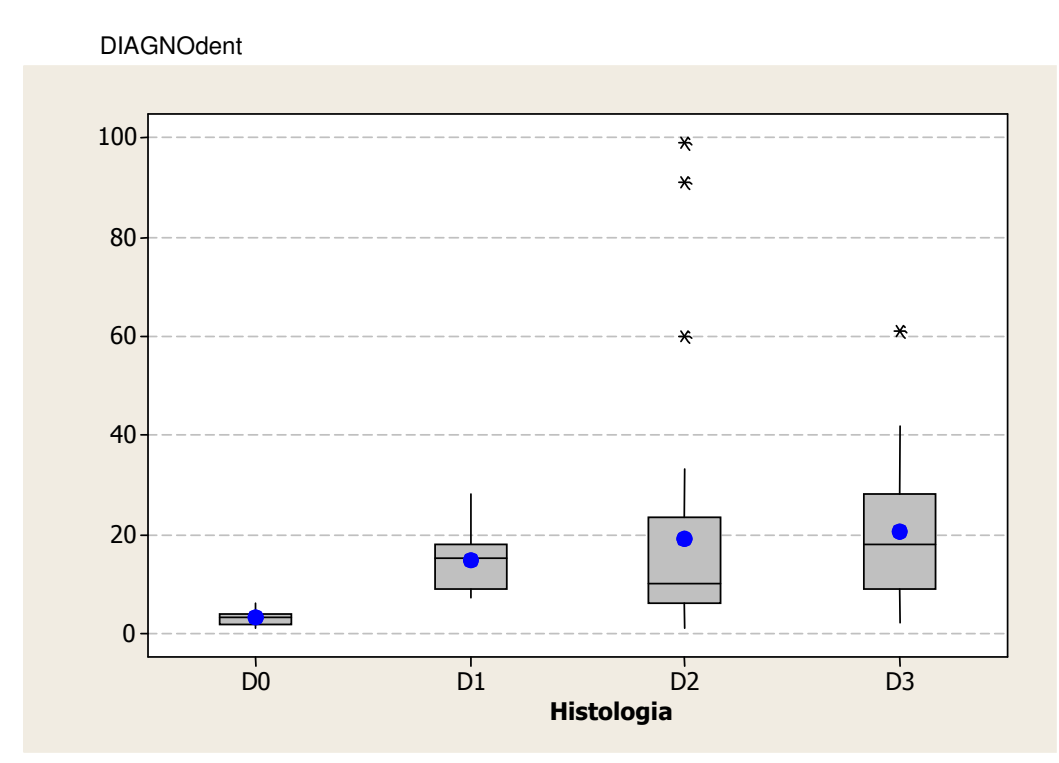

Figura 27: Box-plot para o DIAGNOdent e a histologia in vitro.

O teste de Kruskal-Wallis detectou diferenças estatisticamente significantes entre os grupos $(p<0,01)$. $O$ teste de Dunn demonstrou que o grupo D0 diferia significantemente dos demais.

\subsubsection{Correlação: DIAGNOdent x profundidade das lesões in vitro}

A Figura 28 representa o diagrama de dispersão para as duas medidas. Pode ser observada uma relação positiva entre elas. Obteve-se o valor de 0,45 para o índice de correlação linear de Pearson, o que indica uma correlação baixa / razoável entre as medidas. Comparou-se o valor de "r" com os valores críticos tabelados e se verificou que esta correlação é estatisticamente significante $(p<0,001)$.

Para determinar a reta de regressão e verificar se a relação linear é realmente significativa, uma Análise de Regressão Linear foi realizada entre as medidas. Foi feita a análise de variância para a regressão, em que se concluiu que existe correlação significativa $(p<0,001)$ entre as leituras do DIAGNOdent e as profundidades das lesões.

Dos resultados dos fatores, obtiveram-se os valores dos coeficientes constante $(3,83)$ e profundidade $(16,26)$. Desta forma, a reta de regressão entre 0 DIAGNOdent e a profundidade fica:

DIAGNOdent $=3,83+16,26$. Profundidade 
ou seja, para cada unidade a mais de profundidade, o resultado esperado do DIAGNOdent aumenta em 16,26.

Para explicar o grau de ajuste do modelo, procedeu-se ao Coeficiente de Explicação da regressão $\left(R^{2}\right)$, o qual ficou em 19,9\%, indicando que a explicação não é boa, ou seja, apesar de a regressão ser significativa, observa-se uma tendência de erro na predição dos valores e, portanto, essa função não deve ser utlizada

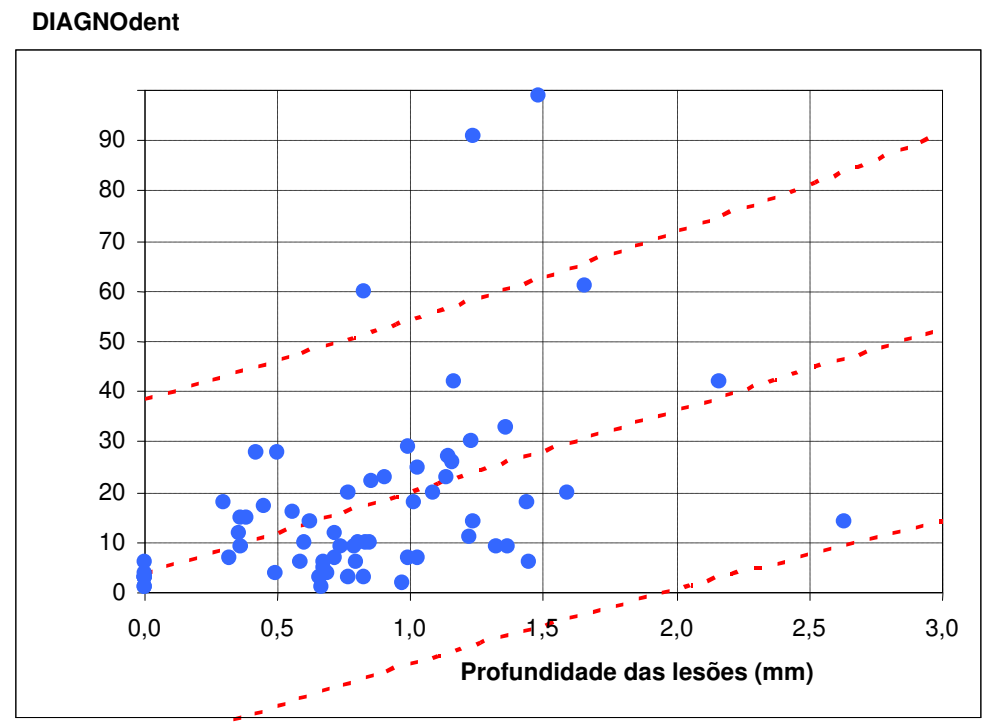

Figura 28: Diagrama de dispersão entre os resultados da profundidade das lesões e do DIAGNOdent in vitro, com a reta de regressão e intervalos para a predição.

\subsection{Estudos com o espectrômetro portátil in vitro}

\subsubsection{Correlação: RACE x padrão ouro in vitro}

$\mathrm{Na}$ Tabela 8 temos as medidas realizadas para a RACE considerando o padrão ouro (histologia). No Box-plot (Figura 29), pode ser observado um aumento nas médias e na variabilidade. Puderam ser observados alguns pontos extremos deslocados.

Tabela 8: Medidas para a RACE in vitro.

\begin{tabular}{c|cccccc}
\hline Histologia & Média & Mediana & Desvio Padrão & Mínimo & Máximo & $N^{\circ}$. amostras \\
\hline D0 & 1,5 & 1,2 & 0,8 & 0,9 & 3,4 & 8 \\
D1 & 1,9 & 1,8 & 0,5 & 1,5 & 2,9 & 7 \\
D2 & 2,6 & 1,9 & 2,4 & 0,9 & 13,6 & 34
\end{tabular}




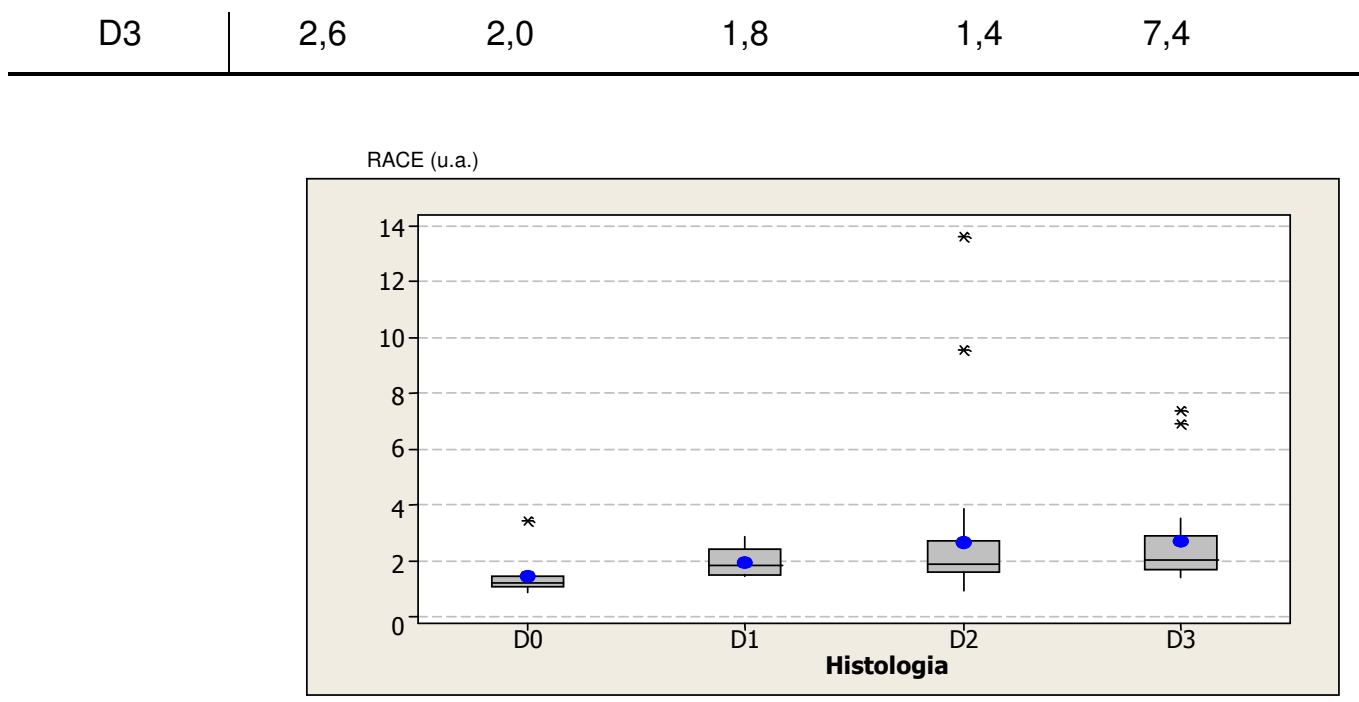

Figura 29: Box-plot para a RACE e a histologia in vitro.

O teste de Kruskal-Wallis verificou diferenças estatisticamente significantes entre os grupos $(p<0,05)$. O teste de Dunn constatou que o grupo D0 diferia significantemente dos grupos D2 e D3.

\subsubsection{Correlação: RACE x profundidade das lesões in vitro}

Na Figura 30 está representado o diagrama de dispersão para as duas medidas. Pode ser observada uma relação positiva entre elas.

Obteve-se o valor de 0,43 para o índice de correlação linear de Pearson, o que indica uma correlação baixa/razoável entre as medidas. Comparou-se o valor de " $r$ " com os valores críticos tabelados e se verificou que esta correlação é estatisticamente significante $(p<0,001)$.

Para determinar a reta de regressão e verificar se a relação linear é realmente significativa, uma Análise de Regressão Linear foi realizada entre as medidas. Foi feita a análise de variância para a regressão, em que se concluiu que existe correlação significativa $(p<0,001)$ entre a razão das áreas sob as curvas e as profundidades das lesões.

Dos resultados dos fatores, obtiveram-se os valores dos coeficientes constante $(1,06)$ e profundidade $(1,67)$. Desta forma, a reta de regressão entre a RACE e a profundidade fica: 
RACE $=1,06+1,67$. Profundidade

ou seja, para cada unidade a mais de profundidade, o resultado esperado da razão aumenta em 1,67.

Para explicar o grau de ajuste do modelo, procedeu-se ao Coeficiente de Explicação da regressão $\left(R^{2}\right)$, o qual ficou em $18,4 \%$ indicando que a explicação não é muito boa, ou seja, apesar de a regressão ser significativa, observa-se uma tendência de erro na predição dos valores e, portanto, essa função não deve ser utlizada.

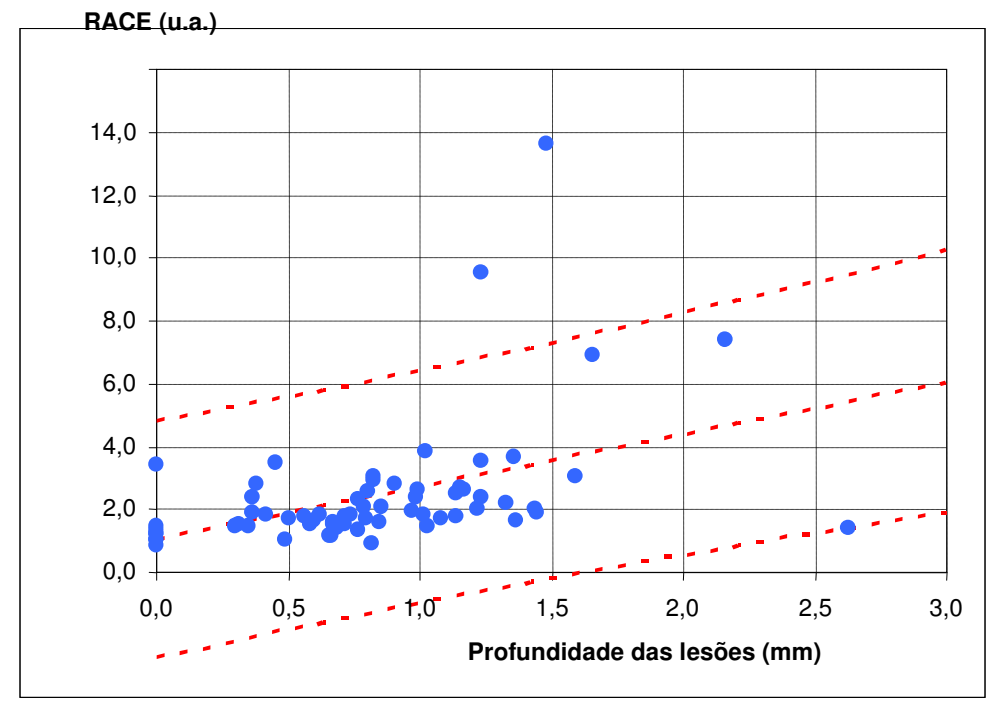

Figura 30: Diagrama de dispersão entre os resultados da RACE e profundidade das lesões in vitro, com a reta de regressão e intervalos para a predição.

\subsection{Correlação: DIAGNOdent x RACE in vitro}

Na Figura 31 está representado o diagrama de dispersão para os dois equipamentos e o intervalo de confiança (95\%). Pôde ser observada uma relação positiva entre elas.

Obteve-se o valor de 0,87 para o índice de correlação linear de Pearson, o que indica uma boa correlação entre as medidas. Comparou-se o valor de "r" com os valores críticos tabelados e se verificou que esta correlação é estatisticamente significante $(p<0,001)$.

Para determinar a reta de regressão e verificar se a relação linear é realmente significativa, uma Análise de Regressão Linear foi realizada entre as medidas. Foi feita a análise de variância para a regressão, em que se concluiu 
que existe correlação significativa $(p<0,001)$ entre a RACE e as leituras com o DIAGNOdent in vitro.

Dos resultados dos fatores, obtiveram-se os valores dos coeficientes constante $(0,83)$ e DIAGNOdent $(0,09)$. Desta forma, a reta de regressão entre a RACE e o DIAGNOdent fica:

$$
\text { RACE }=0,83+0,09 \cdot \text { DIAGNOdent }
$$

ou seja, para cada unidade a mais que o DIAGNOdent detecta, o resultado esperado da RACE aumenta em 0,09.

Para explicar o grau de ajuste do modelo, procedeu-se ao Coeficiente de Explicação da regressão $\left(R^{2}\right)$, o qual ficou em $75,1 \%$, indicando que a explicação é boa, contudo, apesar de a regressão ser significativa, considera-se um pequeno erro na predição dos valores.

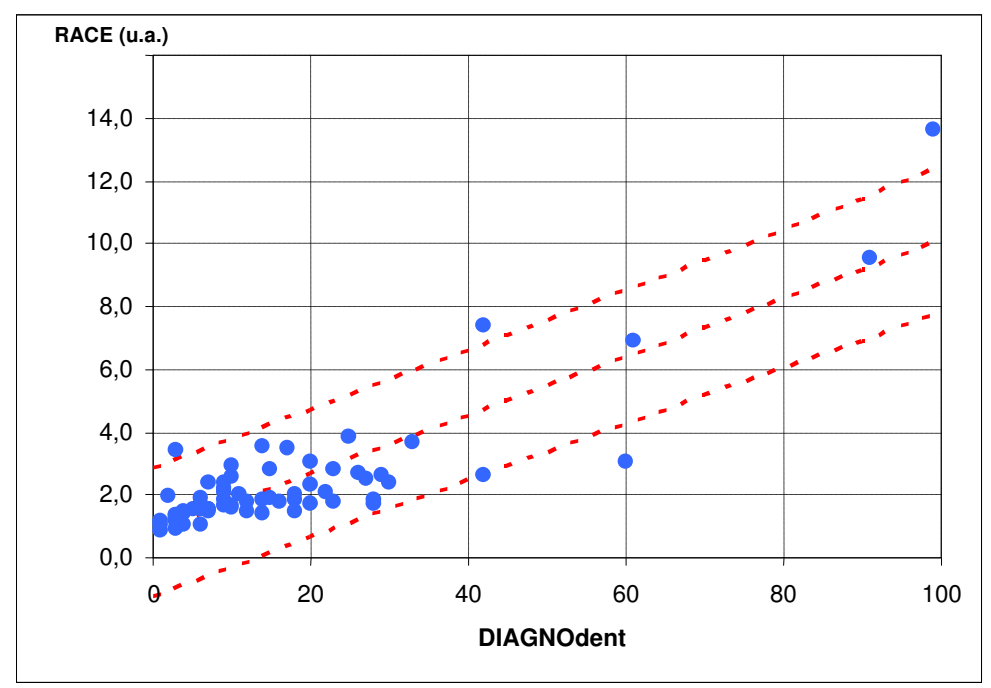

Figura 31: Diagrama de dispersão entre os resultados da RACE e do DIAGNOdent in vitro, com a reta de regressão e intervalos para a predição.

\subsection{Desempenho do DIAGNOdent e do espectrômetro in vitro}

\subsubsection{Determinação do ponto de corte do DIAGNOdent in vitro}

Para que se obtivesse uma boa especificidade sem perda substancial da sensibilidade, o melhor ponto de corte para o DIAGNOdent in vivo foi calculado por meio da soma dos parâmetros sensibilidade e especificidade dados pela análise ROC. 
D0 representou a ausência da doença e D1, D2 e D3 representaram a presença da doença. O melhor ponto de corte foi > 6, como no estudo in vivo, e está representado no gráfico abaixo pelo ponto mais extremo da linha amarela. Portanto, um valor igual ou maior que 7 nas leituras com este equipamento indicou presença de lesão de cárie. A sensibilidade e a especificidade foram extraídas a partir deste ponto de corte e a acurácia, calculada com estes índices (Figura 32).

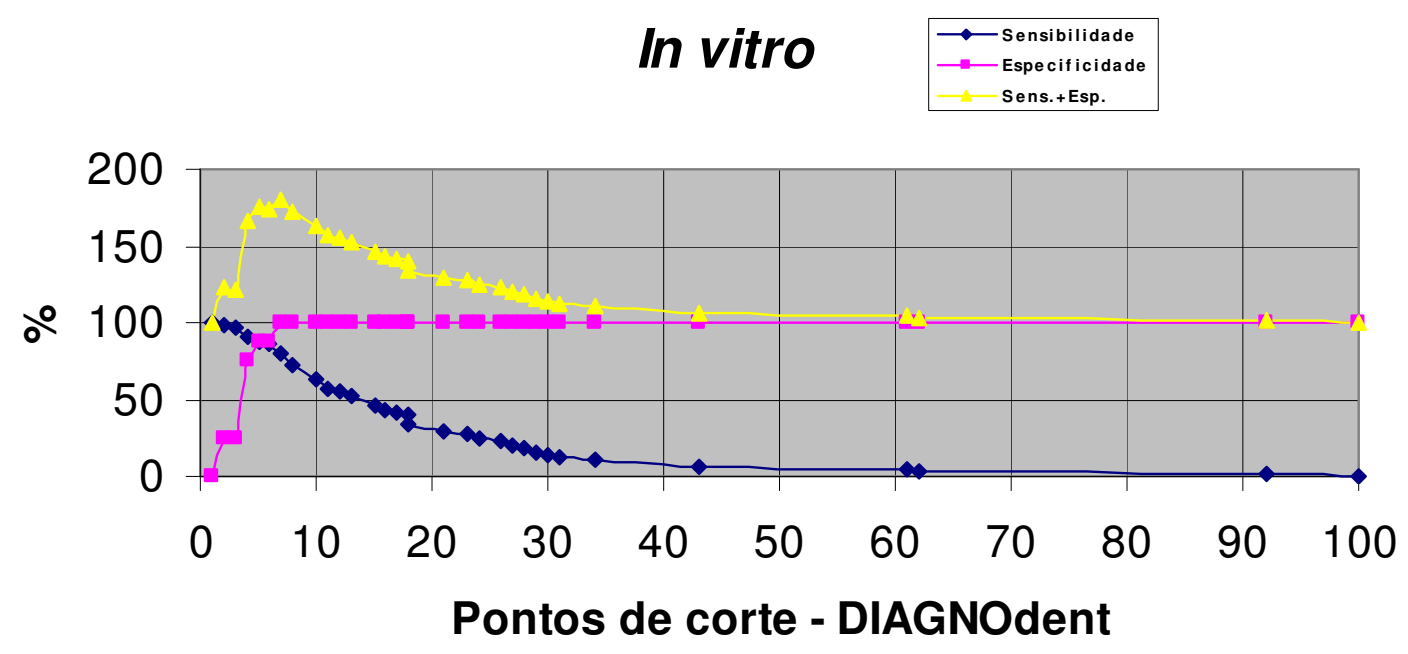

Figura 32: Especificidade, sensibilidade e sua soma relacionadas com diferentes pontos de corte do DIAGNOdent in vitro para o limiar esmalte.

\subsubsection{Determinação do ponto de corte da RACE do EP in vitro}

Da mesma forma que o DIAGNOdent, para que se obtivesse uma boa especificidade sem perda substancial da sensibilidade, o melhor ponto de corte para a RACE in vitro foi calculado por meio da soma dos parâmetros sensibilidade e especificidade dados pela análise ROC.

Assim, considerando o limiar de que Do representou a ausência da doença e D1, D2 e D3 representaram a presença da doença, o melhor ponto de corte da RACE foi $>1,44$ e está representado na Figura 33 pelo ponto mais extremo da linha amarela. Portanto, um valor maior que este nas leituras com o espectrômetro indica presença de lesão de cárie. O ponto de corte para a RACE in vivo foi maior, o que significa que o método é mais sensível in vitro, já que exige uma menor intensidade de fluoescência para diferenciar os tecidos. A 
sensibilidade e a especificidade foram extraídas a partir deste ponto de corte e a acurácia, calculada com estes índices.

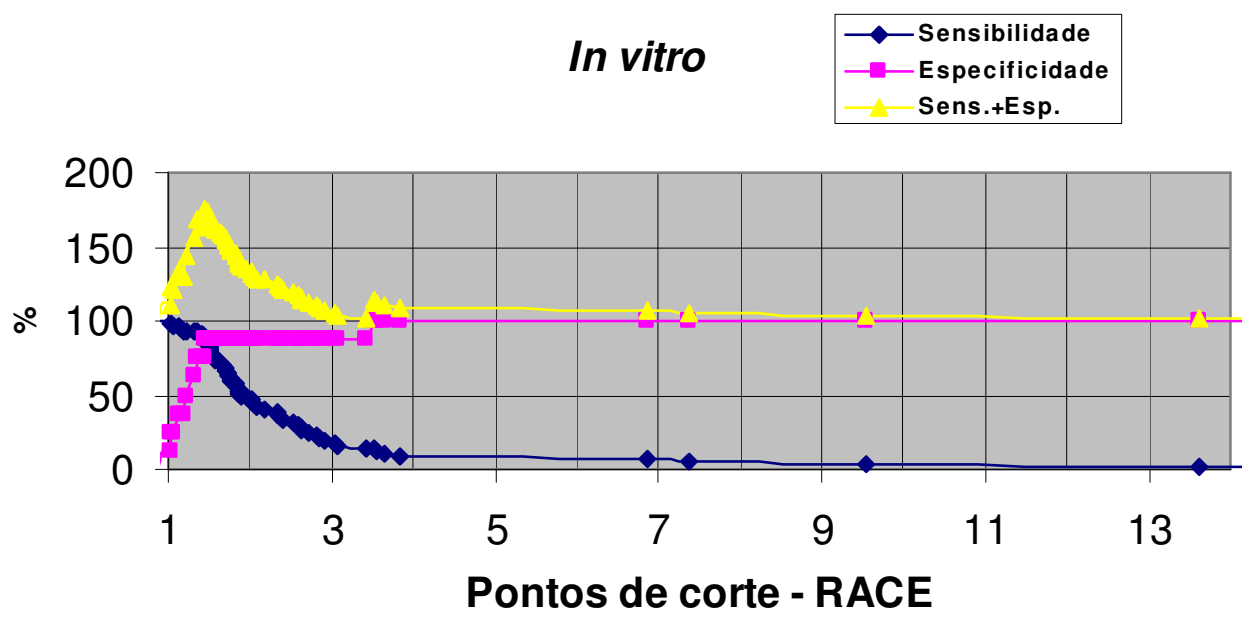

Figura 33: Especificidade, sensibilidade e sua soma relacionadas com diferentes pontos de corte da RACE in vitro para o limiar esmalte.

\subsubsection{Comparação das ASC entre os métodos in vitro}

$\mathrm{Na}$ figura a seguir (Figura 34) podem-se observar as ASC entre os métodos. O teste de McNemar revelou que não houve diferenças estatisticamente significantes entre os métodos in vitro. 


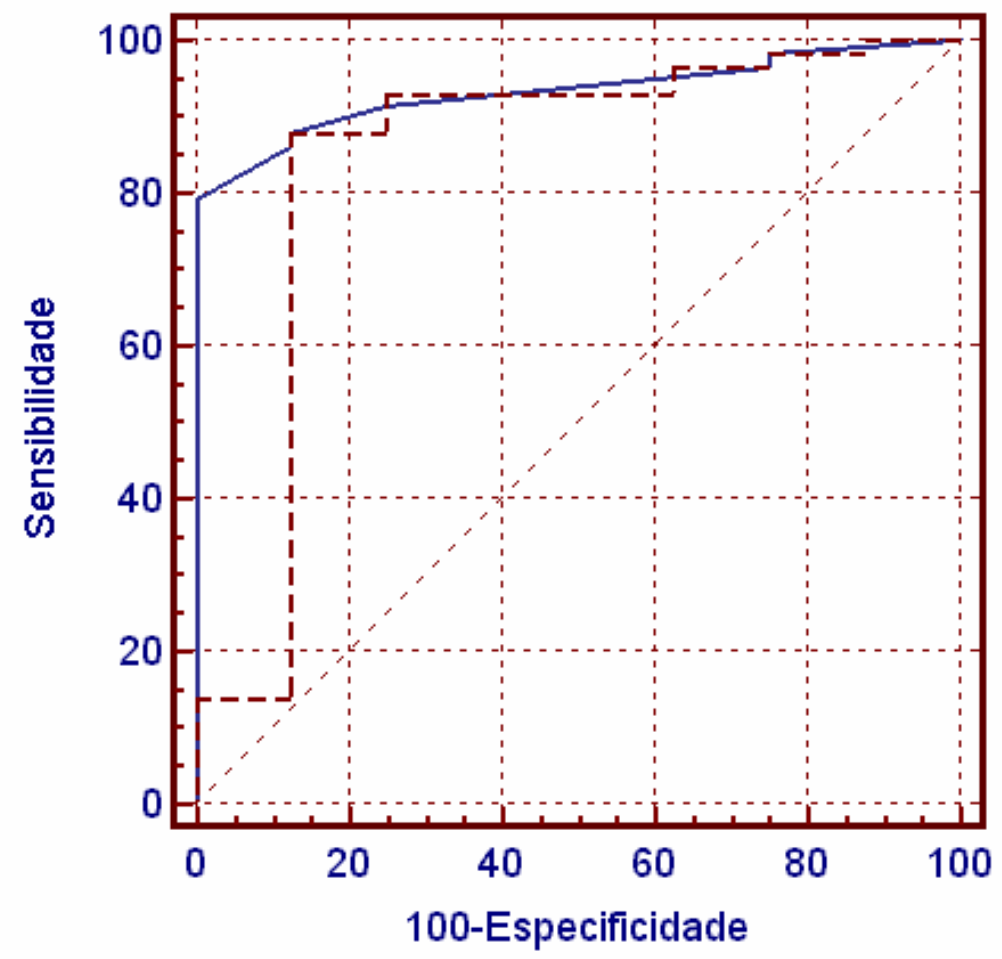

Figura 34: Comparação das ASC entre os métodos DIAGNOdent $(0,93)$ e RACE $(0,85)$ in vitro .

\subsubsection{Performance de ambos os equipamentos in vitro}

A Tabela 9 permite uma visão geral da performance dos diferentes métodos de detecção de lesões de cárie in vitro. $\mathrm{O}$ espectrômetro apresentou numericamente maior sensibilidade do que o DIAGNOdent, 88 e $79 \%$, respectivamente. Por sua vez, a especificidade, a acurácia e a ASC do DIAGNOdent foram maiores quando comparadas com as do espectrômetro in vitro. Contudo, o teste McNemar não revelou diferenças estatisticamente significantes $(p<0,05)$ entre esses valores. 
Tabela 9. Performance dos equipamentos DIAGNOdent e espectrômetro portátil in vitro na detecção de lesões de cárie, expressa em sensibilidade, especificidade, acurácia e área sob a curva ROC (ASC). Do foi considerado sem lesão de cárie e D1, D2 e D3, com lesão de cárie. Na amostragem desse trabalho não houve lesões classificadas em D4.

\begin{tabular}{ccccc}
\hline & Sensibilidade & Especificidade & Acurácia & ASC \\
\hline Espectrômetro in vitro & $0,88^{\mathrm{a}}$ & $0,88^{\mathrm{a}}$ & $0,88^{\mathrm{a}}$ & $0,85^{\mathrm{a}}$ \\
DIAGNOdent in vitro & $0,79^{\mathrm{a}}$ & $1,00^{\mathrm{a}}$ & $0,98^{\mathrm{a}}$ & $0,93^{\mathrm{a}}$ \\
\hline
\end{tabular}

Letras diferentes expressam diferenças estatisticamente significantes entre os valores de uma mesma coluna $(p<0,05)$.

\subsection{DIAGNOdent in vivo $\mathrm{x}$ in vitro}

A performance de cada equipamento foi analisada in vivo e in vitro. No experimento laboratorial, o DIAGNOdent apresentou maior sensibilidade (79\%), enquanto na clínica, o equipamento apresentou sensibilidade de $76 \%$. Essa diferença, contudo, não foi estatisticamente significante $(p<0,05)$ quando avaliada com o teste McNemar. A especificidade, a acurácia e a área sob a curva ROC não mostraram difereças estatisticamente significantes (Tabela 10).

Tabela 10. Performance do DIAGNOdent in vivo e in vitro na detecção de lesões de cárie, expressa em sensibilidade, especificidade, acurácia e área sob a curva ROC (ASC). D0 foi considerado sem lesão de cárie e D1, D2 e D3, com lesão de cárie. Na amostragem desse trabalho não houve lesões classificadas em D4.

\begin{tabular}{ccccc}
\hline & Sensibilidade & Especificidade & Acurácia & ASC \\
\hline DIAGNOdent in vivo & $0,76^{\mathrm{a}}$ & $1,00^{\mathrm{a}}$ & $0,97^{\mathrm{a}}$ & $0,90^{\mathrm{a}}$ \\
DIAGNOdent in vitro & $0,79^{\mathrm{a}}$ & $1,00^{\mathrm{a}}$ & $0,98^{\mathrm{a}}$ & $0,93^{\mathrm{a}}$ \\
\hline
\end{tabular}

Letras diferentes expressam diferenças estatisticamente significantes entre os valores de uma mesma coluna $(p<0,05)$.

\subsection{RACE in vivo $x$ in vitro}

No experimento laboratorial, o espectrômetro apresentou maior sensibilidade (88\%), enquanto na clínica, o equipamento apresentou sensibilidade de $60 \%$. O teste de McNemar revelou que o equipamento apresenta melhor 
performance in vitro do que in vivo $(p<0,05)$. A acurácia do equipamento foi significantemente maior $(p<0,05)$ no estudo clínico. A especificidade e a área sob a curva ROC não mostraram difereças estatisticamente significantes (Tabela 11).

Tabela 11. Performance do espectrômetro in vivo e in vitro na detecção de lesões de cárie, expressa em sensibilidade, especificidade, acurácia e área sob a curva ROC (ASC). D0 foi considerado sem lesão de cárie e D1, D2, D3 e D4, com lesão de cárie.

\begin{tabular}{ccccc}
\hline & Sensibilidade & Especificidade & Acurácia & ASC \\
\hline Espectrômetro in vivo & $0,60^{\mathrm{a}}$ & $1,00^{\mathrm{a}}$ & $0,95^{\mathrm{a}}$ & $0,86^{\mathrm{a}}$ \\
Espectrômetro in vitro & $0,88^{\mathrm{b}}$ & $0,88^{\mathrm{a}}$ & $0,88^{\mathrm{b}}$ & $0,85^{\mathrm{a}}$ \\
\hline
\end{tabular}

Letras diferentes expressam diferenças estatisticamente significantes entre os valores de uma mesma coluna $(p<0,05)$.

\subsection{DIAGNOdent e RACE in vivo e in vitro x área de secção das lesões}

Para verificar se existia correlação entre os resultados do DIAGNOdent e da RACE com a área de secção transversal da lesão in vivo e in vitro, calculouse o índice de correlação linear de Pearson. Não houve correlação significante entre nenhum destes parâmetros, de forma que a área da lesão pareceu não influenciar nas medidas com os equipamentos tanto in vivo quanto in vitro (Figura 35). 


\section{In vivo}
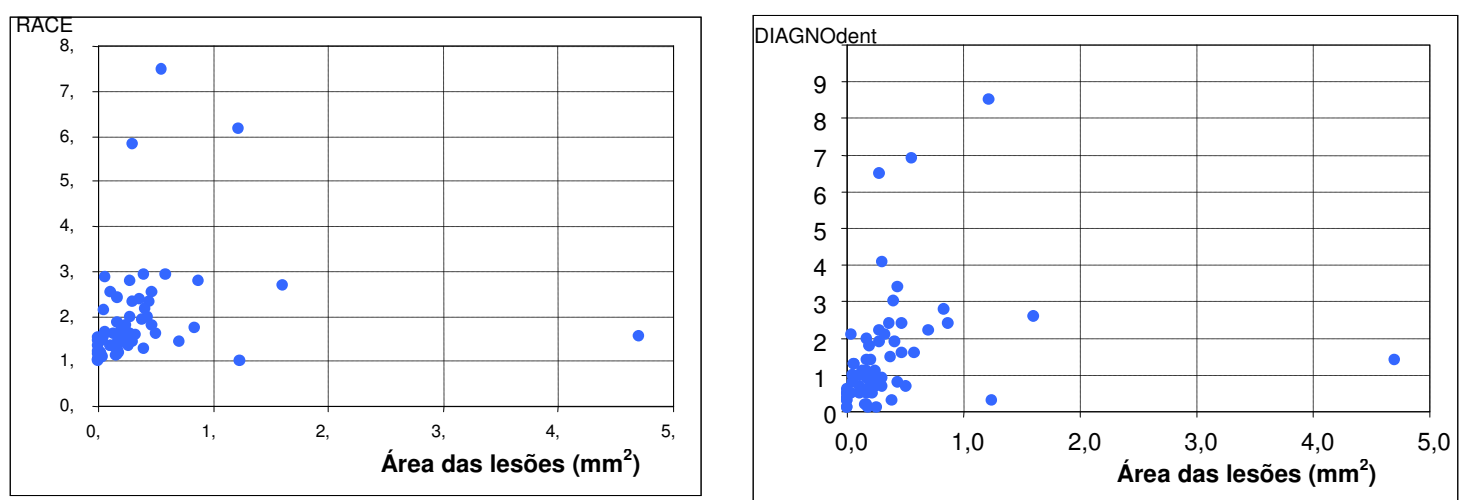

\section{In vitro}
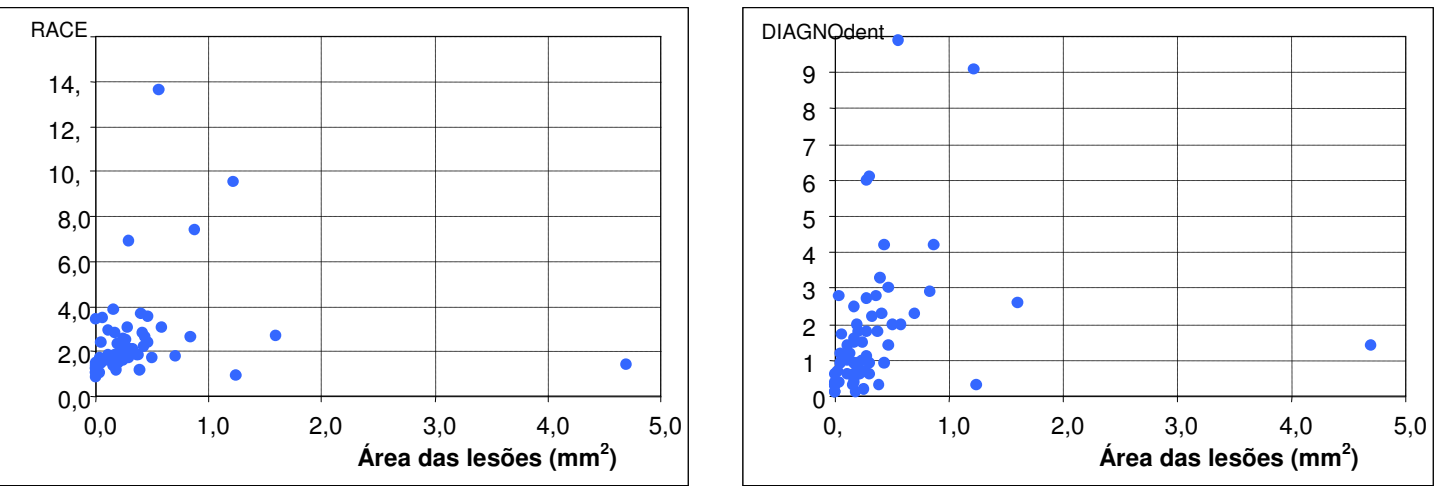

Figura 35: Diagramas de dispersão para a RACE do EP e para o DIAGNOdent, in vivo e in vitro. Não houve correlação entre as medidas e a área de secção transversal das lesões. 


\section{DISCUSSÃO}

A baixa sensibilidade e reprodutibilidade aliadas à subjetividade dos métodos convencionais utilizados para a detecção da cárie têm aumentado a busca por métodos mais precisos, quantitativos e reprodutíveis, principalmente devido a uma nova consciência de que lesões incipientes podem ser revertidas e não simplesmente removidas com processos invasivos e restauradas $3,8,9,14,17,18$, $19,20,21,22,23,24$

Métodos baseados na medição da fluorescência tecidual têm sido investigados como uma nova alternativa para a detecção de lesões de cárie por permitirem o exame não invasivo e quantitativo da substância dura do elemento dentário ${ }^{26,27,28,29}$.

O QLF é um método que utiliza laser de argônio $(\lambda \sim 488 \mathrm{~nm})$ para excitar o tecido dentário e tem sido usado em faces lisas para quantificar pequenas alterações minerais ${ }^{7,25,30}$. Apesar de apresentar bons resultados em lesões iniciais, o método não é adequado para detecção de lesões oclusais e não é de fácil utilização na prática clínica.

Outro método baseado na captação da fluorescência emitida pelo tecido cariado é o DIAGNOdent. Este equipamento dispõe de um laser de diodo que emite luz vermelha $(\lambda \sim 655 \mathrm{~nm})$, a qual é absorvida por componentes inorgânicos e principalmente orgânicos do tecido dentário ${ }^{31,32,33}$. Apesar de ser um aparelho portátil, de fácil utilização clínica e indicado para superfícies oclusais, fatores como a presença de biofilme na superfície examinada, manchas, restaurações, autoclavagem de pontas podem interferir na interpretação dos dados obtidos com o equipamento $34,35,36,37,38,39,40$ e promover resultados insatisfatórios que podem dar à luz sub ou sobretratamentos.

Este estudo foi realizado com a intenção de desenvolver um sistema de detecção de lesões de cárie que fosse capaz de apresentar uma eventual melhora no desempenho em relação ao DIAGNOdent, diante de lesões de cárie mais iniciais. Esse fator, aliado à necessidade de estudos clínicos validados histologicamente, foi preponderante para o desenvolvimento desta pesquisa. 
Para isso, propôs-se a utilização clínica de uma técnica bastante estudada in vitro. A espectroscopia de fluorescência permitiria que a lesão fosse detectada com alta sensibilidade e especificidade por meio da diferenciação entre espectros de regiões sadias e desmineralizadas ${ }^{41,42,43}$.

Dado que os requisitos necessários para que uma fonte de luz possa ser utilizada na detecção da cárie são a monocromaticidade e possuir intensidade adequada $^{26}$, a fonte de excitação selecionada para proceder ao experimento com a espectroscopia de fluorescência foi um laser de diodo (comercialmente disponível como laser pointer) devido ao seu baixo custo e principalmente por seu comprimento de onda de excitação ser no vermelho $(\lambda \sim 657 \mathrm{~nm})$. A excitação do dente com luz vermelha apresenta algumas vantagens em relação à luz azul. A cor vermelha é menos absorvida pelo esmalte do que os comprimentos de ondas mais curtos $(450<\lambda<590 \mathrm{~nm})^{135}$ utilizados com este fim e, por isso, ela penetra mais profundamente no dente, permitindo que ela chegue aos compostos fluorescentes ${ }^{92}$. Além disso, apesar de a intensidade geral da fluorescência ser menor do que com a excitação no azul ${ }^{91}$, com a excitação no vermelho existe uma maior diferenciação entre o tecido sadio e cariado ${ }^{27}$. Ainda, excitando no azul, a relação de intensidade do sinal entre tecido cariado e sadio varia fortementente com a banda específica da fluorescência, enquanto com a excitação vermelha, a razão do sinal é constante na região entre 700 e $800 \mathrm{~nm}^{29}$. Por fim, o comprimento de onda utilizado neste trabalho ( $\lambda \sim 657 \mathrm{~nm}$ ) é bastante próximo ao do DIAGNOdent ( $\lambda \sim 655 \mathrm{~nm})$ e isso possibilitou uma comparação dos dados.

No experimento in vitro deste trabalho, as diferenças de magnitude entre espectros de regiões cariadas e sadias foram da ordem de aproximadamente 1,5. Entretanto, esses resultados estão em desacordo com outra pesquisa ${ }^{27}$, em que as diferenças espectrais entre os tecidos sadios e cariados foram da ordem de magnitude de 7. No presente estudo, contrastes maiores, da ordem de 4 a 7 vezes, só foram observados in vitro em 4 dos 66 sítios analisados, sendo 2 em lesão profunda de esmalte (D2) e 2 em lesão inicial de dentina (D3). Já in vivo, estes pontos foram menos extremos do que in vitro.

Estes valores discrepantes foram provenientes de dois dentes de um mesmo paciente e estão representados nos Box-plots como pontos extremos. Uma possível explicação para isso seria uma maior presença de pigmentação nas 
superfícies desses dentes, já que estas não foram excluídas do experimento ou ainda que algum resíduo de placa bacteriana tenha permanecido após a limpeza devido a uma superfície com fissura mais profunda, alterando os sinais.

Essa hipótese é acentuada pelo fato de que com o DIAGNOdent as leituras desses mesmos sítios apresentaram condição de falso-positivos quando confrontadas com o padrão ouro. Dois sítios com lesões profundas em esmalte (D2) atingiram valores próximos do valor máximo do equipamento e os outros dois sítios com lesões iniciais em dentina (D3) alcançaram valores maiores que 40, 0 que contradiz qualquer protocolo de pontos de corte.

Assim, comparando-se as médias da RACE do EP antes e após a exclusão dos quatro sítios extremos, é possível observar que houve uma diminuição desses valores para D2 e D3, o que ratifica os resultados de que apenas D0 difere significantemente dos demais grupos, já que os resultados para D1, D2 e D3 se aproximaram ainda mais.

\begin{tabular}{|c|c|c|c|c|}
\hline Histologia & D0 & D1 & D2 & D3 \\
\hline Média RACE (antes da exclusão) & 1,2 & 1,8 & 2,0 & 2,1 \\
\hline Média RACE (depois da exclusão) & 1,2 & 1,8 & 1,7 & 1,8 \\
\hline
\end{tabular}

Extrapolando essas medidas, poder-se-ia supor que os métodos de detecção com o DIAGNOdent e com o espectrômetro portátil não seriam capazes de discriminar níveis da doença, mas possuiriam boa capacidade de diferenciação entre tecido sadio e cariado. Essa assertiva contrariaria estudos que afirmam que - DIAGNOdent é mais eficaz em identificar lesões dentinárias $16,17,33,53$. Possíveis motivos para estes resultados poderiam estar relacionados às características do grupo dos dentes selecionados, à prevalência da doença nestes dentes e/ou à subjetividade do método histológico. Esses fatores serão detalhados a seguir.

Apesar de serem utilizados em várias pesquisas $39,52,89,134$, quase sempre por motivos éticos, muito se tem questionado quanto à validade dos estudos que utilizam pré-molares e terceiros molares. Isso se deve ao fato de a prevalência da doença cárie ser menor nestes dentes ${ }^{3,63}$.

Entretanto, para se proceder a um estudo clínico com validação histológica invasiva de dentes quase totalmente sadios, a utilização destes dentes 
parece ser a única alternativa viável até o presente momento. Por isso, os dentes selecionados para realizar este estudo foram os pré-molares.

Os terceiros molares foram evitados devido a sua localização, dificuldade de posicionamento da ponta de inspeção e visualização dos sítios e ainda porque, em muitos dos casos, no momento da exodontia era feita a odontosecção desses elementos, inviabilizando a posterior análise histológica.

A superfície oclusal dos dentes foi escolhida para obtenção das medidas porque essas faces são as mais atingidas pela doença (ainda que em molares), devido a sua complexa morfologia que promove a presença de matéria orgânica e película adquirida, favorecendo a formação das lesões ${ }^{52}$.

No entanto, a morfologia dos pré-molares não é tão complexa quanto a dos molares, bem como sua superfície oclusal não é tão irregular, por isso a prevalência de lesões nestes dentes é menor e os resultados não devem ser generalizados para primeiros e segundos molares permanentes ${ }^{3,63}$.

Braga et al. (2006) constataram que para o DIAGNOdent não existem diferenças estatisticamente significantes nos resultados obtidos entre a média de 3 medidas ou única medida, contanto que seja feita a calibração do equipamento $^{136}$. Contudo, esse estudo foi conduzido laboratorialmente em dentes decíduos e talvez não deva ser extrapolado para estudos em dentes permanentes in vivo, condições do presente trabalho. Portanto, os resultados do experimento in vivo apresentados neste trabalho devem ser interpretados com cautela, pois devido às dificuldades clínicas, um só operador obteve uma só medida com cada equipamento, e embora o fabricante não recomende um número determinado de medidas que devam ser realizadas, vários estudos têm feito a média de vários registros de um mesmo sítio analisado ${ }^{74,118}$.

Neste estudo, o DIAGNOdent apresentou alta acurácia para verificar presença/ausência de lesão de cárie tanto no estudo in vivo $(0,97)$ quanto no in vitro $(0,98)$, corroborando com resultados de estudos anteriores ${ }^{137}$. Clinicamente, o DIAGNOdent apresentou $100 \%$ de especificidade e sensibilidade de $76 \%$. Isso quer dizer que de todos os sítios com lesões de cárie, verificados pelo padrão ouro, $76 \%$ foram corretamente detectados com o equipamento. $O$ valor de detecção da doença está próximo do menor valor observado por alguns autores (75 a 96\%), enquanto a especificidade sobrepujou o maior valor esperado por esses mesmos autores (68 a 86\%) ${ }^{8,134}$. É possível que os resultados do presente 
trabalho tenham sido influenciados, como descrito anteriormente, pelas características do grupo dos dentes selecionados, pela baixa prevalência da doença nestes dentes, bem como pela subjetividade do método histológico.

Em uma população com baixa prevalência da doença cárie, um método de detecção deve apresentar uma alta especificidade, mesmo que em detrimento da sensibilidade, pois isso resulta em uma diminuição de tratamentos desnecessários devido ao número de diagnósticos falso-positivos ser menor 33,63, 125, 134. Nos casos de populações com alta prevalência da doença seria interessante a utilização de métodos com alta sensibilidade. Essa assertiva pode parecer controversa, já que para populações com alta prevalência da doença não há tanta necessidade de métodos tão sensíveis que detectem mínimas alterações minerais ${ }^{53}$.

Considerando apenas o grupo dos pacientes que fizeram parte deste trabalho e não a população de forma geral, a prevalência da doença foi baixa, o que aponta a necessidade de um método de detecção que tenha alta especificidade, mesmo que em detrimento da sensibilidade. $O$ grupo de dentes utilizados, como já foi discutido, possui baixa prevalência de lesões de cárie. Além disso, todos os pacientes que fizeram parte do experimento procuraram as clínicas para fazer tratamento ortodôntico e desse fato supõe-se que esses indivíduos sejam razoavelmente esclarecidos quanto à higiene bucal e que possuam condições socioeconônomicas mais favoráveis, o que influencia diretamente na prevalência da doença em um dado grupo, já que esta possui um aspecto polarizado, isto é, possui os seus mais altos índices concentrados em pequenos grupos populacionais marginalizados ${ }^{141}$.

Desta forma, para o presente estudo o método de detecção da cárie deveria possuir alta especificidade, o que foi observado com os dois equipamentos. O DIAGNOdent apresentou especificidade de $100 \%$ nos experimentos in vivo e in vitro, e o espectrômetro apresentou especificidade de $100 \%$ no experimento in vivo e de $88 \%$ no experimento in vitro. Apesar de ter ocorrido uma diminuição desse parâmetro in vitro, essa diferença não foi estatisticamente significante $(p<0,05)$.

Apesar de a validação histológica com microscopia ser considerada 0 método mais aceito como padrão ouro para o estudo de diagnóstico de lesões de cárie oclusais ${ }^{3}$, os resultados obtidos por esta técnica podem ser influenciados 
por fatores como a variação entre operadores e diferenças na metodologia. Os problemas com a metodologia incluem secções de espessura variada e qualidade do disco de corte que, se for muito espesso, pode desgastar parte da lesão. Os aspectos relacionados ao operador consistem em alterações na forma de seccionar, o operador pode não seccionar o sítio corretamente, neste caso o corte passaria fora da lesão. Além disso, deve-se considerar a concepção individual de lesão de cada examinador, e seu senso de crítica ${ }^{142}$. Esses motivos podem ter contribuído para um descréscimo da correlação entre os resultados obtidos com os equipamentos e o padrão ouro, diminuindo a sua validade.

A técnica de espectroscopia de fluorescência apresentou diferença estatisticamente significante em relação à sensibilidade do método no experimento in vivo $(0,60)$ e in vitro $(0,88)$. Isso quer dizer que o método é mais sensível a variação clínica do que o DIAGNOdent, no qual, apesar de ter apresentado um melhor desempenho no experimento in vitro em relação ao in vivo, essa diferença não foi estatisticamente significante.

Em relação às diferenças entre os estudos in vitro e in vivo, alguns aspectos podem ser questionados. A solução de armazenamento do dente após a exodontia, principalmente as descontaminantes, é um fator em potencial. No entanto, os autores ponderam que haveria uma diminuição das leituras com o DIAGNOdent devido a uma desnaturação protéica ou remoção de moléculas fluorescentes 17, 61,138,139, 140 e neste estudo descontaminantes de qualquer gênero foram evitados. Após a exodontia, os dentes do estudo in vitro permaneceram menos de dois meses em água deionizada, sob refrigeração, e não é provável que tenha sido este o agente causador do discreto aumento nas leituras com este equipamento in vitro.

Outro fator que poderia ser considerado na contribuição da alteração dos resultados dos estudos in vivo e in vitro com o DIAGNOdent seria o fato de que quando o dente é removido da cavidade oral, os componentes orgânicos na superfície, bem como os componentes orgânicos do próprio dente, começam a apresentar mudanças composicionais e estruturais ${ }^{140}$. Entretanto, o resultado mais provável seria a diminuição das leituras.

Se os fatores supracitados fossem realmente os principais responsáveis pelo aumento do sinal de fluorescência nos estudos in vitro, 
provavelmente não só a espectroscopia iria apresentar esse aumento significante na sensibilidade, mas também o DIAGNOdent o apresentaria.

Diante desses fatos, é mais provável que o aumento dos valores dos resultados in vitro com o DIAGNOdent advenha da maior facilidade de obtenção dos resultados em condições laboratoriais do que na clínica ${ }^{14}$. Essa assertiva poderia ser extrapolada para o significante aumento dos valores da RACE in vitro com o espectrômetro portátil, porque a intensidade de fluorescência varia quando se altera o ângulo de detecção da ponta de inspeção ${ }^{15,27}$, dado que um mau posicionamento poderia ocasionar a perda de parte da luz emitida. Além disso, no experimento in vitro houve mais tempo disponível para melhor posicionar a ponta de inspeção sobre o sítio e esta foi fixa em um suporte, o que facilitou a obtenção dos registros. Para o DIAGNOdent isso não seria um fator tão evidente, visto que o equipamento dispõe de uma ponta convergente para superfícies oclusais e registra a maior leitura de toda a superfície varrida, isso talvez explique o aumento não significante das medidas.

Para tratar a cárie, é importante obter informações sobre o grau de progressão da doença e sua atividade. Essas informações são obtidas por meio de uma detecção acurada. A profundidade da lesão se relaciona com a determinação desta detecção, tornando-se uma ferramenta importante para o tratamento adequado da doença ${ }^{121}$.

Assim, enquanto alguns autores ponderam que a correlação entre a profundidade da lesão e as leituras com DIAGNOdent é muito baixa para estudos in vivo ${ }^{31,107,110}$, o que justificaria a advertência expressiva do fabricante em não utilizar o equipamento como uma indicação da profundidade da lesão que o clínico deva remover ${ }^{110}$, outros afirmam existir correlação significante entre essas leituras e a profundidade das lesões e que o equipamento pode ser um indicador da extensão da lesão de cárie ${ }^{68,121,140}$.

Alguns estudos mostraram que o DIAGNOdent apresenta melhor correlação com a profundidade da lesão do que com a perda mineral, por este motivo no presente trabalho optou-se por correlacionar as leituras com a profundidade e não com a perda mineral ${ }^{30,68}$.

Neste estudo, as correlações entre os equipamentos e a profundidade das lesões foram baixas $(r=0,4)$, tanto in vivo quanto in vitro, embora tenham sido estatisticamente significantes ( $p<0,01$ para o DIAGNOdent in vivo e $p<$ 
0,001 para as demais condições). Os resultados deste trabalho corroboram, portanto, com estudos prévios ${ }^{31,107,110 .}$

Diferentemente da profundidade, a área de secção transversal da lesão não apresentou nenhuma correlação com valores de fluorescência em nenhum dos experimentos. Isto indica que a intensidade de fluorescência será maior em lesões mais profundas, mesmo que estas sejam pouco volumosas, do que em lesões volumosas, porém pouco profundas, o que confronta com estudo prévio no qual se defende que as leituras com o DIAGNOdent estão mais correlacionadas com o volume do que com a profundidade da lesão ${ }^{17}$.

Neste estudo, foi observado que o DIAGNOdent apresentou uma razoável correlação com a histologia $(p<0,01)$ tanto no experimento in vivo quanto no in vitro ${ }^{28}$, o mesmo ocorrendo com a espectroscopia de fluorescência $(p<0,001)$.

Foi observada correlação positiva e significante entre os dados dos dois equipamentos, o que sugere que os mesmos fatores que influenciam as leituras com o DIAGNOdent influenciem também as medidas espectrais. Contudo, estudar a influência dos fatores exógenos na espectroscopia não foi objeto deste trabalho e embora precauções como a profilaxia tenham sido tomadas para evitálos, esses fatores devem ser estudados e posteriormente aplicados à espectroscopia para comprovação desta assertiva.

A correlação entre os equipamentos foi um pouco mais significativa no experimento in vitro $(r=0,87)$ do que in vivo $(r=0,83)$. A partir destes dados foi possível escrever uma equação para predição dos dados, assim, cada unidade a mais que o DIAGNOdent detectar, o resultado esperado da RACE do EP será aumentado em um determinado valor. Essa equação tem valor porque os dados do DIAGNOdent se correlacionaram com a histologia. Com isto, vê-se a possibilidade de tornar a avaliação dos espectros mais simples para utilização em clínica.

Quando o tecido dentário foi excitado em vários comprimentos de onda, observou-se que com o aumento do comprimento de onda de excitação havia um deslocamento do comprimento de onda de emissão e foi sugerido que esta propriedade acontecesse devido a efeitos vibracionais, como 0 espalhamento Raman e não à fluorescência ${ }^{91}$. Apesar de possuir reconhecido potencial na detecção de doenças, para que esse espalhamento pudesse ser 
utilizado com este fim, seria necessário um tempo de integração alto, bem como uma alta densidade de potência para que espectros com poucos ruídos fossem obtidos $^{94}$.

A forma dos espectros é dada não só pela fluorescência da amostra, mas também sofre a influência da curva de transmissão dos filtros, do espectrômetro e seu detector. Assim, espectros obtidos com diferentes equipamentos, ainda que com o mesmo comprimento de onda, poderão ter formas diferentes.

Em relação à forma dos espectros, foi relatado que a assinatura espectral não é diferente quando um mesmo tecido sadio e doente é excitado ao mesmo tempo com a mesma fonte de luz ${ }^{26}$.

Nossos espectros mostraram pico de emissão centrados em $\lambda \sim 730 \mathrm{~nm}$ com intensidade do sinal de fluorescência maior para o tecido cariado do que para o dente sadio. Nossos dados concordam com um estudo no qual foi utilizada uma fonte com comprimento de onda de excitação em $655 \mathrm{~nm}$ e se obteve pico de emissão em $\lambda \sim 736 \mathrm{~nm}$ para regiões sadias e cariadas. A intensidade do sinal observada também foi maior para o tecido cariado do que para o dente sadio ${ }^{27}$.

Só a fluorescência integral já é informação de valor para estimar o estado de um dente. Se a intensidade dos picos forem observadas ao longo do tempo, tornar-se-á possível observar diferentes estágios da cárie, ou seja, monitorar a evolução da lesão ${ }^{91,92}$.

A obtenção da razão da área sob a curva dos espectros cariado e sadio (RACE) não é a única forma de analisar os espectros obtidos com o especrtômetro portátil. O DIAGNOdent envolve a análise de dois pontos de comprimentos de onda, portanto, outra opção de análise dos espectros seria proceder à normalização com o pico de luz espalhada e fazer a razão deste valor com o valor do pico de maior intensidade de fluorescência. Assim, inclusive, seria possível evitar variações nos resultados provenientes da posição relativa da fibra sobre a superfície ${ }^{74}$.

O espectro da hidroxiapatita sintética (Figura 14) mostrou baixa intensidade no sinal de fluorescência quando comparado com a intensidade de sinal de uma lesão de cárie. Esse padrão de baixa intensidade de fluorescência foi obtido em outros estudos ${ }^{29,96}$ e nos levam a acreditar na hipótese de que os componentes orgânicos seriam mesmo os responsáveis pelo aumento de sinal de 
fluorescência infravermelha na presença da cárie. Assim, também se poderia deduzir que as medidas com o espectrômetro são afetadas por esses mesmos componentes orgânicos, e não só o DIAGNOdent, inclusive porque houve uma forte correlação entre os dois equipamentos.

Como foi descrito anteriormente, os componentes orgânicos costumam influenciar ou ser os principais responsáveis pela origem da fluorescência obtida com excitação no vermelho, no azul e até no ultravioleta ${ }^{15,29,92,93,96,98,143}$. Assim, obter-se-ia o melhor desempenho dos métodos de detecção de lesões de cárie baseados na captação de fluorescência, se todos os fatores que pudessem influenciar nas medidas fossem conhecidos, para que fossem evitados.

A menor lesão de esmalte das amostras naturais estudadas teve profundidade de aproximadamente $300 \mu \mathrm{m}$ e foi detectada pelo espectrômetro. Pesquisas futuras poderão verificar a menor alteração mineral detectável pelo equipamento.

A técnica de tomografia por coerência óptica permite que alterações minerais com cerca de $10 \mu \mathrm{m}$ sejam detectadas. Porém, os estudos preliminares realizados com essa técnica mostram que ela ainda se encontra bastante distante da realidade das clínicas odontológicas, devido ao seu alto custo e difícil manuseio ${ }^{82,83,84}$.

Os resultados apresentados com o sistema desenvolvido são equivalentes aos do DIAGNOdent. Porém, o espectrômetro permite que diferentes análises sejam feitas a partir dos espectros, bem como pode utilizar-se de um detector CCD altamente sensível, o que poderia ser considerado um benefício em favor de sua utilização.

Para utilização em clínica, constatou-se que o sistema de detecção utilizando um espectrômetro portátil ainda precisa de alguns aperfeiçoamentos, como uma peça de mão com ponta convergente e angulada que permita o acesso de lesões em faces oclusais de dentes posteriores e a elaboração de um dispositivo que registre e armazene de forma automática a banda de fluorescência de maior intensidade, pois no momento de captura dos espectros, qualquer movimento do operador pode alterar a posição da peça de mão e, conseqüentemente, não capturar o espectro real que condiga com a lesão. 


\section{CONCLUSÕES}

De acordo com as condições utilizadas neste estudo, chega-se à seguinte conclusão:

O sistema desenvolvido foi testado para a detecção in vivo de lesões de cárie e apresentou correlação positiva com o equipamento comercial DIAGNOdent, correlação com a profundidade da lesão equiparada com este equipamento e maior capacidade para detectar o tecido cariado in vitro, embora tenha apresentado menor sensibilidade in vivo.

O sistema ainda não apresenta condições adequadas para utilização clínica. Estes foram os primeiros passos na busca de parâmetros que permitam sua utilização nestas condições. Os melhores resultados no experimento laboratorial sugerem que com ponta convergente e angulada e software dedicado, o método é promissor para utilização em clínicas odontológicas em um futuro próximo. 


\section{REFERÊNCIAS BIBLIOGRÁFICAS}

1. LOESCHE, W.J. Produção de ácidos na placa. In: LOESCHE, W.J. $\boldsymbol{A}$ doença cárie: uma infecçao tratável. Springgield: Thomas, 1982: 128150.

2. THYLSTRUP, A.; FEJERSKOV, O. Cariologia Clínica. 3. ed. São Paulo: Editora Santos, 2001.

3. BADER J.D.; SHUGARS D.A.; BONITO A.J. A systematic review of the performance of methods for identifying carious lesions. J Public Health Dent, v. 62, n. 4, p. 201-213, 2002.

4. FEJERSKOV, O. Concepts of dental caries and their consequences for understanding the disease. Community Dent Oral Epidemiol, v. 25, n. 1, p. 5-12, 1997.

5. CLARKSON, B.H. Introduction to cariology. Dent Clin North Am, v. 43, n. 4, p. 569-578, 1999.

6. MILICICH, G.W. Diagnóstico de cárie e como usar o DIAGNOdent. Disponível em: <www.advancedental-ltd.com>. Acesso em: 17 de junho de 2006.

7. TRANAEUS, S.; SHI, X.Q.; ANGMAR-MANSSON, B. Caries risk assessment: methods available to clinicians for caries detection. Community Dent Oral Epidemiol, v. 33, p. 265-273, 2005.

8. HEINRICH-WELTZIEN, R.; KUHNISCH, J.; VAN DER VEEN, M.; JOSSELIN DE JONG, E.; STOBER, L. Quantitative light-induced fluorescence (QLF)- A potential method for the dental practitioner. Quintessence Int, v. 34, n. 3, p. 181-188, 2003.

9. FEATHERSTONE, J.D.B. The continuum of dental caries - evidence for a dynamic process. J Dent Res, v. 83, n. Spec No C, p. C39-43, 2004.

10. MARTHALER, T.M. Caries status in Europe and predictions of future trends. Caries Res, v. 24, p. 381-396, 1990.

11. HUGOSON, A.; KOCH, G.; HALLONSTEN, A.L.; NORDERYD, J.; ABERG A. Caries prevalence and distribution in 3-20-year-olds in Jonkoping, Sweden, in 1973, 1978, 1983, 1993. Community Dent Oral Epidemiol, v. 28, p. 83-89, 2000. 
12. HUGOSON, A.; KOCH, G.; SLOTTE, C.; BERGENDAL, T.; THORSTENSSON, B.; THORSTENSSON, H. Caries prevalence and distribution in 20-80-year-olds in Jonkoping, Sweden, in 1973, 1983, 1993. Community Dent Oral Epidemiol, v. 28, p. 90-96, 2000.

13. VERDONSCHOT, E.H.; WENZEL, A.; TRUIN, G.J.; KONIG, K.G. Performance of electrical resistance measurements adjunct to visual inspection in the early diagnosis of occlusal caries. J Dent , v. 21, p. 332337, 1993.

14. EKSTRAND, K.R.; RICKETTS, D.N.J.; KIDD, E.A.M.; QVIST, V.; SCHOU, S. Detection, diagnosing, monitoring and logical treatment of occlusal caries in relation to lesion activity and severety: an in vivo examination with histological validation. Caries Res, v. 32, p. 247-254, 1998.

15. TRANAEUS, S.; LINDGREN, L-E; KARLSSON, L.; ANGMAR-MANSSON, $B$. In vivo validity and reliability of IR fluorescence measurements for caries detection and quantification. Swed Dent J , v. 28, p. 173-182, 2004.

16. ÁSTVALDSDÓTTIR, A.; HOLBROOK, W.P.; TRANAEUS, S. Consistency of DIAGNOdent instruments for clinical assessment of fissure caries. Acta Odontol Scand, v. 62, p. 193-198, 2004.

17. SHI, X.Q.; WELANDER, U.; ANGMAR-MANSSON, B. Occlusal caries detection with KaVo DIAGNOdent and radiography: an in vitro comparison. Caries Res, v. 34, n. 2, p. 151-158, 2000.

18. STOOKEY, G.K. Caries prevention. J Dent Educ, v. 62, p. 803-811, 1998.

19. ZANIN, F.A.; BRUGNERA, A.; PECORA, J.D. New technologies in dentistry. SPIE, v. 3593, p. 127-132, 1999.

20. GERLACH, R.F.; SOUZA, A.P.; CURY, J.A.; LINE, S.R.P. Fluoride effect on the activity of enamel matrix proteinases in vitro. Eur J Oral Sci , v. 108, p. 48-53, 2000.

21. ATTRILL, D.C.; ASHLEY, P.F. Occlusal caries detection in primary teeth: a comparison of DIAGNOdent with conventional methods. Br Dent J, v. 190, n. 8, p. 440-443, 2001.

22. CROLL, T.P.; TYMA, M.S. Caries detection using laser fluorescence. Compend Cont Educ Dent, v. 22, n. 10, p. 838-844, 2001. 
23. ALWAS-DANOWSKA, H.M.; PLASSCHAERT, A.J.M.; SULIBORSKI, S.; VERDONSCHOT, E.H. Reliability and validity issues of laser fluorescence measurements in occlusal caries diagnosis. J Dent, v. 30, p. 129-134, 2002.

24. TONIOLI, M.B.; BOUSCHLICHER, M.R.; HILLIS, S.L. Laser fluorescence detection of occlusal caries. Am J Dent , v. 15, p. 268-273, 2002.

25. BJELKHAGEN, H.; SUNDSTROM, F.; ANGMAR-MANSSON, B.; RYDEN, $\mathrm{H}$. Early detection of enamel caries by the luminescence excited by visible laser light. Swed Dent J, v. 6, n. 1, p. 1-7, 1982.

26. SUNDSTROM, F.; FREDRIKSSON, K.; MONTAN, S.; HAFSTROMBJORKMAN, U.; STROM, J. Laser-induced fluorescence from sound and carious tooth substance: spectroscopic studies. Swed Dent J , v. 9, n. 2, p. 71-80, 1985.

27. HIBST, R.; PAULUS, R. A new approach on fluorescence spectroscopy for caries detection. SPIE, v. 3593, p. 141-147, 1999.

28. BADER, J.D.; SHUGARS, D.A. A systematic review of the performance of a laser fluorescence device for detecting caries. J Am Dent Assoc, v. 135, p. 1413-1426, 2004.

29. HIBST, R.; PAULUS, R.; LUSSI, A. Detection of occlusal caries by laser fluorescence: Basic and Clinical investigations. Med Laser Appl, v. 16, n. 3, p. 205-213, 2001.

30. TRANAEUS, S.; AL-KHATEEB, S.; BJORKMAN, S.; TWEMAN, S.; ANGMAR-MANSSON, B. Application of quantitative light-induced fluorescence to monitor incipient lesions in caries-active children. A comparative study of remineralisation by fluoride varnish and professional cleaning. Eur J Oral Sci, v. 109, n. 2, p. 71-75, 2001.

31. SHI, X.Q.; TRANAEUS, S.; ANGMAR-MANSSON, B. Validation of DIAGNOdent for quantification of smooth-surface caries: an in vitro study. Acta Odontol Scand, v. 59, p. 74-78, 2001.

32. MENDES, F.M.; PINHEIRO, S.L.; BENGSON, A.L. Effect of alteration in organic material of the occlusal caries on DIAGNOdent readings. Pesqui Odontol Bras, v. 18, n. 2, p. 141-144, 2004. 
33. LUSSI, A.; IMWINKELRIED, S.; PITTS, N.; LONGBOTTOM, C.; REICH, E. Performance and reproducibility of a laser fluorescence system for detection of occlusal caries in vitro. Caries Res, v. 33, n. 4, p. 262-266, 1999.

34. ROCHA-CABRAL, R.M.; MENDES, F.M.; NICOLAU, J.; ZEZELL, D.M. The influence of PVC seal wrap and probe tips autoclaving on the in vitro performance of laser fluorescence device in occlusal caries in primary teeth. J Clin Pediatr Dent, v. 30, 2006.

35. MENDES, F.M.; HISSADOMI, M.; IMPARATO, J.C.P. Effects of drying time and the presence of plaque on the in vitro performance of laser fluorescence in occlusal caries of primary teeth. Caries Res, v. 38, p. 104108, 2004.

36. SANCHEZ-FIGUERAS, A. Occlusal pit-and-fissure caries diagnosis: a problem no more. Compend Contin Educ Dent, v. 24, n. 5, p. 3-11, 2003.

37. CORTES, D.F.; ELLWOOD, R.P.; EKSTRAND, K.R. An in vitro comparison of a combined FOTI / visual examination o occlusal caries with other caries diagnostic methods and the effect of stain on their diagnostic performance. Caries Res, v. 37, p. 8-16, 2003.

38. BOSTON, D.W. Initial in vitro evaluation of DIAGNOdent or detecting secondary carious lesions associated with resin composite restorations. Quintessence Int , v. 34, n. 2, p. 109-116, 2003.

39. SUBHASH, N.; THOMAS, S.S.; MALLIA, R.J.; JOSE, M. Tooth caries detection by curve fitting of laser-induced fluorescence emission: a comparative evaluation with reflectance spectroscopy. Lasers in Surgery and Medicine, v. 37, p. 320-328, 2005.

40. HAFSTROM-BJORKMAN, U.; SUNDSTROM, F.; TEN BOSCH, J.J. Fluorescence in dissolved fractions of human enamel. Acta Odontol Scand, v. 49, n. 3, p. 133-138, 1991.

41. ANGMAR-MANSSON, B.; TEN BOSCH, J.J. Quantitative light-induced fluorescence (QLF): a method for assessment of incipient caries lesions. Dentomaxillofac Radiol , v. 30, n. 6, p. 298-307, 2001.

42. KESLER, G.; MASYCHEV, V.; SOKOLOVSKY, A.; ALEXANDROV, M.; KESLER, A.; KOREN, R. Photon undulatory non-linear conversion 
diagnostic method for caries detection: a pilot study. J Clin Laser Med Surg, v. 21, n. 4, p. 209-217, 2003.

43. BORISOVA, E.G.; UZUNOV, T.T.; AVRAMOV, L.A. Early differentiation between caries and tooth demineralization using laser-induced autofluorescence spectroscopy. Lasers Surg Med, v. 34, n. 3, p. 249253, 2004.

44. LEGEROS, R.Z. Calcium phosphates in demineralization/remineralization process. J Clin Dent , v. 10, n. 2, 65-73, 1999.

45. TEN CATE, A.R. Histologia bucal: desenvolvimento, estrutura e função. 5. ed. Rio de Janeiro: Guanabara Koogan, 2001. 439 p.

46. BOARI, H.G.D. Avaliação clínica da eficiência do laser de Nd: YAG associado ao flúor fosfato acidulado na prevenção de cárie de sulcos e fissuras de crianças e adolescentes. 2000. Dissertação (Mestrado) Instituto de Pesquisas Energeticas e Nucleares, São Paulo.

47. BRATTHALL,D.; PETERSON, H.; SUNDBERG, H. Reasons for the caries decline: what do the experts believe? Eur J Oral Sci, v. 104, p. 416-422, 1996.

48. SILVERSTONE, L.M. The effect of fluoride in the remineralizatio of enamel caries and caries-like lesions in vitro. J Public Health Dent, v. 42, n. 1, p. 42-53, 1982.

49. TEN CATE, J.M.; BUIJS, M.J.; DAMEN, J.J.M. pH-cycling of enamel and dentin lesions in the presence of low concentrations of fluoride. Eur $\mathbf{J}$ Oral Sci , v. 103, p. 362-367, 1995.

50. MARTHALER TM. Changes in dental caries 1953-2003. Caries Res, v. 38, n. 3, p. 173-181, 2004.

51. ZERO, D.T. Dental caries process. Dent Clin North Am, v. 43, n. 4, p. 635-664, 1999.

52. FERREIRA ZANDONÁ, A.G.; ANALOUI, M.; BEISWANGER, B.B.; ISAACS, R.L.; KAFRAWY, A.H.; ECKERT, G.J.; STOOKEY, G.K. An in vitro comparison between laser fluorescence and visual examination for detection of demineralization in occlusal pits and fissures. Caries Res, v. 32, n. 3, p. 210-218, 1998. 
53. MENDES, F.M.; GANZERLA, E.; NUNES, A.F.; PUIG, A.V.C.P.; IMPARATO, J.C.P. Use of high-powered magnification to detect occlusal caries in primary teeth. Am J Dent, v. 19, p. 19-22, 2006.

54. CAMPOS, J.A.D.B.; CORDEIRO, R.C.L. Validade do diagnóstico de lesões de cárie em faces oclusais de dentes permanentes jovens. $\boldsymbol{R e v}$ Assoc Paul Cir Dent , v. 54, n. 1, p. 35-39, 2000.

55. NYVAD, B. Diagnosis versus detection of caries. Caries Res, v. 38, p. 192-198, 2004.

56. DOUGLAS, C.W.; MCNEIL, B.J. Clinical decision analysis methods applied to diagnostic in dentistry. J Dent Edu, v. 47, n. 11, p. 708-712, 1983.

57. MENDES, F.M. Avaliação do uso de corantes fluorescentes associados ao DIAGNOdent para detecção de perda mineral decorrente da cárie dentária. 2005. Tese (Doutorado) - Universidade de São Paulo, São Paulo.

58. OAKLEY, C.; BRUNETTE, D.M. The use of diagnostic data in clinical dental practice. Dent Clin North Am, v. 46, n. 1, p. 87-115, 2002.

59. PRETTY, I.A.; MAUPOME, G. A closer look at diagnosis in clinical dental practice: part 1. Reliability, validity, specificity and sensitivity of diagnostic procedures. J Can Dent Assoc, v. 70, n. 4, p. 251-255, 2004.

60. DOUGLAS, C.W. Evaluating diagnostic tests. Adv Dent Res, v. 7, p. 6669, 1993.

61. FRANCESCUT, P.; LUSSI, A. Correlation between fissure discoloration, DIAGNOdent measurements, and caries depth: an in vitro study. Pediatr Dent , v. 25, p. 559-564, 2003.

62. LUSSI, A. Comparison of different methods for the diagnosis of fissure caries without cavitation. Caries Res, v. 27, p. 409-416, 1993.

63. LUSSI, A.; FRANCESCUT, P. Performance of conventional and new methods for the detection of occlusal caries in deciduos teeth. Caries Res, v. 37, p. 2-7, 2003.

64. VERDONSCHOT, E.H.; BRONKHORST, E.M.; BURGERSDIJK, K.G.; KONIG, K.G.; SCHAEKEN, M.J.M.; TRUIN, G.J. Performance of some diagnostic systems in examination for small occlusal carious lesions.

Caries Res, v. 26, p. 59-64, 1992. 
65. REIS, A.; ZACH, V.L.; LIMA, A.C.; NAVARRO, M.F.L.; GRANDE, R.H.M. Occlusal caries detection: a comparison of DIAGNOdent and two conventional diagnostic methods. J Clin Dent, v. 15, n. 3, p. 76-82, 2004.

66. BLACK, G.V. Operative Dentistry. V. I. 7. ed. Henry Kimpton, London, 1924.

67. HOSOYA, Y.; MATSUZAKA, K.; INOUE, T.; MARSHALL, G. Influence of tooth-polishing pastes and sealants on DIAGNOdent values. Quint essence Int, v. 35, n. 8, p. 605-611, 2004.

68. MENDES, F.M.; SIQUEIRA, W.L.; MAZZITELLI, J.F.; PINHEIRO, S.L.; BENGTSON, A.L. Performance of DIAGNOdent for detection and quantification of smooth-surface caries in primary teeth. J Dent, v. 33, n. 1, p. 79-84, 2005.

69. EKSTRAND, K.R.; RICKETTS, D.N.J.; KIDD, E.A.M. Reproducibility and accuracy of three methods for assessment of demineralization depth of the occlusal surface: an in vitro examination. Caries Res, v. 31, n. 3, p. 224-231, 1997.

70. REIS, A.; MENDES, F.M.; AGNES, V.; AGNES, G.; GRANDE, R.H.M.; LOGUERCIO, A.D. Performance of methods of occlusal caries detection in permanent teeth under clinical and laboratory conditions. J Dent, v. 34, p. 89-96, 2006.

71. ROCHA, R.O.; ARDENGHI, T.M.; OLIVEIRA, I.B.; RODRIGUES, C.R.M.D.; CIAMPONI, A.L. In vivo effectiveness of laser fluorescence compared to visual inspection and radiography for the detection of occlusal caries in primary teeth. Caries Res, v. 37, p. 437-441, 2003.

72. WENZEL, A.; VERDONSCHOT, E.H.; TRUIN, G.J.; KONIG, K.G. Accuracy of visual inspection, fiber-optic transillumination, and various radiographic image modalities for the detection of occlusal caries in extracted non-cavitated teeth. J Dent Res, v. 71, n. 12, p. 1934-1937, 1992. 
73. FEATHERSTONE, J.D.B. Caries detection and prevention with laser energy. Dent Clin North Am, v. 44, n. 4, p. 955-969, 2000.

74. RIBEIRO FIGUEIREDO, A.C.; KURACHI, C.; BAGNATO, V.S. Comparison of fluorescence detection of carious dentin for different excitation wavelengths. Caries Res, v. 39, p. 393-396, 2005.

75. ANGMAR-MANSSON, B.; AL-KHATEEB, S.; TRANAEUS, S. Caries diagnosis. J Dent Edu, v. 62, n. 10, p. 771-779, 1998.

76. HUYSMANS, M-C.H.D.N.J.M., LONGBOTTOM, C.; HINTZE, H.; VERDONSCHOT, E.H. Surface-specific electrical occlusal caries diagnosis: reproducibility, correlation with histological lesion depth, and tooth type dependence. Caries Res, v. 32, p. 33-336, 1998.

77. HINTZE, H.; WENZEL, A.; DANIELSEN, B.; NYVAD, B. Reliability of visual examination, fibre-optic transillumination, and bite-wing radiography, and reproducibility of direct visual examination following tooth separation for the identification of cavitated carious lesions in contacting approximal surfaces. Caries Res, v. 32, p. 204-209, 1998.

78. FORGIE, A.H.; PINE, C.M.; PITTS, N.B. The use of magnification in a preventive approach to caries detection. Quintessence Int, v. 33, p. 1316, 2002.

79. BOSTON, D.W.; SAUBLE, J.E. Evaluation of laser fluorescence for differentiating caries dye-stainable versus caries dye-unstainble dentin in caries lesions. Am J Dent, v. 18, n. 6, p. 351-354, 2005.

80. McCOMB, D. Caries-detector dyes- how accurate and useful are they? J Can Dent Assoc, v. 66, n. 4, p. 195-198, 2000.

81. MELLER, C.; HEYDUCK, C.; TRANAEUS, S.; SPLIETH, C. A new in vivo method for measuring caries activity using quantitative light-induced fluorescence. Caries Res, v. 40, p. 90-96, 2006.

82. DE FREITAS, A.Z.; ZEZELL, D.M.; VIEIRA, N.D.; RIBEIRO, A.C.; GOMES, A. S. L. Imaging carious human dental tissue with optical coherence tomography. J Appl Phys, v. 99, n. 2, 2006. 
83. OTIS, L.L.; EVERETT, M.J.; SATHYAM, U.S.; COLSTON, B.W. Optical Coherence Tomography: a new imaging technology for dentistry. JADA, v. 131 , p. $511-514,2000$.

84. DE MELO, L.S.; DE ARAUJO, R.E.; FREITAS, A.Z.; ZEZELL, D.M.; VIEIRA, N.D.; GIRKIN, J.; HALL, A.; CARVALHO, M.T.; GOMES, A.S. Evaluation of enamel dental restoration interface by optical coherence tomography. J Biomed Opt, v. 10, n. 6, p. 064027, 2005.

85. TEN BOSCH, J.J. Light Scattering and related methods in caries diagnosis. 1996, Indiana. Proceedings of Indiana Conference. USA, 1996, p. 81-88.

86. EKSTRAND, K,R. Improving clinical visual detection - potential for caries clinical trials. J Dent Res, v. 83, n. Spec No C, p. C67-C71, 2004.

87. KIDD, E.A.M.; FEJERSKOV, O. What constitutes dental caries? Histopathology of carious enamel and dentin related to the action of cariogenic biofilms. J Dent Res, v. 83, n. Spec No C, p. C35-C38, 2004.

88. MUJAT, C.; VAN DER VEEN, M.H.; RUBEN, J.L.; DOGARIU, A.; TEN $\mathrm{BOSCH}$, J.J. The influence of drying on quantitative laser fluorescence on optical pathlengths in incipient natural caries lesions. Caries Res, v. 38, p. 484-492, 2004.

89. BANERJEE, A.; BOYDE, A. Autofluorescence and mineral content of carious dentine: scanning optical and backscattered electron microscopic studies. Caries Res, v. 32, p. 219-226, 1998.

90. BORISOVA, E.; UZUNOV, T.; AVRAMOV, L. Laser-induced autofluorescence study of caries model in vitro. Lasers Med Sci, v. 21, n. 1, p. 34-41, 2006.

91. BUCHALLA, W. Comparative fluorescence spectroscopy shows differences in noncavitated enamel lesions. Caries Res, v. 39, p. 150-156. 2005. 
92. TAUBINSKY, I.M.; ALEXANDROV, M.T.; KOZ'MA, S.Y.U.; CHERNY, V.V. Prospects for applying fluorescence spectroscopy to diagnose the hard tissues of a tooth. Crit Rev Biomed Eng, v. 28, n. 5-6, p. 137-144, 2000.

93. RAMANUJAM, N. Fluorescence spectroscopy in vivo. In: Encyclopedia of Analytical Chemistry. Chinchester: 2000, p. 20-56.

94. RICHARDS-KORTUM, R.; SEVICK-MURACA, E. Quantitative optical spectroscopy for tissue diagnosis. Annu Rev Phys Chem, v. 47, p. 555606, 1996.

95. SONG, K-B; CHOI,Y-H; JEONG, S-H; SEOL, H-J; KIM, H-I; KWON, YH. Detection of incipient carious lesions formed on human teeth in vitro using ultraviolet laser. Photomed Laser Sur, v. 23, n. 5, p. 498-503, 2005.

96. SPITZER, D.; TEN BOSCH, J.J. The total luminescence of bovine and human dental enamel. Calc Tiss Res, v. 20, p. 201-208, 1976.

97. SUBHASH, N.; THOMAS, S.S.; MALLIA, R.J.; JOSE, M. Tooth caries detection by curve fitting of laser-induced fluorescence emission: a comparative evaluation with reflectance spectroscopy. Lasers Surg Med, v. 37, p. 320-328, 2005.

98. KONIG, K.; HIBST, R.; MEYER, H.; FLEMMING, G.;

SCHNECKENBURGER, $\mathrm{H}$. Laser-induced autofluorescence of carious regions of human teeth and caries-involved bacteria. SPIE, v. 2080, p. 170-180, 1993.

99. KONIG, K.; FLEMMING, G.; HIBST, R. Laser-induced autofluorescence spectroscopy of dental caries. Cell Mol Biol, v. 44, n. 8, p. 1293-1300, 1998.

100.LENNON, A.M.; BUCHALLA, W.; BRUNE, L.; ZIMMERMANN, O.; GROSS, U.; ATTIN, T. The ability of selected oral microorganisms to emit red fluorescence. Caries Res, v. 40, p. 2-5, 2006.

101.BANERJEE, A.; GILMOUR, A.; KIDD, E.; WATSON, T. Relationship between S. Mutans and autofluorescence of carious dentin. Am J Dent, v. 17, p. 233-236, 2004. 
102.SHIGETANI, Y.; OKAMOTO, A.; ABU-BAKR, N.; TANABE, K.; KONDO, S.; IWAKU, M. Caries diagnosis using a laser fluorescence systemobservation of autofluorescence of dental caries. Dent Mater J, v. 22, n. 1, p. 56-65, 2003.

103. HIBST, R.; GALL, R. Development of a diode laser-based fluorescence caries detector. Caries Res, v. 32, n. 4, p. 294, 1998.

104. HAFSTROM-BJORKMAN, U.; SUNDSTROM, F.; DE JOSSELIN DE JONG, E.; OLIVEBY, A.; ANGMAR-MANSSON, B. Comparison of laser fluorescence and longitudinal microradiography for quantitative assessment of in vitro enamel caries. Caries Res, v. 26, p. 241-247, 1992.

105. EMAMI, Z.; AL-KHATEEB, S.; DE JOSSELIN DE JONG, E.;

SUNDSTROM, F.; TROLLSAS, K.; ANGMAR-MANSSON, B. Mineral loss in incipient caries lesions quantified with laser fluorescence and longitudinal microradiography. Acta Odontol Scand, v. 54, p. 8-13, 1996.

106. JOSSELIN DE JONG, E.; SUNDSTROM, F.; WESTERLING, H.; TRANAEUS, S.; ANGMAR-MANSSON, B.; TEN BOSCH, J.J. A new method for in vivo quantification of changes in initial enamel caries with laser fluorescence. Caries Res, v. 29, p. 2-7, 1995.

107. TRANAEUS, S.; SHI, X.Q.; LINDGREN, L.; TROLLSAS, K.; ANGMARMANSSON, B. In vivo repeatability and reproducibility of quantitative lightinduced fluorescence. Caries Res, v. 36, p. 3-9, 2002.

108. LAGERWEIJ, M.D.; VAN DER VEEN, M.H.; ANDO, M.; LUKANTSOVA, L. The validity and reproducibility of three light-induced systems: an in vitro study. Caries Res, v. 33, p. 220-226, 1999.

109. AL-KHATEEB, S.; TEN CATE, J.M.; ANGMAR-MANSSON, B.; JOSSELIN DE JONG, E.; SUNDSTROM, G.; EXTERKATE, R.A.M.; OLIVEBY A. Quantification of formation and remineralization of artificial enamel lesions with a new portable fluorescence device. Adv Dent Res, v. 11, n. 4. p. 502-506, 1997.

110.TAM, L.E.; McCOMB, D. Diagnosis of Occlusal Caries: Part II. Recent Diagnostic Technologies. J Can Dent Assoc, v. 67, n. 8, p. 459-463, 2001.

111.PRETTY, I.A.; EDGAR, W.M.; HIGHAM, S.M. The effect of dehydration on quantitaive light-induced fluorescence analysis of early enamel demineralization. J Oral Rehabil, v. 31, p. 179-184, 2004. 
112. AMAECHI, B.T.; HIGHAM, S.M.; JOSSELIN DE JONG, E. Possible factors influencing the use of quantitative light-induced fluorescence for caries detection and assessment. Caries Res, v. 34, p. 325, 2000.

113. ANDO, M.; ECKERT, G.J.; STOOKEY, G.K.; ZERO, D.T. Effect of imaging geometry on evaluating natural white-spot lesions using quantitative lightinduced fluorescence. Caries Res, v. 38, n. 1, p. 39-44, 2004.

114.PRETTY, I.A.; EDGAR, W.M.; HIGHAM, S.M. The effect of ambient light on QLF analyses. J Oral Rehabil, v. 29, p. 369-373, 2002.

115. AMAECHI, B.T.; HIGHAM, S.M. Quantitative light-induced fluorescence: a potential tool for general dental assessment. J Biomed Opt, v. 7, p. 7-13, 2002.

116. FERREIRA ZANDONA, A.G.; ANALOUI, M.; SCHEMEHORN, B.R.; ECKERT, G.J.; STOOKEY, G.K. Laser fluorescence detection of demineralization in artificial occlusal fissures. Caries Res, v. 32, p. 31-40, 1998.

117.HALL, A.F.; ANDO, M.; SCHEMEHORN, B.R.; STOOKEY, G.K. DyeEnhanced Laser Fluorescence method. 1996, Indiana. Proceedings of Indiana Conference. USA, 1996, p. 119-143.

118. KUHNISCH, J.; ZIEHE, A.; BRANDSTADT, A.; HEINRICH-WELTZIEN, R. An in vitro study of the reliability of DIAGNOdent measurements. $J$ Oral Rehabil, v. 31, p. 895-899, 2004.

119.LUSSI, A.; HELLWIG, E. Performance of a new laser fluorescence device for the detection of occlusal caries in vitro. J Dent, 2006. In Press.

120.LENNON, A.M.; BUCHALLA, W.; SWITALSKI, L.; STOOKEY, G. Residual caries detection using visible fluorescence. Caries Res, v. 36, p. 315-319, 2002.

121.SHINOHARA, T.; TAKASE, Y.; AMAGAI, T.; HARUYAMA, C.; IGARASHI, A.; KUKIDOME, N.; KATO, J.; HIRAI, Y. Criteria for a diagnosis of caries through the DIAGNOdent. Photomed Laser Sur, v. 24, n. 1, p. 50-58, 2006.

122.PINELLI, C.; SERRA, M.C.; LOFFREDO, L.C.M. Validity and reproducibility of a laser system or detecting the activity of white-spot lesions on free smooth surfaces in vivo. Caries Res, v. 36, p. 19-24, 2002. 
123. EL-HOUSSEINY, A.A.; JAMJOUM, H. Evaluation of visual, explorer, and a laser device for detection of early occlusal caries. J Clin Pediatr Dent, v. 16, n. 1, p. 41-49, 2001.

124. LUSSI, A.; REICH, E. The influence of toothpastes and prophylaxis pastes on fluorescence measurements for caries detection in vitro. Eur $\mathbf{J}$ Oral Sci, v. 113, n. 2, p. 141-144, 2005.

125.BAMZAHIM, M.; SHI, X.Q.; ANGMAR-MANSON, B. Occlusal caries detection and quantification by DIAGNOdent and electronic caries monitor: in vitro comparison. Acta Odontol Scand, v. 60, p. 360-364, 2002.

126. LUSSI, A.; HIBST, R.; PAULUS, R. DIAGNOdent: an optical method for caries detection. J Dent Res, v. 83, n. Spec No C, p. C80-C83, 2004.

127.SHEEHY, E.C.; BRAILSFORD, S.R.; KIDD, E.A.; BEIGHTON, D.; ZOITOPOULOS, L. Comparison between visual examination and a laser fluorescence system for in vivo diagnosis of occlusal caries. Caries Res, v. 35, n. 6, p. 421-426, 2001.

128. BRAUN, A.; KRAUSE, F.; JEPSEN, S. The influence of the calibration mode of a laser fluorescence device on caries detection. Caries Res, v. 39, p. 144-149, 2005.

129.MENDES, F.M.; DE OLIVEIRA, E.; DE FARIA, D.L.; NICOLAU, J. Ability of laser fluorescence device associated with fluorescent dyes in detecting and quantifying early smooth surface caries lesions. J Biomed Opt, v. 11, n. 2, p. 0240071-02400716, 2006.

130. ALFANO, R.; LAM, W.; ZARRABI, H.; ALFANO, M.; CORDERO, J.; TATA, B.; SWENBERG, E. Human teeth with and without caries studied by laser scattering, fluorescence and absorption spectroscopy. IEEE Journal of Quantum Eletronics, v. 20, n. 12, p. 1512-1515, 1984.

131. RIBEIRO, A.; ROSSEAU, C.; GIRKIN J, HALL A, STRANG R, WHITTERS $J$, CREANOR S, GOMES AA. Preliminary investigation of a spectroscopic technique for the diagnosis of natural caries lesions. J Dent, v. 33, n. 1, p. 73-80, 2005.

132. MENDES, F.M. Avaliação da efetividade do aparelho de laser diodo no monitoramento da remineralização in vitro de lesões incipientes de cárie em dentes decíduos. 2002. Dissertação (Mestrado) - Universidade de São Paulo, São Paulo. 
133. ELLWOOD, R.P.; CORTES, D.F. In vitro assessment of methods of applying the electrical caries monitor for the detction of occlusal caries. Caries Res, v. 38, p. 45-53, 2004.

134.LUSSI, A.; MEGERT, B.; LONGBOTTOM, C.; TEICH, E.; FRANCESCUT, $P$. Clinical performance of a laser fluorescence device for detection of occlusal caries lesions. Eur J Oral Sci, v. 109, p. 14-19, 2001.

135. NIEMZ, MH. Laser - tissue interactions: Fundamentals and applications. Springer Verlag: 1996: 297 p.

136. BRAGA, M.M.; MENDES, F.M.; IMPARATO, J.C.P.; MARTINS, C.R.M.D. Effect of the calibration method of the laser fluorescence device for detecting occlusal caries in primary molar teeth. 2006. In press.

137. AGNES, V.; AGNES, G.; BATISTTELLA, M.; GRANDE, R.H.M.; LOGUERCIO, A.D.; REIS, A. Clinical effectiveness of laser fluorescence, visual inspection and radiography in the detection of occlusal caries.

Caries Res, v. 39, p. 490-495, 2005.

138. LUSSI, A.; HACK, A.; HUG, I.; HECKENBERGER, H.; MEGERT, B.; $\mathrm{STICH}, \mathrm{H}$. Detection of approximal caries with new laser fluorescence device. Caries Res, v. 40, p. 97-103, 2006.

139. FRANCESCUT, P.; LUSSI, A. Impact on DIAGNOdent values of formalin and chloramines storage solutions. Caries Res, v. 34, p. 325, 2000.

140.BURIN, C.; BURIN, C.; LOGUERCIO, A.D.; GRANDE, R.H.M.; REIS A. Occlusal caries detection: a comparison of laser fluorescence system and conventional methods. Ped Dent, v. 27, n. 4, p.307-312, 2005.

141. PARIZOTTO, SP. Prevalência de cárie na dentição decídua de crianças da comunidade indígena Kaiowá-Guarani do Mato Grosso do Sul e associação com fatores de risco. 2004. Tese (Doutorado) Universidade de São Paulo, São Paulo.

142. HUYSMANS, M.C.D.N.J.M.; LONGBOTTOM, C. The challenges of validating diagnostic methods and selecting appropriate gold standards. $\boldsymbol{J}$ Dent Res, v. 83, n. Spec No C, p. C48-C52, 2004.

143.KONIG, K.; SCHNECKENBURGER, H.; HIBST, R. Time-gated in vivo autofluorescence imaging of dental caries. Cell Mol Biol, v. 45, n. 2, p. 233-239, 1998. 


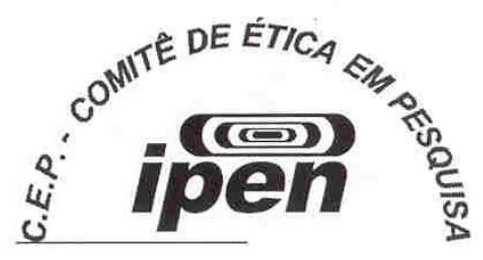

Parecer - Projeto № 078/CEP-IPEN/SP

Com base nos pareceres apresentados pelos relatores, o protocolo de pesquisa "Diagnóstico de cáries por fluorescência: correlação entre a histologia e os resultados obtidos com o Diagnodent e a espectrsocopia", de responsabilidade da pesquisadora Dra. Denise Maria Zezell foi considerado APROVADO.

Tendo em vista a legislação vigente, devem ser encaminhados a este Comitê relatórios referentes ao andamento da pesquisa em 10 de abril de 2004 e 10 de outubro de 2004. Após o término da pesquisa, uma cópia do trabalho, em CD ou disquete, deve ser encaminhada a este CEP.

São Paulo, 10 de outubro de 2003

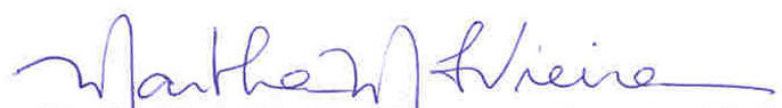

Profa. Dra. Martha Marques Ferreira Vieira Coordenadora do CEP-IPEN 